Forschungszentrum Karlsruhe in der Helmholtz-Gemeinschaft

Wissenschaftliche Berichte FZKA 7446

\title{
Review and Proposal for Best-fit of Wire-wrapped Fuel Bundle Friction Factor and Pressure Drop Predictions Using Various Existing Correlations
}

E. Bubelis, M. Schikorr

Institut für Reaktorsicherheit

Programm Nukleare Sicherheitsforschung 



\section{Forschungszentrum Karlsruhe}

in der Helmholtz-Gemeinschaft

Wissenschaftliche Berichte

FZKA 7446

\section{Review and proposal for best-fit of wire-wrapped fuel bundle friction factor and pressure drop predictions using various existing correlations}

Evaldas Bubelis and Michael Schikorr

Institut für Reaktorsicherheit

Programm Nukleare Sicherheitsforschung

Forschungszentrum Karlsruhe $\mathrm{GmbH}$, Karlsruhe 
Für diesen Bericht behalten wir uns alle Rechte vor

Forschungszentrum Karlsruhe $\mathrm{GmbH}$

Postfach 3640, 76021 Karlsruhe

Mitglied der Hermann von Helmholtz-Gemeinschaft

Deutscher Forschungszentren (HGF)

ISSN 0947-8620

urn:nbn:de:0005-074461 
Abstract

This report provides an overview of the existing wire-wrapped fuel bundle friction factor/pressure drop correlations and evaluates qualitatively which of the existing friction factor correlations are the best in retracing the results of a large set of the experimental data available on wire-wrapped fuel assemblies tested under different coolant conditions. 
Dieser Bericht gibt einen Überblick über die bestehenden Korrelationen für Reibbeiwerte und Druckverluste in Brennstabbündeln mit Wendeldrahtabstandshaltern. Es wird qualitativ bewertet, welche der bestehenden Korrelationen die Ergebnisse einer großen Reihe von experimentellen Daten für die verschiedensten Bedingungen des Kühlmittels am besten wiedergeben. 


\section{TABLE OF CONTENTS}

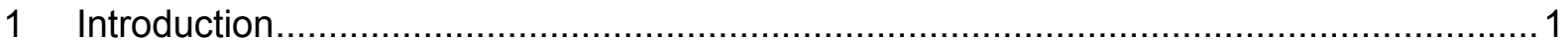

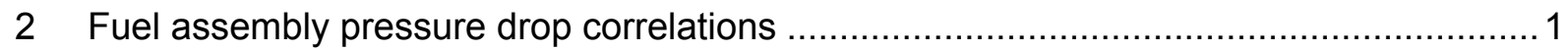

3 Friction factor correlations for wire-wrapped fuel assemblies ....................................... 2

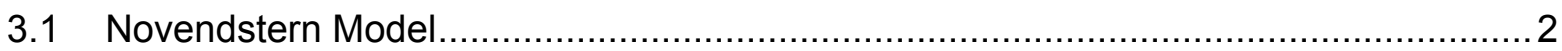

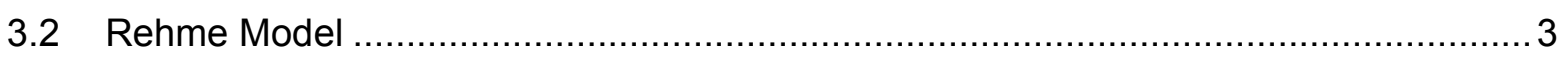

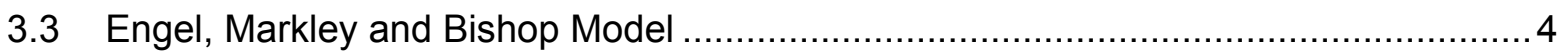

3.4 Cheng and Todreas Models - simplified and detailed ........................................... 4

3.5 Baxi and Dalle-Donne Model ..........................................................................

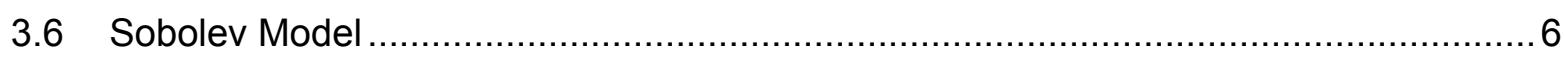

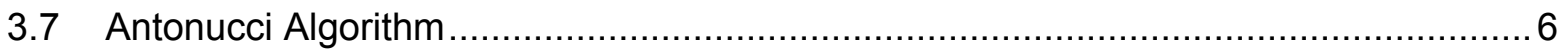

4 Modified friction factor correlations for wire-wrapped fuel assemblies ........................... 7

4.1 Modified Engel, Markley and Bishop model............................................................. 7

4.2 Modified Baxi and Dalle-Donne Model ............................................................ 7

5 SIM-ADS code used for wire-wrapped fuel bundle friction factor correlations validation .. 8

6 Analysis of the experimental data based on water experiments ................................. 10

6.1 Choi et al., 2003 (Choi et al, 2003) water experiments........................................... 10

6.2 Chun et al., 2001 (Chun M.H. and Seo K.W., 2001) water experiments ................... 15

6.3 Arwikar et al., 1979 (Arwikar K. and Fenech H, 1979) water experiments ................. 18

6.4 Chiu et al., 1979 (Chiu C. et al, 1979) water experiments ....................................... 21

6.5 Tong/Bishop, 1968 (Tong L.S., 1968) water experiments ..................................... 23

6.6 Marten et al., 1982 (Marten K., Yonekawa S. and Hoffmann H, 1982) water

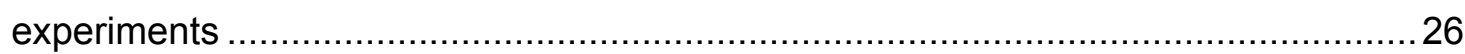

6.7 Itch, 1981 (Cheng S.K., 1984) water experiments................................................... 28

6.8 Spencer, 1980 (Cheng S.K., 1984) water experiments ........................................ 31

6.9 Rehme, 1973 (Rehme K., 1973) water experiments ...............................................32

6.10 Vijayan et al., 1999 (Vijayan P.K. et al, 1999) water experiments ............................42

7 Analysis of the CFD modeling results based on Gajapathy et al., 2007 (Gajapathy R. et al., 2007) sodium cooled PFBR fuel bundle investigation ...........................................46

8 Analysis of the experimental data by Geffraye, 2008 (Geffraye G., 2008) based on

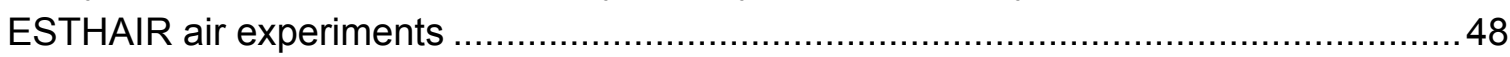

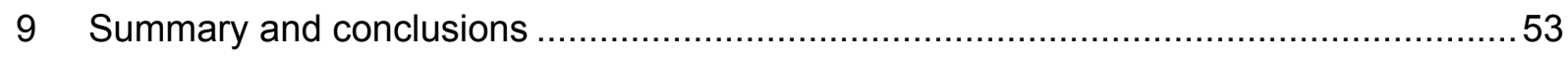

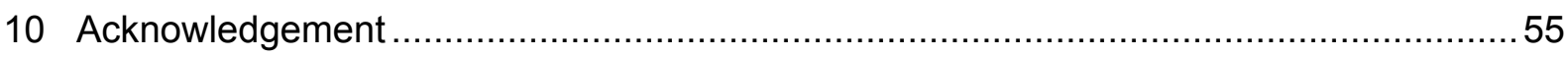

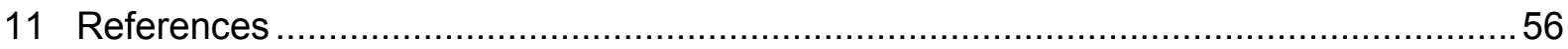

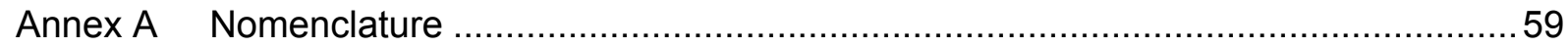

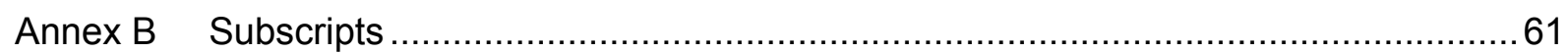




\section{LIST OF TABLES}

Table. 1. Judgmental evaluation (engineering judgment) of different friction factor correlations against experimental data sets 


\section{LIST OF FIGURES}

Fig. 1. Schematic diagram of the experimental facility. 1) water tank, 2) pump, 3) damper, 4) flow manifold, 5) test section: (water, Choi et al., 2003 (Choi et al, 2003)) 11

Fig. 2. Test section and locations of pressure taps: (water, Choi et al., 2003 (Choi et al, 2003))

Fig. 3. a) Relative magnitude of pressure drop in the fuel assembly, b) Comparison of Novendstern correlation with measured data: (water, Choi et al., 2003 (Choi et al, 2003))

Fig. 4. Comparison of SIM-ADS calculated and experimental pressure drop in the wirewrapped fuel assembly (compare with the topmost curve in Fig. 3a): (water, Choi et al., 2003)

Fig. 5. Comparison of experimental and SIM-ADS calculated pressure drops in the different regions (inlet, outlet, fuel section, etc) of the wire-wrapped fuel assembly (compare with Fig. 3a): (water, Choi et al., 2003) using the above FA inlet and FA outlet models and Rehme for the fuel section.

Fig. 6. Comparison of the SIM-ADS calculated and experimental friction factor values for the wire-wrapped fuel assembly (compare with Fig. 3b): (water, Choi et al., 2003)

Fig. 7. Schematic diagram of the test loop: (water, Chun et al., 2001 (Chun M.H. and Seo K.W., 2001))

Fig. 8. Reynolds number vs. friction factor (test section B2): (water, Chun et al., 2001 (Chun M.H. and Seo K.W., 2001))

Fig. 9. Comparison of the SIM-ADS calculated and experimental friction factor values for the wire-wrapped fuel assembly (compare with Fig. 8 (Chun M.H. and Seo K.W., 2001)): (water, Chun et al., 2001)

Fig. 10. Schematic diagram of the water circulation system: (water, Arwikar et al., 1979 (Arwikar K. and Fenech H, 1979))

Fig. 11. Friction factor versus Reynolds number: (water, Arwikar et al., 1979 (Arwikar K. and Fenech H, 1979))

Fig. 12. Comparison of the SIM-ADS calculated and experimental friction factor values for the wire-wrapped fuel assembly (compare with Fig. 11): (water, Arwikar et al., 1979)

Fig. 13. Comparison of results for bundle average friction factors: (water, Chiu et al., 1979 (Chiu C. et al, 1979; Carajilescov P. and Fernandez E. F., 1999))

Fig. 14. Comparison of the SIM-ADS calculated and the experimental friction factor values for the wire-wrapped fuel assembly (compare with Fig. 13): (water, Chiu et al., 1979)

Fig. 15. Comparison of results for bundle average friction factors: (water, Tong/Bishop, 1968 (Carajilescov P. and Fernandez E. F., 1999; Tong L.S., 1968))

Fig. 16. Comparison of the SIM-ADS calculated and experimental friction factor values for the wire-wrapped fuel assembly (compare with Fig. 15, case $H / D=8$ ): (water, Tong/Bishop, 1968)

Fig. 17. Comparison of the SIM-ADS calculated and the experimental friction factor values for the wire-wrapped fuel assembly (compare with Fig. 15, case $H / D=16)$ : (water, Tong/Bishop, 1968) 
Fig. 18. Comparison between experimental data and predictions for wire-wrapped bundle friction factor: (water, Marten et al., 1982 (Marten K., Yonekawa S. and Hoffmann H, 1982; Cheng S.K. and Todreas N.E., 1986))

Fig. 19. Comparison of the SIM-ADS calculated and experimental friction factor values for the wire-wrapped fuel assembly (compare with Fig. 18, case $P / D=1.041$; $\mathrm{H} / \mathrm{D}=17.01)$ : (water, Marten et al., 1982)

Fig. 20. Comparison of the SIM-ADS calculated and experimental friction factor values for the wire-wrapped fuel assembly (compare with Fig. 18, case $P / D=1.101$; $H / D=12.31$ ): (water, Marten et al., 1982)

Fig. 21. Comparison between experimental data and predictions for wire-wrapped bundle friction factor: (water, Itch, 1981 (Cheng S.K. and Todreas N.E., 1986; Cheng S.K., 1984))

Fig. 22. Comparison of the SIM-ADS calculated and experimental friction factor values for the wire-wrapped fuel assembly (compare with Fig. 21, case 127-pin, $P / D=1.176 ; H / D=38.0)$ : (water, Itch, 1981)

Fig. 23. Comparison of the SIM-ADS calculated and experimental friction factor values for the wire-wrapped fuel assembly (compare with Fig. 21, case 169-pin, $P / D=1.214 ; \mathrm{H} / \mathrm{D}=47.39$ ): (water, Itch, 1981)

Fig. 24. Comparison of the SIM-ADS calculated and experimental friction factor values for the wire-wrapped fuel assembly (compare with Fig. 21, case 217-pin, $P / D=1.252 ; H / D=51.74$ ): (water, Spencer, 1980)

Fig. 25. Friction factor $f$ as a function of the Reynolds number Re for different leads of wire wraps. Test parameters: pitch-to-diameter ratio 1.417, 19 rods bundle (Fig. 4, (Rehme K., 1973)): (water, Rehme, 1973)

Fig. 26. Comparison of the SIM-ADS calculated and experimental friction factor values for the wire-wrapped fuel assembly (compare with Fig. 25, case 19-rods, $P / D=1.417$; wire lead length $300 \mathrm{~mm}$ ): (water, Rehme, 1973)

Fig. 27. Comparison of the SIM-ADS calculated and experimental friction factor values for the wire-wrapped fuel assembly (compare with Fig. 25, case 19-rods, $P / D=1.417$; wire lead length $600 \mathrm{~mm}$ ): (water, Rehme, 1973)

Fig. 28. Friction factor $f$ as a function of the Reynolds number Re for different leads of wire wraps. Test parameters: pitch-to-diameter ratio 1.125, 19 rods bundle (Fig. 5, (Rehme K., 1973)): (water, Rehme, 1973)

Fig. 29. Comparison of the SIM-ADS calculated and experimental friction factor values for the wire-wrapped fuel assembly (compare with Fig. 28, case 19-rods, $P / D=1.125$; wire lead length $200 \mathrm{~mm}$ ): (water, Rehme, 1973)

Fig. 30. Comparison of the SIM-ADS calculated and experimental friction factor values for the wire-wrapped fuel assembly (compare with Fig. 28, case 19-rods, $P / D=1.125$; wire lead length $300 \mathrm{~mm}$ ): (water, Rehme, 1973)

Fig. 31. Friction factor $f$ as a function of the Reynolds number Re for different pitch-todiameter ratios. Test parameters: lead of the wire-wrap $100 \mathrm{~mm}, 7$ rods bundle (Fig. 6, (Rehme K., 1973)): (water, Rehme, 1973)

Fig. 32. Comparison of the SIM-ADS calculated and experimental friction factor values for the wire-wrapped fuel assembly (compare with Fig. 31, case 7-rods, $P / D=1.343$; wire lead length $100 \mathrm{~mm}$ ): (water, Rehme, 1973) 
Fig. 33. Comparison of the SIM-ADS calculated and experimental friction factor values for the wire-wrapped fuel assembly (compare with Fig. 31, case 7-rods, $P / D=1.275$; wire lead length $100 \mathrm{~mm}$ ): (water, Rehme, 1973)

Fig. 34. Friction factor $f$ as a function of the Reynolds number Re for different numbers of rods in a rod bundle. Test parameters: pitch-to-diameter ratio 1.275 , lead of the wire-wrap $150 \mathrm{~mm}$ for the upper 3 curves and $600 \mathrm{~mm}$ for the lower 3 curves (Fig. 8, (Rehme K., 1973)): (water, Rehme, 1973)

Fig. 35. Comparison of the SIM-ADS calculated and experimental friction factor values for the wire-wrapped fuel assembly (compare with Fig. 34, case 19-rods, $P / D=1.275$; wire lead length $150 \mathrm{~mm}$ ): (water, Rehme, 1973)

Fig. 36. Comparison of the SIM-ADS calculated and experimental friction factor values for the wire-wrapped fuel assembly (compare with Fig. 34, case 19-rods, $P / D=1.275$; wire lead length $600 \mathrm{~mm}$ ): (water, Rehme, 1973)

Fig. 37. Schematic of the low pressure flow test facility : (water, Vijayan et al., 1999 (Vijayan P.K. et al, 1999))

Fig. 38. Friction factor data for 19-rod bundle (wire-wrap spacers): (water, Vijayan et al., 1999 (Vijayan P.K. et al, 1999))

Fig. 39. Comparison of the SIM-ADS calculated and experimental friction factor values for the wire-wrapped fuel assembly (compare with Fig. 38): (water, Vijayan et al., 1999)

Fig. 40. Comparison of pin bundle friction coefficient with and without helical wire-wrap: (sodium, Gajapathy et al., 2007 (Gajapathy R. et al., 2007))

Fig. 41. Comparison of the SIM-ADS calculated and experimental friction factor values for the wire-wrapped fuel assembly, as well as for the case without a wire-wrap (compare with Fig. 40): (sodium, Gajapathy et al., 2007)

Fig. 42. a) View of the test loop, b) View of the fuel bundle: (air, ESTHAIR exp. (Berthoux M., 2006))

Fig. 43. Friction factor vs. Reynolds number as reported in Ref. (Geffraye G., 2008): (air, ESTHAIR exp. (Geffraye G., 2008))

Fig. 44. Comparison of the SIM-ADS calculated and experimental friction factor values for the wire-wrapped fuel assembly (compare with Fig. 43): (air, ESTHAIR exp.) 51

Fig. 45. Friction factor measured on the $4^{\text {th }}$ winding pitch. Comparison with existing correlations: (air, ESTHAIR exp. (Berthoux M. and Carenza A., 2008)) 



\section{Introduction}

Different authors provide us with friction factor correlations for wire-wrapped fuel bundles based on a particular set of experimental data. These correlations usually are very good for the prediction of friction factors for wire-wrapped fuel bundle within the parameter range for which they were derived based on certain fluid and certain fuel bundle parameters. But when one tries to apply these friction factor correlations to another fluid (coolant) or different fuel bundle parameters, one often obtains predictions of the friction factor that are not always correlateable to the experimental data. So an important question arises, which friction factor correlation should one use in order to obtain reliable prediction of the friction factor for any coolant and any set of fuel bundle parameters. This report tries to address this very important issue, based on the qualitative evaluation of the most commonly used friction factor correlations provided to us by different authors, while analyzing more than ten different sets of experimental data that are available today on the internet. These experiments were conducted using different coolants (water, sodium, air), different sets of fuel bundle parameters, by different scientists in different countries and organizations.

\section{Fuel assembly pressure drop correlations}

The total pressure drop in a fuel assembly is usually calculated using the following formula:

$\Delta \mathrm{p}_{\mathrm{FA}}=\Delta \mathrm{p}_{\text {inlet }}+\Delta \mathrm{p}_{\text {outlet }}+\Delta \mathrm{p}_{\text {orf }}+\Delta \mathrm{p}_{\text {fric }}+\Delta \mathrm{p}_{\text {spacer }}$

Fuel assembly inlet, outlet and orificing pressure losses are determined by:

$$
\Delta p_{\text {inlet }}+\Delta p_{\text {outlet }}+\Delta p_{\text {orf }}=\left(K_{\text {inlet }}+K_{\text {outlet }}+K_{\text {orf }}\right) * 0.5 * \rho^{*} v^{2}
$$

with $\rho$ being the density and $v$ the velocity of the coolant and $K$ as the associated pressure loss coefficients. Pressure loss due to the flow friction along a smooth pipe is calculated as: 
$\Delta p_{\text {fric }}=f_{\text {fric }} *\left(L / D_{e}\right) * 0.5 * \rho * v^{2}$,

where $L$ is the tube length, $D_{e}$ the hydraulic diameter of the flow channel, and $f_{\text {fric }}$ for the turbulent single phase flow can be estimated using the Blasius formula, namely

$f_{\text {fric }}=0.316 / R e^{0.25}$,

where Re represents the Reynolds number of the flow channel. In a similar manner, the pressure loss due to the spacer (in this case due to the wire-wrap) is calculated as:

$\Delta p_{\text {spacer }}=f_{w w}^{*}\left(L / D_{e}\right) * 0.5 * \rho * v^{2}$

where $f_{w w}$ (friction factor) correlations for the wire-wrap spacer configuration will be discussed in more detail in section 3 of this report.

\section{Friction factor correlations for wire-wrapped fuel assemblies}

The various friction factor correlations for the wire-wrapped fuel bundles that are available today are summarized in this section.

\subsection{Novendstern Model}

Friction factor for the wire-wrapped fuel bundle in the Novendstern model (Novendstern E. H., 1972) is calculated based on the following correlations:

$$
f=f_{1} \cdot X_{1}^{2} \cdot \frac{D_{e}}{D_{e 1}}
$$

where: $f_{1}=f_{s} \cdot M ; f_{s}=\frac{0.316}{\operatorname{Re}_{s}^{0.25}}$ 
$\mathrm{Re}_{\mathrm{s}}$ - average Reynolds number for non-wire-wrap configuration of the fuel bundle, and

$$
M=\left\{\frac{1.034}{\left(P_{t} / D_{r}\right)^{0.124}}+\frac{29.7 \cdot\left(P_{t} / D_{r}\right)^{6.94} \cdot \mathrm{Re}_{1}^{0.086}}{\left(H /\left(D_{r}+D_{w}\right)\right)^{2.239}}\right\}^{0.885},
$$

$\mathrm{Re}_{1}$ - Reynolds number for the center sub-channel of the hot SA in the wire-wrap configuration with

$$
\begin{aligned}
& \operatorname{Re}_{1}=\frac{\rho \cdot v_{1} \cdot D_{e 1}}{\mu}=\operatorname{Re} \cdot X_{1} \cdot \frac{D_{e 1}}{D_{e}}, \operatorname{Re}=\frac{\rho \cdot v \cdot D_{e}}{\mu}, v_{1}=X_{1} \cdot v, \\
& X_{1}=\frac{A}{N_{1} \cdot A_{1}+N_{2} \cdot A_{2} \cdot\left(\frac{D_{e 2}}{D_{e 1}}\right)^{0.714}+N_{3} \cdot A_{3} \cdot\left(\frac{D_{e 3}}{D_{e 1}}\right)^{0.714}}, \quad A=N_{1} \cdot A_{1}+N_{2} \cdot A_{2}+N_{3} \cdot A_{3} .
\end{aligned}
$$

where all the various symbols are defined in the nomenclature section of this report. For our analysis we assumed only one averaged sub-channel, i.e. $X_{1}=1$ and $D_{e 1}=D_{e}$.

\subsection{Rehme Model}

Friction factor for the wire-wrapped fuel bundle in the Rehme model (Rehme, K., 1973 ) is calculated based on the following correlations:

$f=\left(\frac{64}{\operatorname{Re}} \cdot F^{0.5}+\frac{0.0816}{\operatorname{Re}^{0.133}} \cdot F^{0.9335}\right) \cdot \frac{N_{r} \cdot \pi \cdot\left(D_{r}+D_{w}\right)}{S_{t}}$,

where: $F=\left(\frac{P_{t}}{D_{r}}\right)^{0.5}+\left[7.6 \cdot \frac{\left(D_{r}+D_{w}\right)}{H} \cdot\left(\frac{P_{t}}{D_{r}}\right)^{2}\right]^{2.16}$, and

where all the various symbols are defined in the nomenclature section of this report. 


\subsection{Engel, Markley and Bishop Model}

Friction factors for the wire-wrapped fuel bundle in the Engel, Markley and Bishop model (Engel F. C. et al, 1979) is calculated based on the following correlations:

Laminar flow: $f=\frac{110}{\mathrm{Re}}$ for $\mathrm{Re}<400$,

Turbulent flow: $f=\frac{0.55}{\operatorname{Re}^{0.25}}$ for $\operatorname{Re}>5000$,

Transition flow: $f=\frac{110}{\operatorname{Re}} \cdot(1-\psi)^{0.5}+\frac{0.55}{\operatorname{Re}^{0.25}} \cdot \psi^{0.5} \quad$ for $400 \leq \mathrm{Re} \leq 5000$,

where: $\quad \psi=\frac{(\operatorname{Re}-400)}{4600}$, and

where all the various symbols are defined in the nomenclature section of this report.

\subsection{Cheng and Todreas Models - simplified and detailed}

Friction factor for the wire-wrapped fuel bundle in the simplified Cheng and Todreas model (Cheng S. K. and Todreas N. E., 1986) is calculated based on the following correlations:

Laminar flow: $f=\frac{C_{f L}}{\operatorname{Re}} \quad$ for $\quad \mathrm{Re} \leq \mathrm{Re}_{\mathrm{L}}$,

Turbulent flow: $f=\frac{C_{f T}}{\operatorname{Re}^{0.18}} \quad$ for $\quad \mathrm{Re}_{\mathrm{T}} \leq \mathrm{Re}$,

Transition flow: $f=\frac{C_{f L}}{\operatorname{Re}} \cdot(1-\psi)^{1 / 3}+\frac{C_{f T}}{\operatorname{Re}^{0.18}} \cdot \psi^{1 / 3} \quad$ for $\mathrm{Re}_{\mathrm{L}}<\mathrm{Re}<\operatorname{Re}_{\mathrm{T}}$, 
where: $\log \left(\frac{\operatorname{Re}_{L}}{300}\right)=1.7 \cdot\left(\frac{P_{t}}{D_{r}}-1.0\right), \log \left(\frac{\operatorname{Re}_{T}}{10000}\right)=0.7 \cdot\left(\frac{P_{t}}{D_{r}}-1.0\right)$,

$\psi=\left(\log (\mathrm{Re})-\left(1.7 \cdot \frac{P_{t}}{D_{r}}+0.78\right)\right) /\left(2.52-\frac{P_{t}}{D_{r}}\right)$

$C_{f L}=\left(-974.6+1612.0 \cdot\left(\frac{P_{t}}{D_{r}}\right)-598.5 \cdot\left(\frac{P_{t}}{D_{r}}\right)^{2}\right) \cdot\left(\frac{H}{D_{r}+D_{w}}\right)^{0.06-0.085 \cdot\left(P_{t} / D_{r}\right)}$,

$C_{f T}=\left(0.8063-0.9022 \cdot \log \left(\frac{H}{D_{r}+D_{w}}\right)+0.3526 \cdot\left(\log \left(\frac{H}{D_{r}+D_{w}}\right)\right)^{2}\right) \cdot\left(\frac{P_{t}}{D_{r}}\right)^{9.7} \cdot\left(\frac{H}{D_{r}+D_{w}}\right)^{1.78-2 \cdot\left(P_{t} / D_{r}\right)}$

and where all the various symbols are defined in the nomenclature section of this report.

Friction factors for the wire-wrapped fuel bundle in the detailed Cheng and Todreas model is calculated based on the center, side and corner sub-channels equations that are described in more detail in Ref. (Cheng S. K. and Todreas N. E., 1986) as well.

\subsection{Baxi and Dalle-Donne Model}

Friction factor for the wire-wrapped fuel bundle in the Baxi and Dalle-Donne model (Pergamon Press, 1981) is calculated based on the following correlations:

Laminar flow: $\mathrm{Re} \leq 400$

$f_{l}=\left(\frac{K}{\operatorname{Re}}\right) \cdot\left(\frac{T_{W}}{T_{B}}\right), \quad K=\frac{80}{\sqrt{H}} \cdot\left(\frac{P_{t}}{D_{r}}\right)^{1.5} ;$ where $\mathrm{H}$ in $(\mathrm{cm})$.

Turbulent flow: $\mathrm{Re} \geq 5000$

$f_{t}=f_{s} \cdot M$, where $\mathrm{fs}=$ smooth friction factor in a tube (Blasius) $=0.316 / \mathrm{Re}^{0.25}$, 
$M=\left[\frac{1.034}{\left(P_{t} / D_{r}\right)^{0.124}}+\frac{29.6 \cdot\left(P_{t} / D_{r}\right)^{6.94} \cdot \mathrm{Re}^{0.086}}{\left(H /\left(D_{r}+D_{w}\right)\right)^{2.239}}\right]^{0.885}$.

Transition flow: $400<\operatorname{Re}<5000$

$f=f_{l} \cdot(1-\psi)^{1 / 2}+f_{t} \cdot \sqrt{\psi}$,

$f_{l}=$ laminar friction factor, $f_{t}=$ turbulent friction factor, $\psi=(\operatorname{Re}-400) / 4600$, and

where all the various symbols are defined in the nomenclature section of this report.

\subsection{Sobolev Model}

Friction factor for the wire-wrapped fuel bundle in the Sobolev model (Sobolev V., 2006) is calculated based on the following equation:

$f=\left(1+600 \cdot\left(\frac{D_{r}}{H}\right)^{2} \cdot\left(\frac{P_{t}}{D_{r}}-1\right)\right) \cdot\left(\frac{0.210}{\operatorname{Re}^{0.25}} \cdot\left(1+\left(\frac{P_{t}}{D_{r}}-1\right)^{0.32}\right)\right)$, and

where all the various symbols are defined in the nomenclature section of this report.

\subsection{Antonucci Algorithm}

This algorithm was kindly provided to us by Mr. Carlomaria Antonucci (ENEA, Italy) for our purpose of investigating friction factors for wire-wrapped fuel bundle configurations. This algorithm is based on Cheng and Todreas detailed model, which is described in more detail in Ref. (Cheng S. K. and Todreas N. E., 1986). Friction factors for the wire-wrapped fuel bundle in the detailed Cheng and Todreas model are calculated based on the center, side and corner sub-channels equations. 


\section{Modified friction factor correlations for wire- wrapped fuel assemblies}

After performing the analysis using the different experimental data sets, some of the above presented friction factor correlations for the wire-wrapped fuel bundles were slightly modified in order to obtain an improved agreement with the available experimental data sets. The modified friction factor correlations for the wire wrapped fuel bundles are presented below in this section.

\subsection{Modified Engel, Markley and Bishop model}

Friction factors for the wire-wrapped fuel bundle in the modified Engel, Markley and Bishop model are calculated based on the following modified correlations:

Laminar flow: $f=\frac{110}{\operatorname{Re}}$ for $\operatorname{Re}<400$,

Turbulent flow: $f=\frac{(0.37}{\operatorname{Re}^{0.25}}$ for $\operatorname{Re}>5000$,

Transition flow: $f=\frac{110}{\operatorname{Re}} \cdot(1-\psi)^{0.5}+\frac{(0.37}{\operatorname{Re}^{0.25}} \cdot \psi^{0.5} \quad$ for $400 \leq \operatorname{Re} \leq 5000$,

where: $\quad \psi=\frac{(\operatorname{Re}-400)}{4600}$,

and where all the various symbols are defined in the nomenclature section of this report.

\subsection{Modified Baxi and Dalle-Donne Model}

Friction factors for the wire-wrapped fuel bundle in the modified Baxi and Dalle-Donne model is calculated based on the following correlations: 
Laminar flow. $\operatorname{Re} \leq 400$

$f_{l}=\left(\frac{K}{\operatorname{Re}}\right) \cdot\left(\frac{T_{W}}{T_{B}}\right), \quad K=\frac{300}{\sqrt{H}} \cdot\left(\frac{P_{t}}{D_{r}}\right)^{1.5} ;$ where $\mathrm{H}$ in $(\mathrm{cm})$.

Turbulent flow: $\operatorname{Re} \geq 5000$

$f_{t}=f_{s} \cdot M$, where $\mathrm{fs}=$ smooth friction factor in a tube $($ Blasius $)=0.316 / \mathrm{Re}^{0.25}$,

$M=\left[\frac{1.034}{\left(P_{t} / D_{r}\right)^{0.124}}+\frac{29.6 \cdot\left(P_{t} / D_{r}\right)^{6.94} \cdot \operatorname{Re}^{0.086}}{\left(H /\left(D_{r}+D_{w}\right)\right)^{2.239}}\right]^{0.885}$.

Transition flow: $400<\operatorname{Re}<5000$

$f=f_{l} \cdot(1-\psi)^{1 / 2}+f_{t} \cdot \sqrt{\psi}$,

$f_{l}=$ laminar friction factor, $f_{t}=$ turbulent friction factor, $\psi=(\operatorname{Re}-400)$

and where all the various symbols are defined in the nomenclature section of this report.

\section{SIM-ADS code used for wire-wrapped fuel bundle friction factor correlations validation}

SIM-ADS (Schikorr W. M., 2001) is a PC-based; multi node point kinetic model that describes the nuclear and thermal-hydraulic characteristics of critical and sub-critical reactor cores. Two separate neutronic core models are run simultaneously, namely a single node PK model that acts as driver for a multi-node (16-axial nodes) thermo-hydraulic model, and a multi-node neutronic model (16 axial neutronically coupled nodes) which allows the axial power profile to change during the transient according to nodal temperature and nodal reactivity variations. In the single node PK neutronic model, the axial power profile is assumed to remain unchanged during the transient. 
Under "normal", simple transient conditions that are not dependent on a transient axial power profile, both neutronic models (single node and 16-axial nodes) should yield identical results in core averaged parameters, thereby serving as a constant calculational crosscheck.

The neutron kinetics of each nuclear model is described by 6-delayed neutron precursor groups on the nodal level, and a complete set of nodal dependant reactivity feedback coefficients (16-node neutronic model) such as Doppler, coolant, fuel expansion, diagrid expansion, void, control rod, Xenon (for thermal reactors), etc. The nodal time characteristics of the decay heat after shutdown is described by 6 decay heat groups.

The 16-axial node, full-scope thermal-hydraulic model assumes an initial axial and radial power distribution (provided as input to the kinetics models by the detailed neutronic analysis performed during the core design phase), and then calculates the radial heat transfer through a typical fuel pin consisting of the detailed description of the heat transfer mechanisms between cladding and coolant, the heat transfer through the clad material, the heat transfer in the gap between clad and fuel, and the fuel matrix itself assuming appropriate material property data and applicable coolant type dependant heat transfer correlations (correlation for Nusselt numbers, friction factors, etc.). This heat transfer analysis is performed for the peak pin and the average pin of the core where the radial core power distribution is assumed to be representable by radial power form factors.

The primary loop is nodalized into several appropriate hydraulic nodes with corresponding volumes, internal masses and surface areas (lower vessel plenum, the 16 axial core nodes, upper vessel plenum, the piping to and from the HX, (HX and DHRS itself are modeled by appropriate internal nodalization) to account for all relevant thermal-hydraulic effects including radiation (from vessel wall) to the ambient and all relevant pressure loss calculations inside the core region (i.e. due to grid or wire-wrap spacers) and the primary system (heat exchangers, pumps, loops, etc). 
Particular attention is placed on the correct formulation of all relevant heat transfer mechanisms between cladding surface and coolant (such as for example roughened surface areas) in the core region and in the HX and DHRS systems, in particular accounting for the physical phenomena encountered in various flow regimes (i.e turbulent and laminar flow under forced flow and natural convection conditions) for heavy metals ( $\mathrm{Na}$, or $\mathrm{Pb}$, or $\mathrm{LBE}$ ), water or gas coolants (He, Air or CO2).

The code system SIM-ADS has been used to perform the transient analysis of both the LBE-cooled and He-cooled PDS-XADS ADS designs during the PDS-XADS Project and during the MOST molten salt project to analyze the AMSTER molten salt reactor design (Vergnes J. and Lecarpentier D., 2002) as well as during the currently ongoing EUROTRANS project (Bianchi F. et al., 2006). SIM-ADS has been tested and validated extensively against actual LWR plant data (plant transient data) for both PWRs and BWRs, Superphenix (SPX1) plant data, and by code to code comparisons of results obtained using RELAP, SAS-SFR, TRAC and other large transient code systems.

\section{Analysis of the experimental data based on water experiments}

\subsection{Choi et al., 2003 (Choi et al, 2003) water experiments}

A schematic diagram of the experimental facility used by Choi et al (Choi et al, 2003) to measure the pressure drop in a 271-pin wire-wrapped fuel assembly is shown in Fig. 1. The experimental facility consists of water tank, main pump, water chiller, damper, flow manifold and test section. In order to maintain the water temperature constant at the desired value, the Freon/water chiller is installed. The damper is installed to reduce the riffling of the water circuit, which is electrically controlled by the pressure of nitrogen cover gas. Fig. 2 shows the test section of the fuel assembly. The inlet orifice and the hexagonal shaped duct that contains the fuel assembly are shown in this figure. The locations $B, C, D, E, F$ in this 
figure are the locations of the pressure taps. Pressure tap A is located at the side wall of the casing that encloses the inlet orifice.

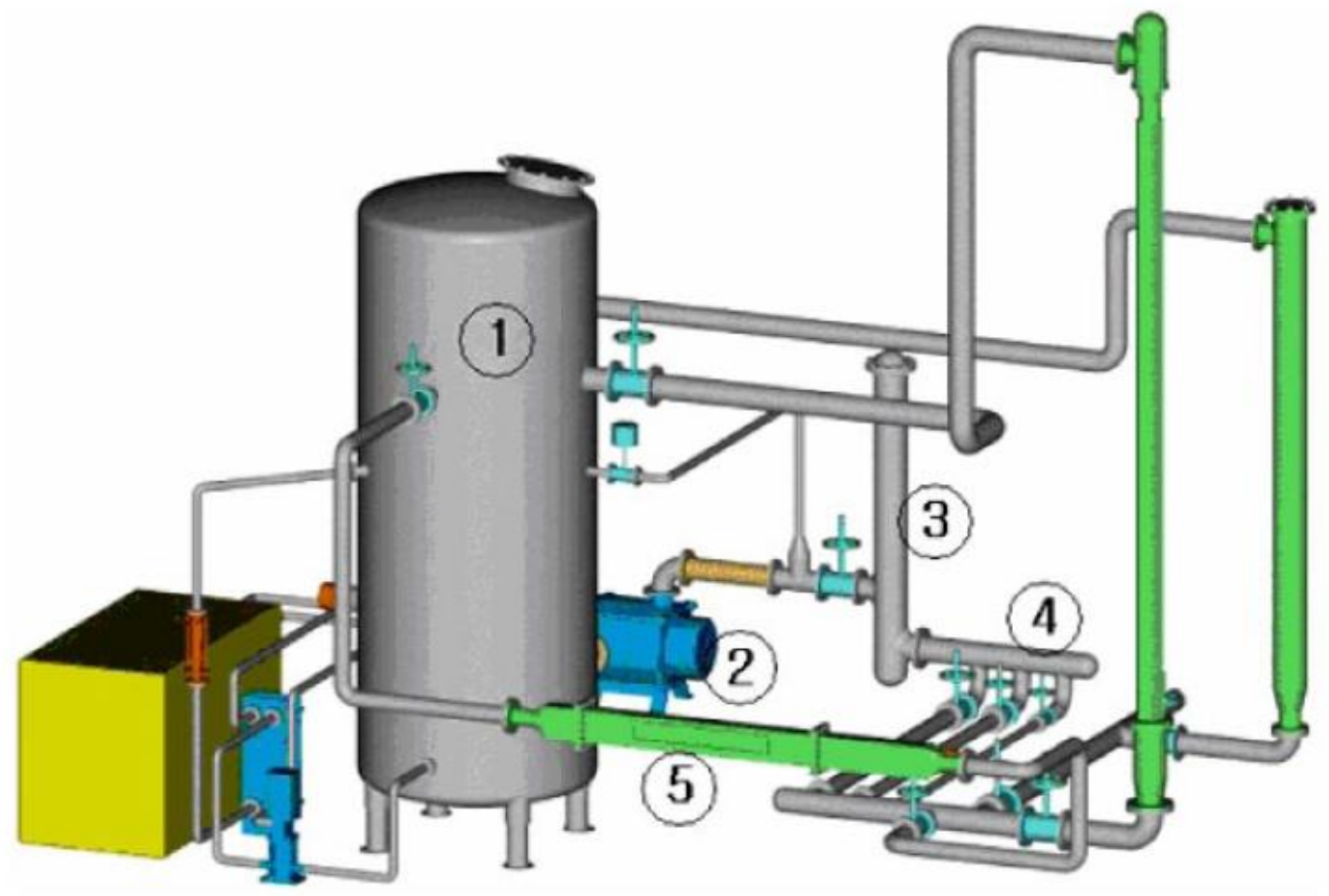

Fig. 1. Schematic diagram of the experimental facility. 1) water tank, 2) pump, 3) damper, 4) flow manifold, 5) test section: (water, Choi et al., 2003 (Choi et al, 2003))
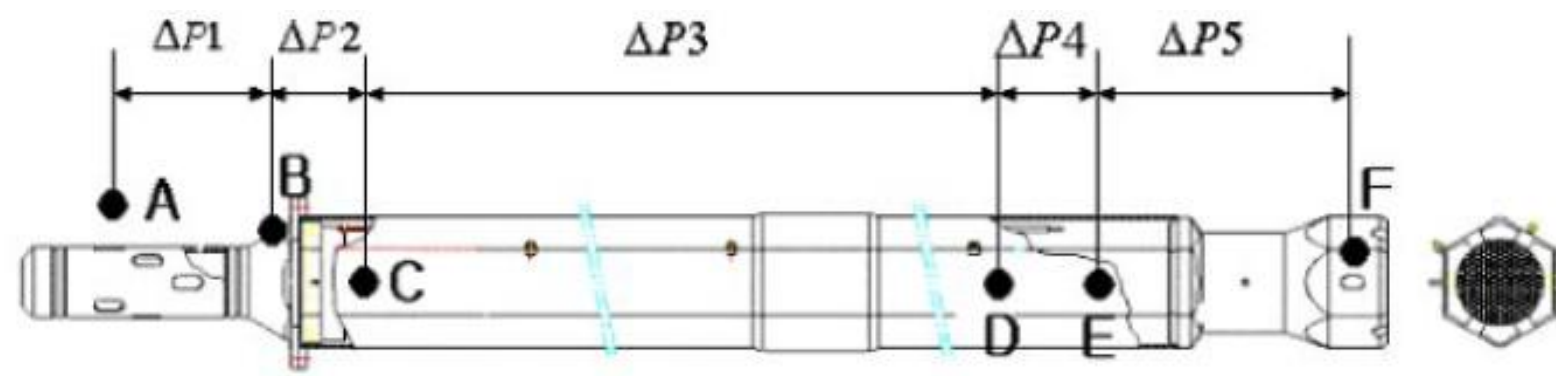

Fig. 2. Test section and locations of pressure taps: (water, Choi et al., 2003 (Choi et al, 2003))

The diameter of the fuel rod used in these experiments is $7.4 \mathrm{~mm}$ and the diameter of the wire is $1.4 \mathrm{~mm}$. The rod pitch to rod diameter ratio is 1.2 and the wire lead length to rod diameter ratio is 24.84 . The experimental range of flow rate is $2.2 \div 60 \mathrm{l} / \mathrm{s}$ and the experimental range of Reynolds number based on the hydraulic diameter of the fuel assembly is $1100 \div 78000$. A series of experiments have been conducted changing the fluid temperature 
and the flow rate. Fig. $3 a$ shows the relative magnitude of pressure drop (Exp.A: $19 \div 25^{\circ} \mathrm{C}$ ) for five different sections in a fuel assembly: inlet orifice, fuel assembly inlet, wire-wrapped fuel assembly, fuel assembly outlet and fuel assembly upper region. Fig. 3b shows the comparison of the measured friction factor data (Exp.A: $19 \div 25^{\circ} \mathrm{C}$, Exp.B: $30 \div 34^{\circ} \mathrm{C}$, Exp.C: $25 \div 29^{\circ} \mathrm{C}$, Exp.D: $31 \div 36^{\circ} \mathrm{C}$, Exp.E: $63 \div 65^{\circ} \mathrm{C}$ ) with Novendstern empirical correlation for the pressure drop in a wire-wrapped fuel assembly.

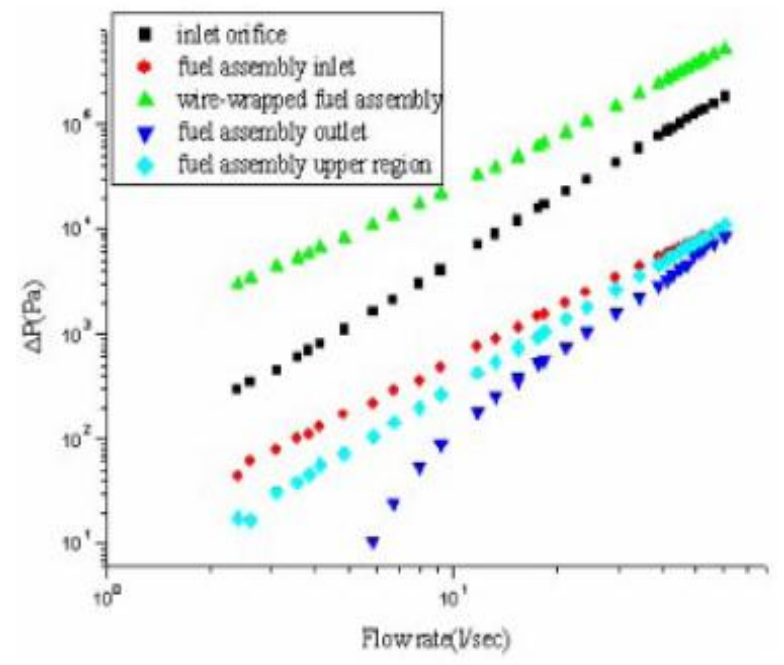

a)

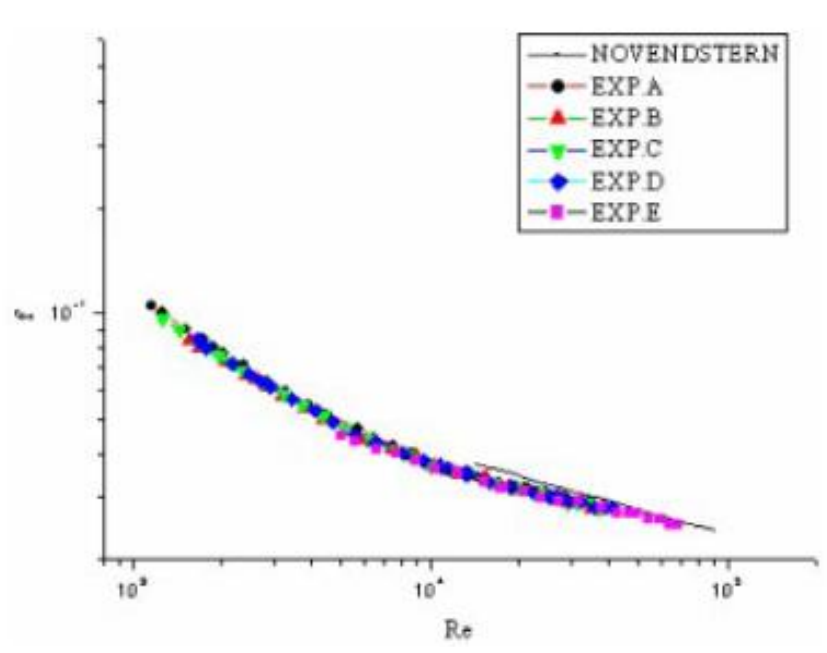

b)

Fig. 3. a) Relative magnitude of pressure drop in the fuel assembly, b) Comparison of Novendstern correlation with measured data: (water, Choi et al., 2003 (Choi et al, 2003))

Based on the data provided in Ref. (Choi et al, 2003), corresponding calculations were performed with SIM-ADS code and the calculation results were then compared to the experimental data of Fig.3. Fig. 4 shows the comparison of the calculation results for the wire-wrapped FA pressure drop (in the fuel region) as calculated using different friction factor correlations (see section 3 and 4) with the experimental data (compare with the topmost curve in Fig. 3a; note different units, i.e. Pa vs mbar). As can be seen in Fig. 4, all friction factor correlations provide a good fit to the experimental data in the turbulent regime (flow 
rate $>6 \mathrm{~kg} / \mathrm{s}$ ). The best fit to the experimental data over the entire mass flow range is observed (visual inspection) to be in order: Rehme, Novendstern and Engel (modified).

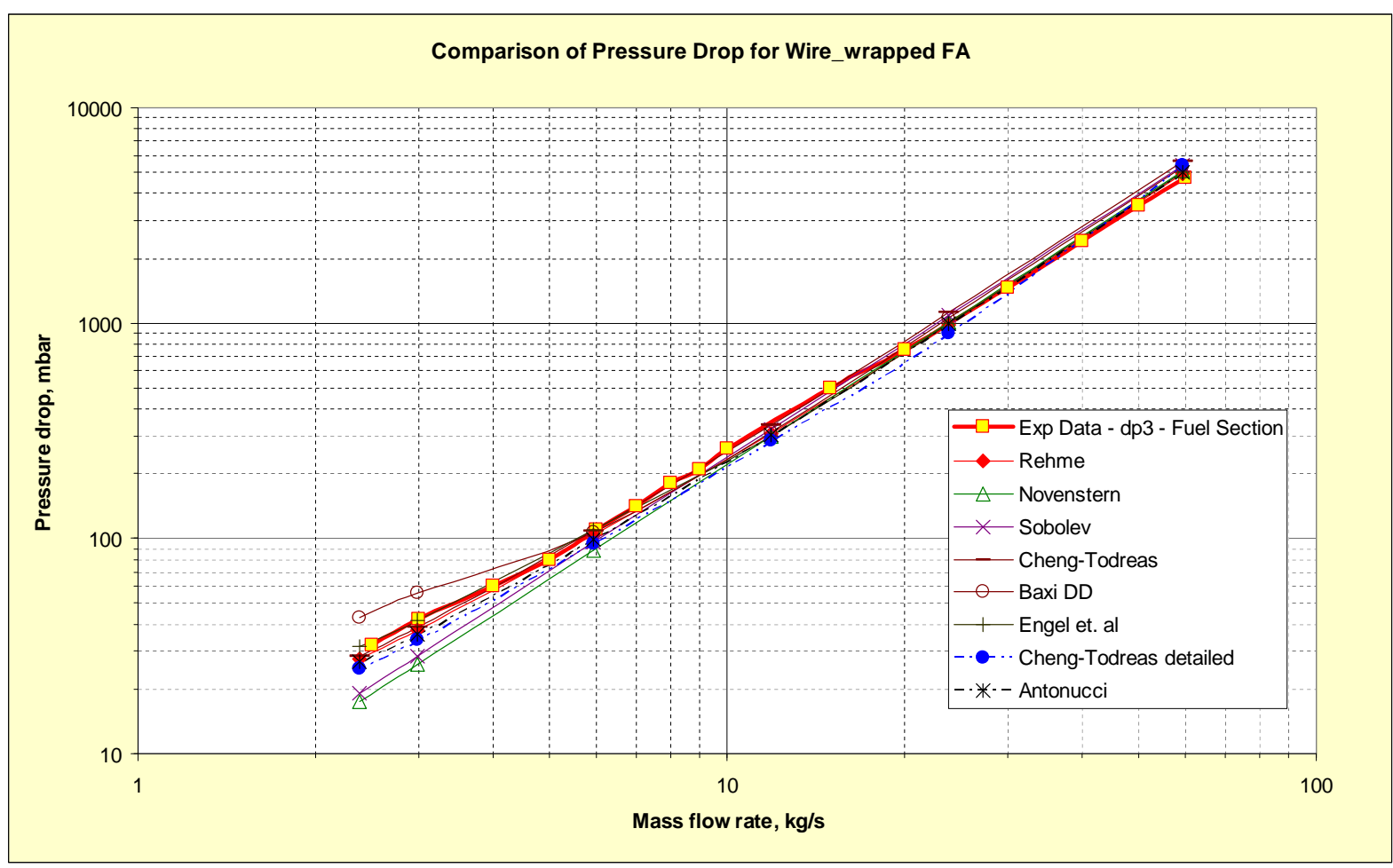

Fig. 4. Comparison of SIM-ADS calculated and experimental pressure drop in the wirewrapped fuel assembly (compare with the topmost curve in Fig. 3a): (water, Choi et al., 2003)

Fig. 5 shows the comparison for the pressure drops in different parts of the wirewrapped FA as calculated by SIM-ADS code and using Rehme friction factor correlation in the core region in comparison with the experimental data (compare with Fig. 3a).

The following formulations of the friction coefficients were obtained for FA inlet and outlet regions in order to obtain excellent agreement with the experimental data:

FA inlet friction coefficient $-K_{\text {inlet }}=1 /\left(0.025^{\star} R e^{0.5}\right)$;

FA outlet friction coefficient $-K_{\text {outlet }}=0.35^{\star} R e^{0.15}$. 
As can be observed, excellent agreement with the experimental data was obtained in most (inlet orifice and wire-wrapped fuel assembly) regions of the FA using Rehme correlation and the friction coefficients as presented above.

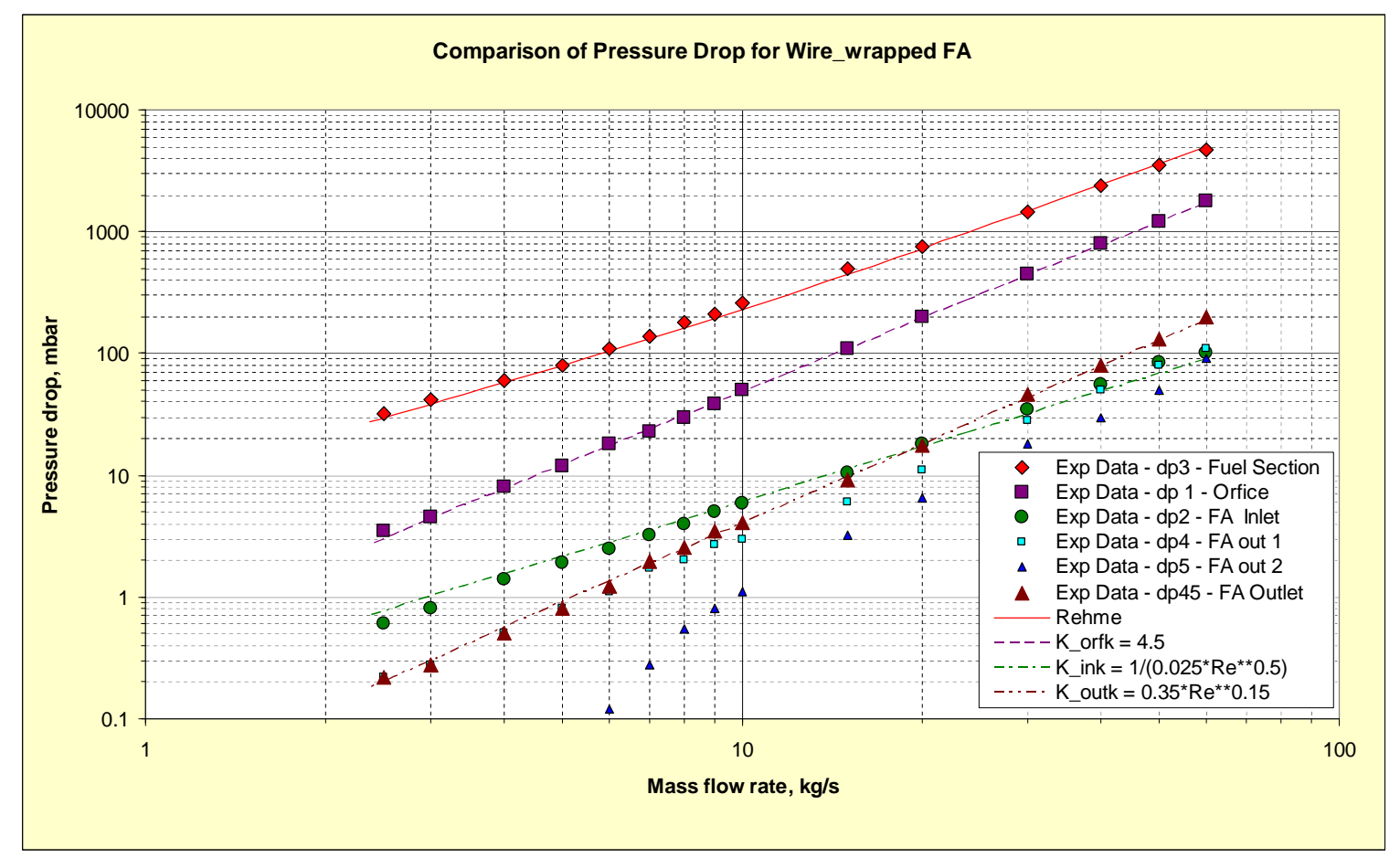

Fig. 5. Comparison of experimental and SIM-ADS calculated pressure drops in the different regions (inlet, outlet, fuel section, etc) of the wire-wrapped fuel assembly (compare with Fig. 3a): (water, Choi et al., 2003) using the above FA inlet and FA outlet models and Rehme for the fuel section.

Fig. 6 shows the comparison of the friction factor values for the wire-wrapped FA as calculated using the different friction factor correlations (see section 3 and 4 ) with the experimental data (compare with Fig. 3b). As can be seen from Fig. 6, friction factor correlations best fitting experimental data over the entire flow regime (laminar and turbulent) are in order (visual inspection): Rehme, Novendstern and Engel (modified). Sobolev and Novendstern correlations should be used only in turbulent region $(\operatorname{Re}>5000)$. 


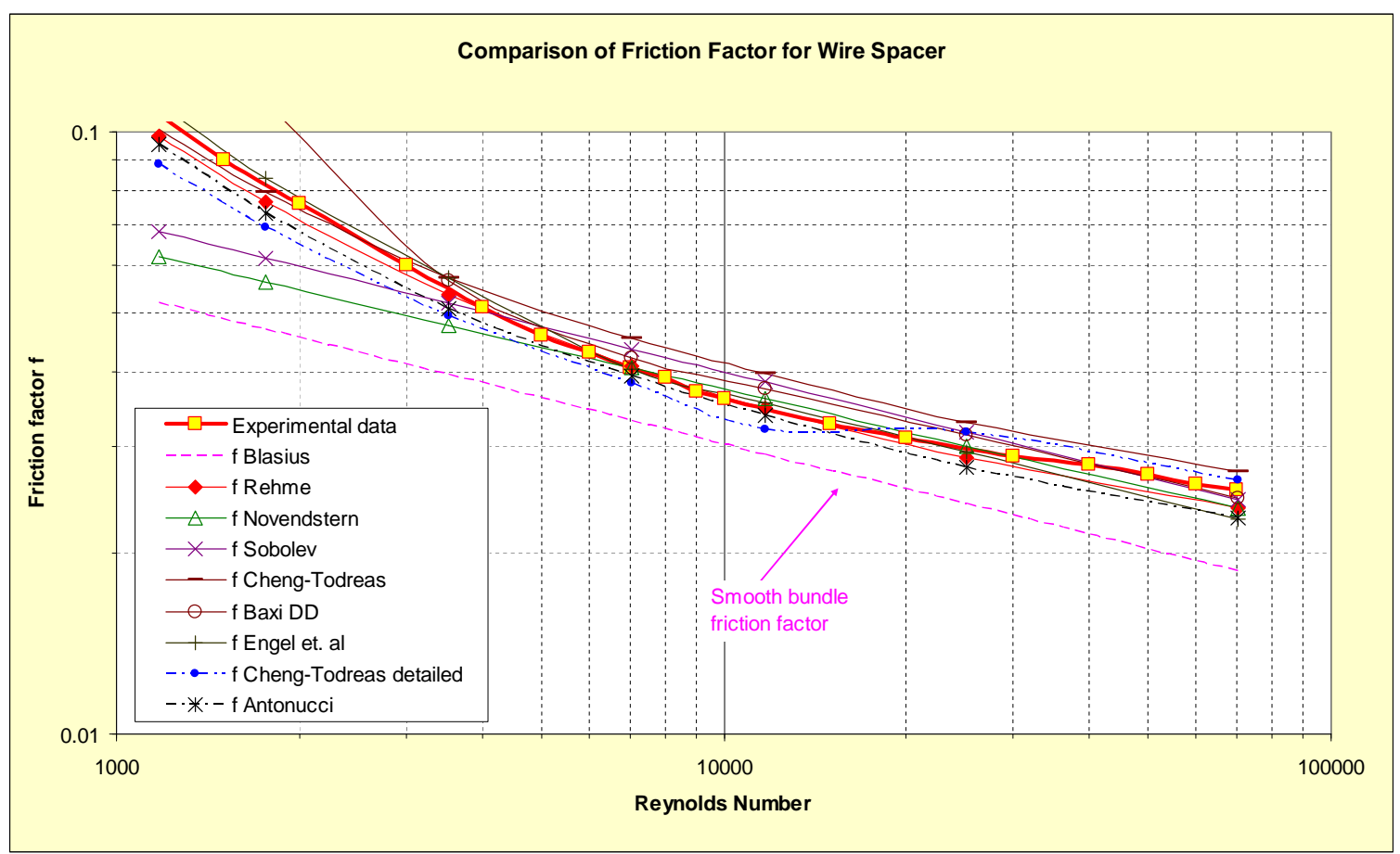

Fig. 6. Comparison of the SIM-ADS calculated and experimental friction factor values for the wire-wrapped fuel assembly (compare with Fig. 3b): (water, Choi et al., 2003)

\subsection{Chun et al., 2001 (Chun M.H. and Seo K.W., 2001) water experiments}

The schematic diagram of the water test loop used by Chun et al (Chun M.H. and Seo K.W., 2001) to measure the pressure drop in a 19-pin wire wrapped fuel assembly is shown in Fig. 7. One test section (B2) (Chun M.H. and Seo K.W., 2001) of the 19-pin FA that was analyzed here using the SIM-ADS code has the following characteristics: wire lead to diameter ratio is 25.0 , pitch to diameter ratio is 1.256 , bundle equivalent hydraulic diameter is 4.75 $\mathrm{mm}$, pin outer diameter is $8.0 \mathrm{~mm}$, pin pitch is $10.04 \mathrm{~mm}$, FA length is $1.3 \mathrm{~m}$, wire diameter is $2.0 \mathrm{~mm}$, wire lead length is $20 \mathrm{~cm}$. 


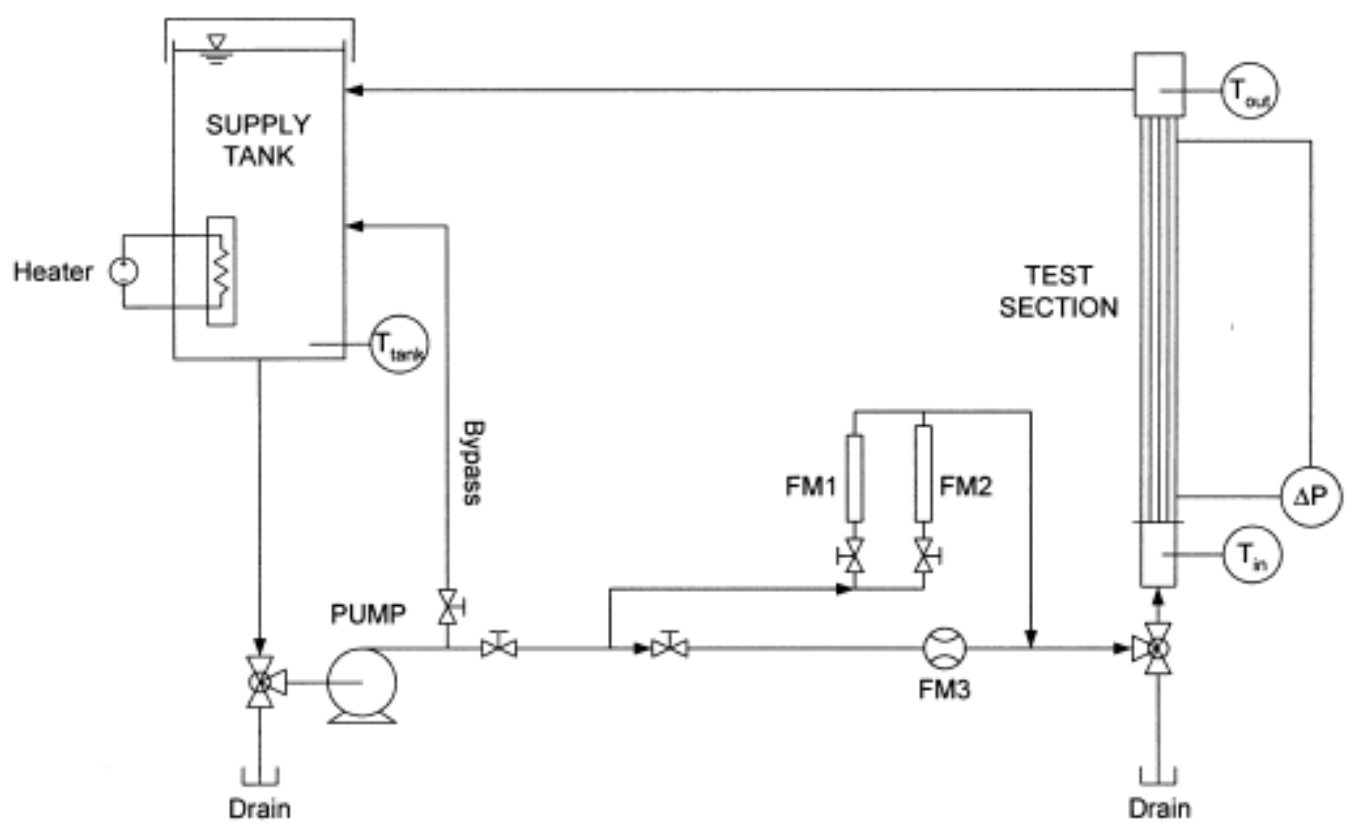

Fig. 7. Schematic diagram of the test loop: (water, Chun et al., 2001 (Chun M.H. and Seo K.W., 2001))

Experimental data for the FA friction factor values obtained with B2 test section are presented in Fig. 8. This figure shows the friction factor versus Reynolds number curves obtained by the authors of Ref. (Chun M.H. and Seo K.W., 2001) using five different friction factor correlations for wire-wrapped FAs along with the experimental data obtained with the test section B2 described above. From Fig. 8 one can deduce that the flow transition between the laminar and turbulent regions is quite smooth and continuous. The departure from the laminar flow occurs at a lower Reynolds number than that of the circular tube, while the fully turbulent flow occurs at a higher Reynolds number than that of the circular tube (Chun M.H. and Seo K.W., 2001). 


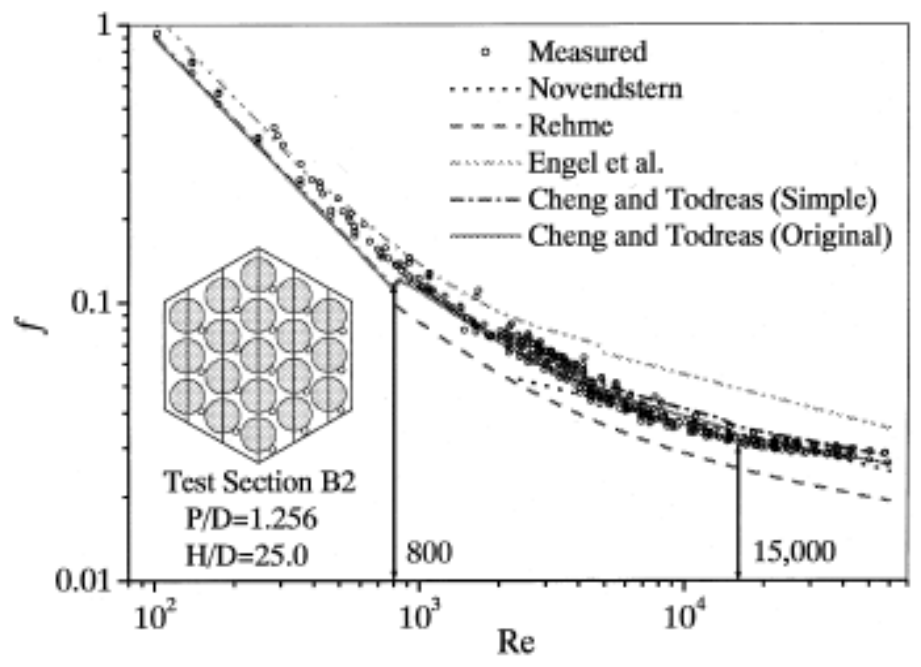

Fig. 8. Reynolds number vs. friction factor (test section B2): (water, Chun et al., 2001 (Chun M.H. and Seo K.W., 2001))

Based on the data provided in Ref. (Chun M.H. and Seo K.W., 2001), corresponding calculations were performed with the SIM-ADS code and the calculation results compared to the experimental data (presented in Fig. 8). Fig. 9 shows the comparison of the friction factor values for the wire-wrapped FA as calculated using different friction factor correlations (see section 3 and 4) with the experimental data (compare with Fig. 8). As can be seen from Fig. 9, friction factor correlations best fitting experimental data are in order (visual inspection): Engel (modified) - excellent fit, all the others - good fit. As it was already mentioned before, Sobolev and Novendstern correlations can be used only in the turbulent region $(\operatorname{Re}>5000)$. 


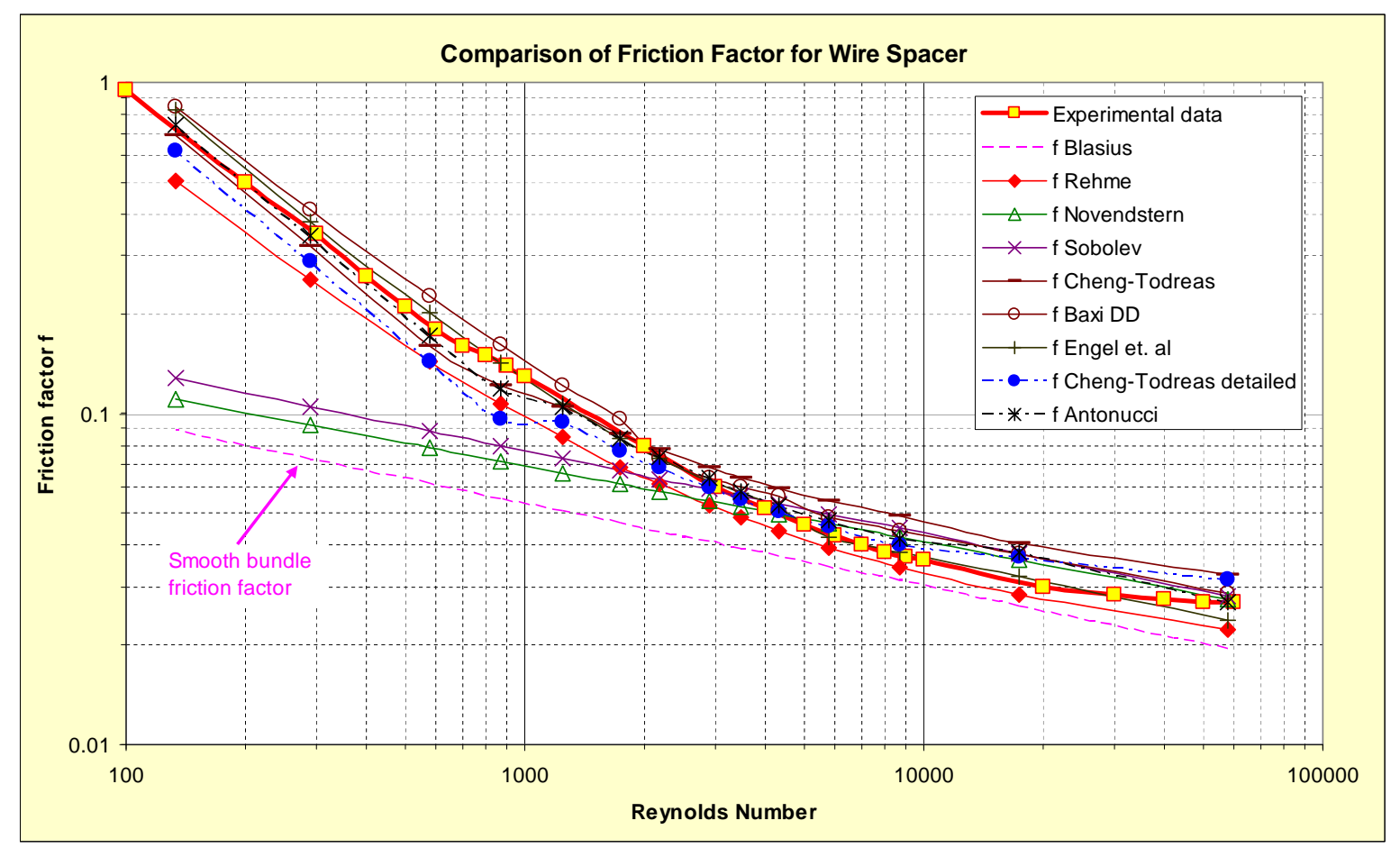

Fig. 9. Comparison of the SIM-ADS calculated and experimental friction factor values for the wire-wrapped fuel assembly (compare with Fig. 8 (Chun M.H. and Seo K.W., 2001)): (water, Chun et al., 2001)

\subsection{Arwikar et al., 1979 (Arwikar K. and Fenech H, 1979) water experiments}

Fig. 10 shows a schematic diagram of the closed loop water circulation system used by Arwikar et al (Arwikar K. and Fenech H, 1979) for their experiments. Water is pumped from a storage tank through the experimental section in the downward vertical direction. To counteract the temperature increase resulting from the mechanical energy of the pumps and to control the water loop temperature, the storage tank is provided with refrigerated cooling coils. It is possible to operate the loop at any fixed flow rate $(0.2 \div 30 \mathrm{l} / \mathrm{s})$ and temperature $\left(4 \div 43^{\circ} \mathrm{C}\right)$ ranges.

The experimental bundle consists of 61 stainless steel tubes arranged in a triangular pitch layout with a pitch to diameter ratio of 1.05 . The tubes have a $21.1 \mathrm{~mm}$ outside diameter and are $\sim 76.2 \mathrm{~cm}$ long. Each tube is tightly wrapped with a $1.067 \mathrm{~mm}$ diameter stainless steel wire at a helical pitch of $30.48 \mathrm{~mm}$ (Arwikar K. and Fenech $\mathrm{H}, 1979$ ). The tube bundle is 
placed in a hexagonal Plexiglas box with $25.4 \mathrm{~mm}$ thick walls. The inner sides of the box are each $10.287 \mathrm{~cm}$ wide and by squeezing the box with circular clamps, a tight fit between the box and the bundle was obtained which eliminates clearances between the wire-wraps of the peripheral tubes of the bundle and the inner faces of the box at all points wherever contact is made.

The weighted average $\Delta p$ values obtained from the pressure tapping readings have been used by Arwikar et al (Arwikar K. and Fenech H, 1979) to calculate friction factors which have been plotted against Reynolds number (based on bundle average values of hydraulic diameter and velocity) in Fig. 11. For comparison, Fig. 11 also includes standard friction factor curves for pipes and the curve representing Novendstern correlation for the experimental bundle.

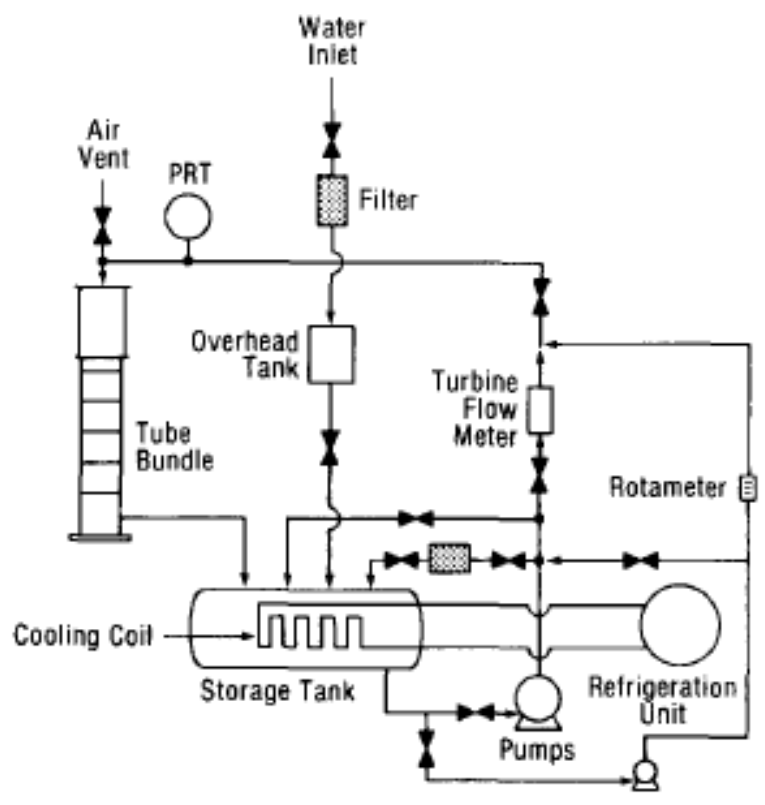

Fig. 10. Schematic diagram of the water circulation system: (water, Arwikar et al., 1979 (Arwikar K. and Fenech $\mathrm{H}$, 1979))

The experimental curve seems to be identical to the laminar pipe curve for very low Reynolds numbers $(\operatorname{Re}<400$ ), but is slightly higher beyond the value of $\operatorname{Re}=400$ and the transition sets in much earlier $(\operatorname{Re} \sim 1100)$ as compared to pipe flow $(\operatorname{Re}=2000)$. The flow 
seems to be completely turbulent beyond $\mathrm{Re}>2000$ and the curve does not follow any of the turbulent pipe flow curves plotted with relative roughness as a parameter (Arwikar K. and Fenech H, 1979).

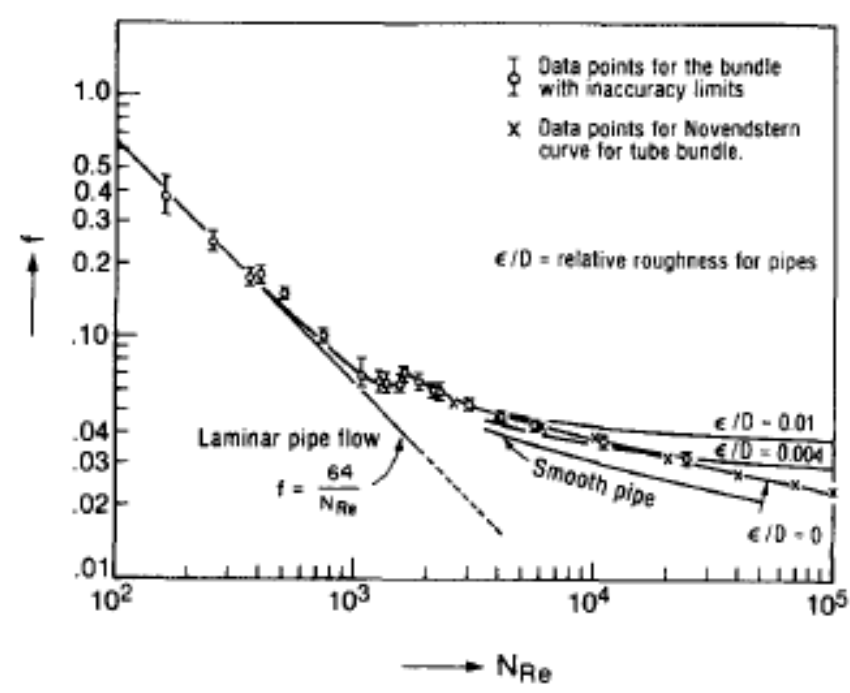

Fig. 11. Friction factor versus Reynolds number: (water, Arwikar et al., 1979 (Arwikar K. and Fenech $\mathrm{H}$, 1979))

Based on the data provided in Ref. (Arwikar K. and Fenech H, 1979), corresponding calculations were performed with the SIM-ADS code using the various models for wirewrapped FA, and the calculation results compared to the experimental data (presented in Fig. 11). Fig. 12 shows the comparison of the friction factor values for the wire-wrapped FA as calculated using different friction factor correlations (see section 3 and 4) with the experimental data (compare with Fig. 11). As can be seen from Fig. 12, friction factor correlations best fitting experimental data are in order (visual inspection): Novendstern, Baxi and DalleDonne (modified), Engel (modified). As it was already mentioned before, Sobolev and Novendstern correlations can be used only in turbulent region ( $R e>2000)$. 


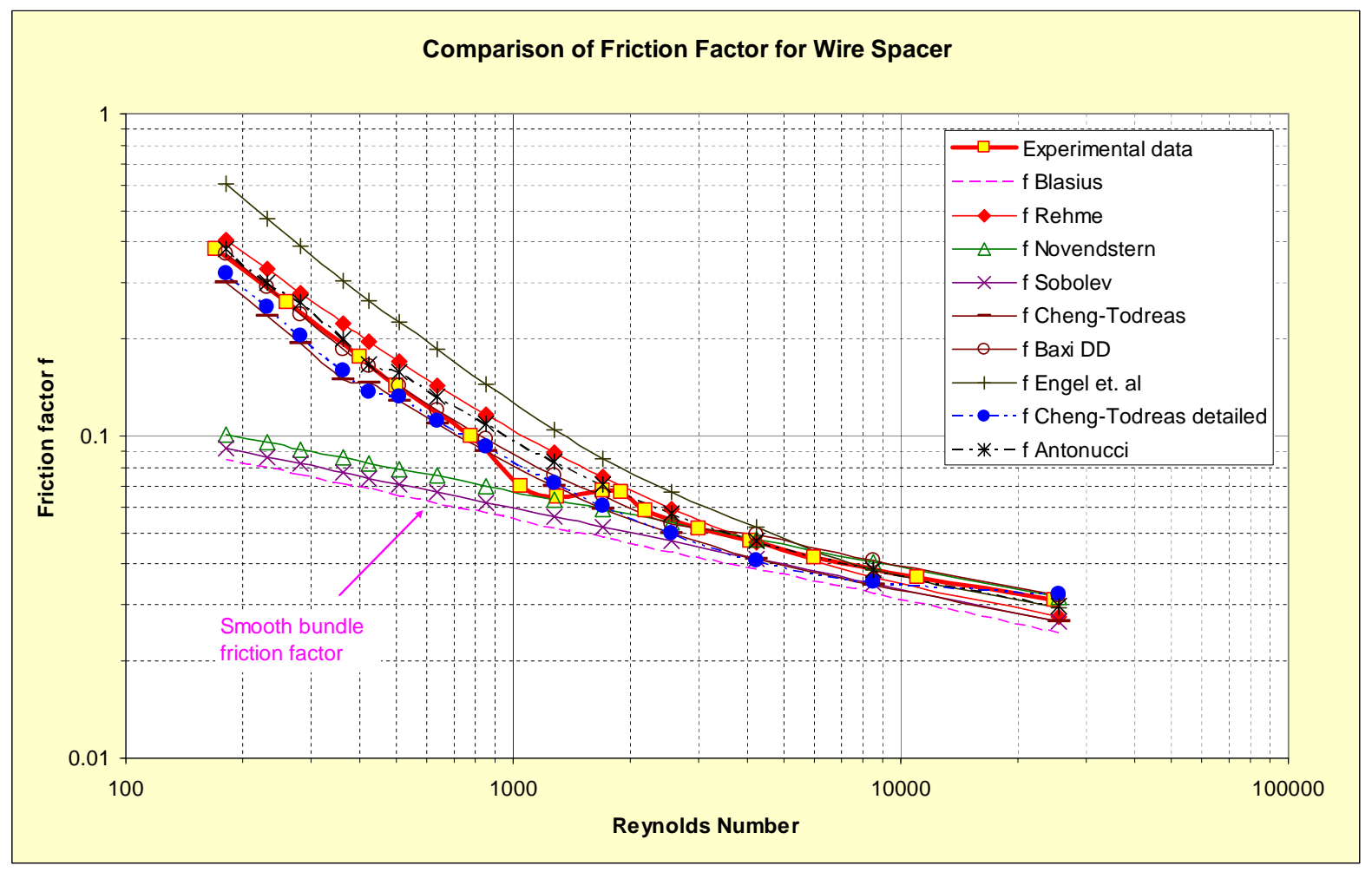

Fig. 12. Comparison of the SIM-ADS calculated and experimental friction factor values for the wire-wrapped fuel assembly (compare with Fig. 11): (water, Arwikar et al., 1979)

\subsection{Chiu et al., 1979 (Chiu C. et al, 1979) water experiments}

Friction factor measurement results for wire wrapped fuel bundle as obtained by Chiu et al (Chiu C. et al, 1979) were presented by Carajilescov et al in Ref. (Carajilescov P. and Fernandez E. F., 1999) (see Fig. 13). Along with the experimental data, Fig. 13 also presents calculation results by Carajilescov et al (curves - 'Present Method') using their own developed method for friction factor calculation in wire-wrapped rod bundles (Carajilescov P. and Fernandez E. F., 1999), as well as calculation results obtained using friction factor correlations proposed by Hawley, Engel and Novendstern. Rod bundle parameters for the Chiu et al (Chiu C. et al, 1979) experimental setup are: number of pins/rods is 61 , pitch to diameter ratio is 1.063 , wire lead length to diameter ratio is 8.0 and pin/rod diameter is $12.73 \mathrm{~mm}$. 


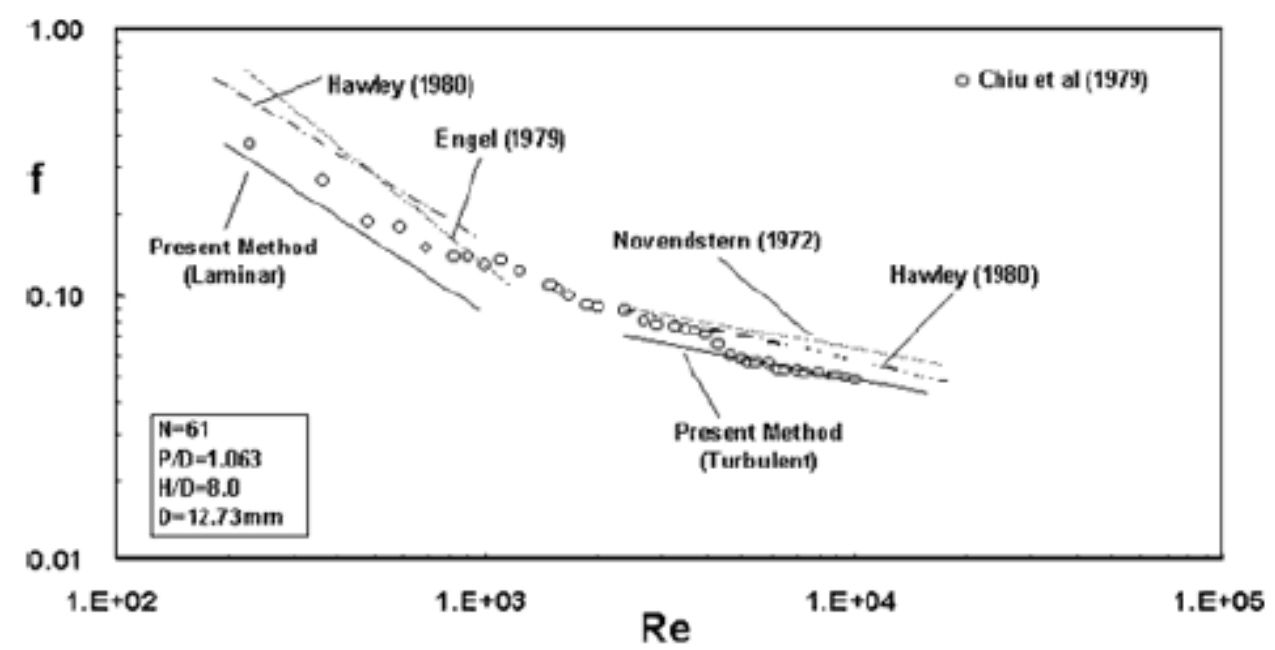

Fig. 13. Comparison of results for bundle average friction factors: (water, Chiu et al., 1979 (Chiu C. et al, 1979; Carajilescov P. and Fernandez E. F., 1999))

Based on the Chiu et al (Chiu C. et al, 1979) data provided in Ref. (Carajilescov P. and Fernandez E. F., 1999), corresponding calculations were performed with the SIM-ADS code and the calculation results compared to the experimental data (presented in Fig. 13). Fig. 14 shows the comparison of the friction factor values for the wire-wrapped FA as calculated using different friction factor correlations (see section 3 and 4) with the experimental data (compare with Fig. 13). As can be seen from Fig. 14, friction factor correlations best fitting experimental data are in order: Rehme and Sobolev. As it was already mentioned before, Sobolev and Novendstern correlations can be considered only in turbulent region $(\mathrm{Re}>$ 2000). 


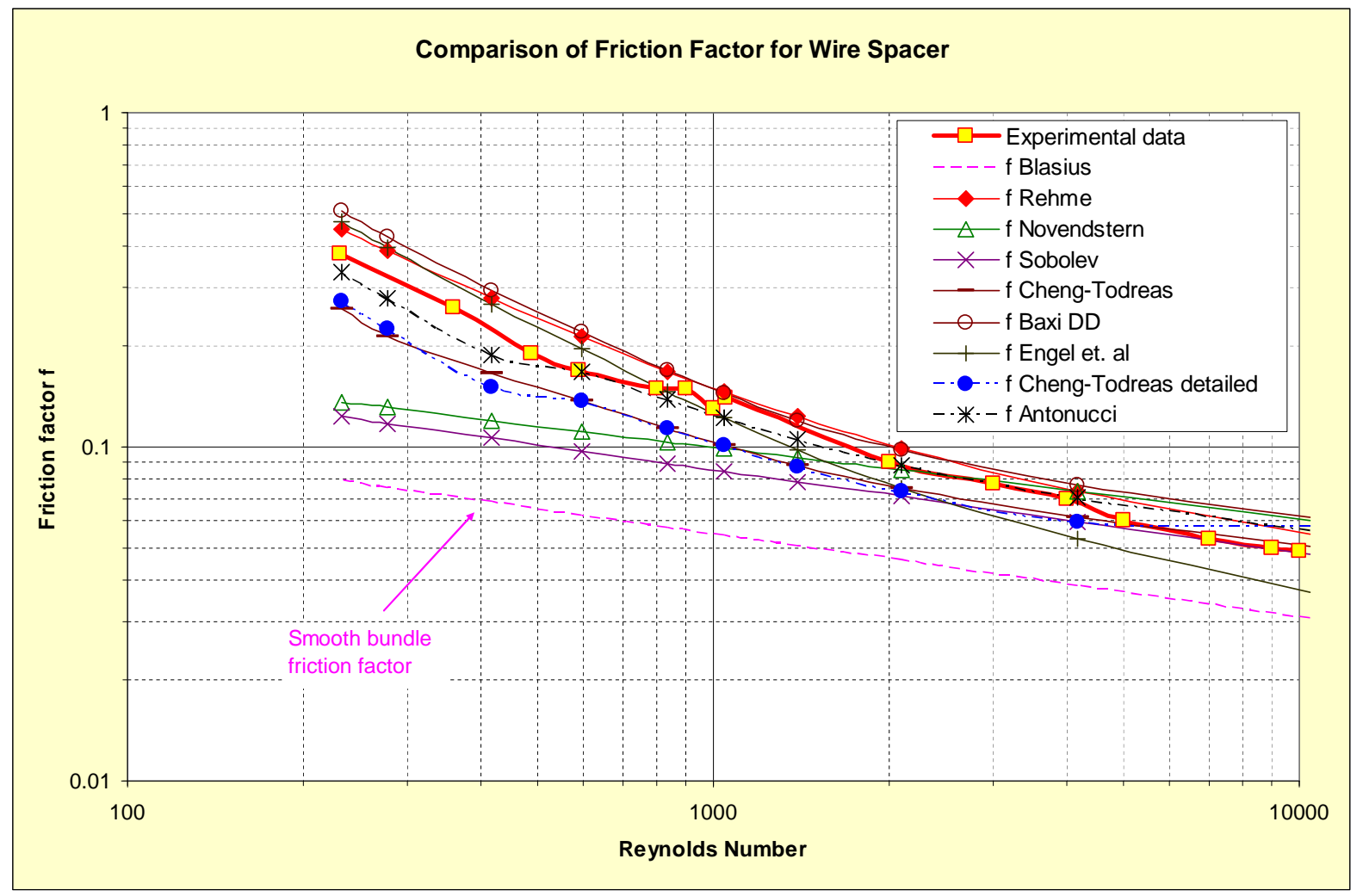

Fig. 14. Comparison of the SIM-ADS calculated and the experimental friction factor values for the wire-wrapped fuel assembly (compare with Fig. 13): (water, Chiu et al., 1979)

\subsection{Tong/Bishop, 1968 (Tong L.S., 1968) water experiments}

Friction factor measurement results for wire wrapped fuel bundle as obtained by Tong/Bishop (Tong L.S., 1968) were presented by Carajilescov et al in Ref. (Carajilescov P. and Fernandez E. F., 1999) (see Fig. 15). Along with the experimental data, Fig. 15 also presents calculation results by Carajilescov et al (curves - 'Present Method') using their own developed method for friction factor calculation in wire-wrapped rod bundles (Carajilescov P. and Fernandez E. F., 1999). Rod bundle parameters for the Tong/Bishop (Tong L.S., 1968) experimental setup are: number of pins/rods is 19 , pitch to diameter ratio is 1.205 , wire lead length to diameter ratios are 8,16 and 24; pin/rod diameter is assumed to be $12.73 \mathrm{~mm}$ (as no information is provided in Ref. (Carajilescov P. and Fernandez E. F., 1999)). 


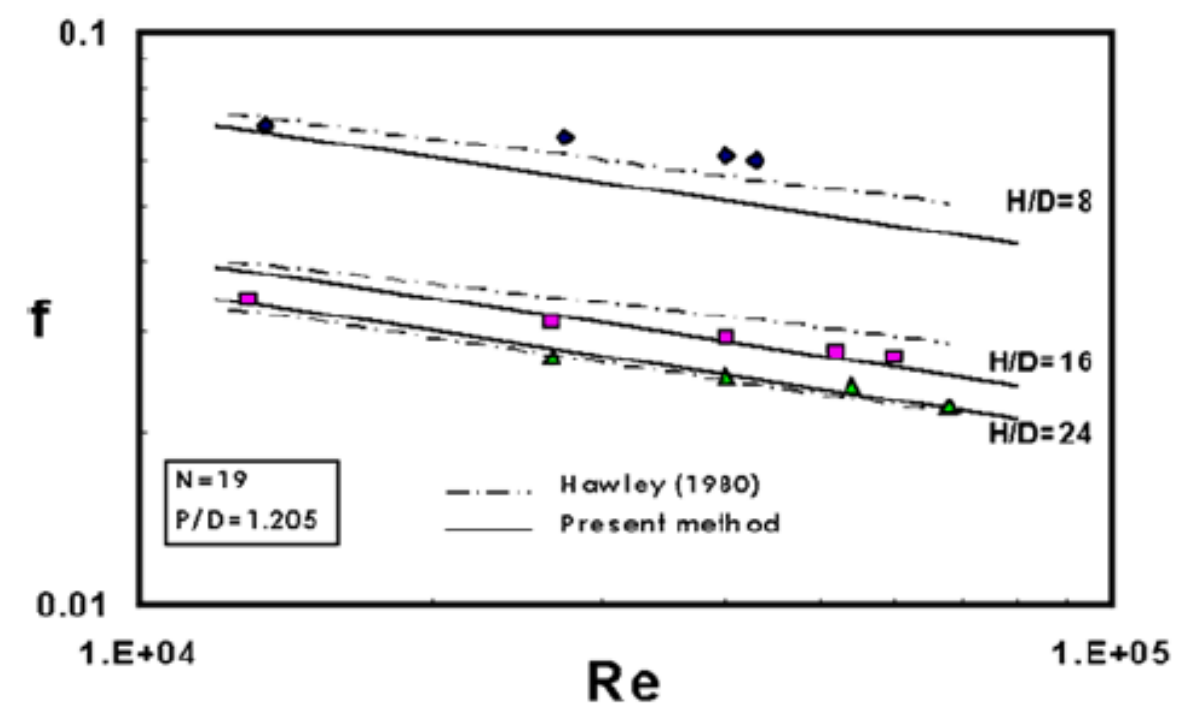

Fig. 15. Comparison of results for bundle average friction factors: (water, Tong/Bishop, 1968 (Carajilescov P. and Fernandez E. F., 1999; Tong L.S., 1968))

Based on the Tong/Bishop (Tong L.S., 1968) data provided in Ref. (Carajilescov P. and Fernandez E. F., 1999), corresponding calculations were performed with the SIM-ADS code and the calculation results compared to the experimental data (presented in Fig. 15). Figs. 16 and 17 shows the comparison of the friction factor values for the wire-wrapped FA as calculated using different friction factor correlations (see section 3 and 4) with the experimental data (compare with Fig. 15). As can be seen from Figs. 16 and 17, friction factor correlations best fitting experimental data are in order: Rehme and Engel (modified). 


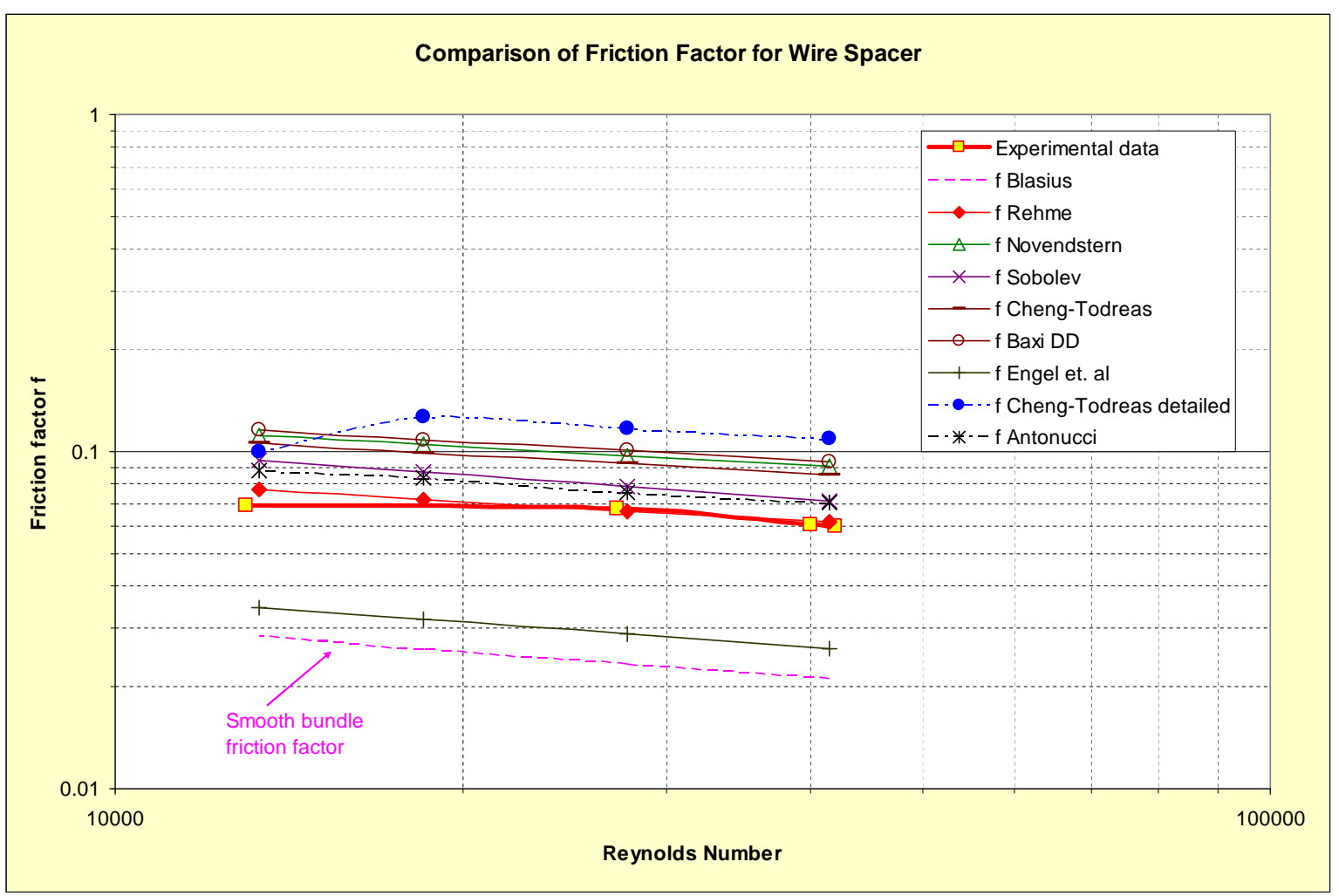

Fig. 16. Comparison of the SIM-ADS calculated and experimental friction factor values for the wire-wrapped fuel assembly (compare with Fig. 15, case $H / D=8$ ): (water, Tong/Bishop, 1968)

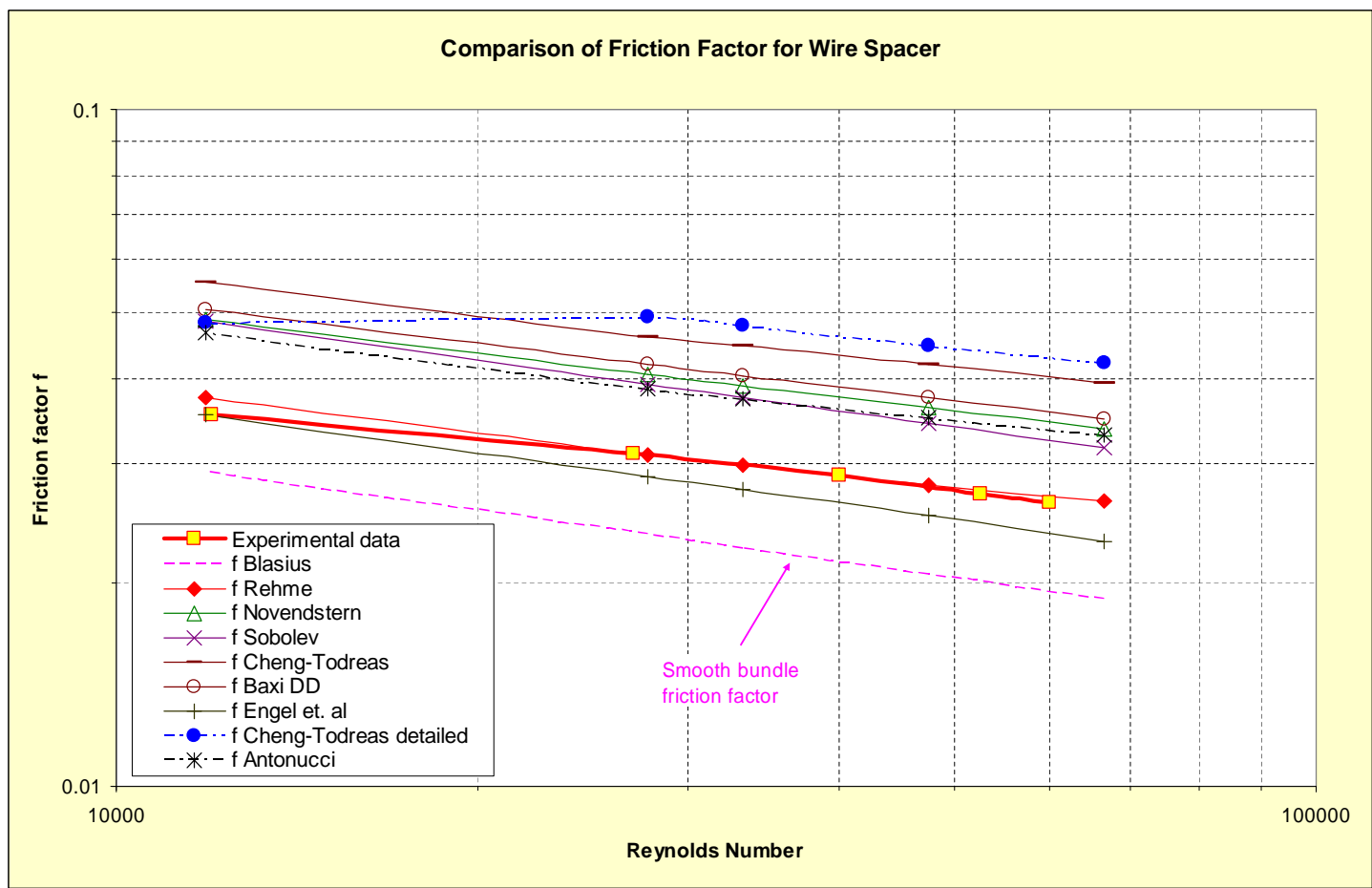

Fig. 17. Comparison of the SIM-ADS calculated and the experimental friction factor values for the wire-wrapped fuel assembly (compare with Fig. 15, case $H / D=16$ ): (water, Tong/Bishop, 1968) 


\subsection{Marten et al., 1982 (Marten K., Yonekawa S. and Hoffmann H, 1982) water experiments}

Friction factor measurement results for wire wrapped fuel bundle as obtained by Marten et al (Marten K., Yonekawa S. and Hoffmann H, 1982) were presented by Cheng and Todreas in Ref. (Cheng S.K. and Todreas N.E., 1986) (see Fig. 18). Along with the experimental data, Fig. 18 also presents calculation results by Cheng and Todreas (curves - 'Proposed Correlation') using their own developed method for friction factor calculation in wirewrapped rod bundles (Cheng S.K. and Todreas N.E., 1986). Rod bundle parameters for the Marten et al (Marten K., Yonekawa S. and Hoffmann H, 1982) experimental setup are: number of pins/rods is 37 , pitch to diameter ratios are $1.041,1.072$ and 1.101 , wire lead length to diameter ratios are $17.01,7.78$ and 12.31 , correspondingly; pin/rod diameter is assumed to be $12.0 \mathrm{~mm}$ (as no information is provided in Ref. (Cheng S.K. and Todreas N.E., 1986)).

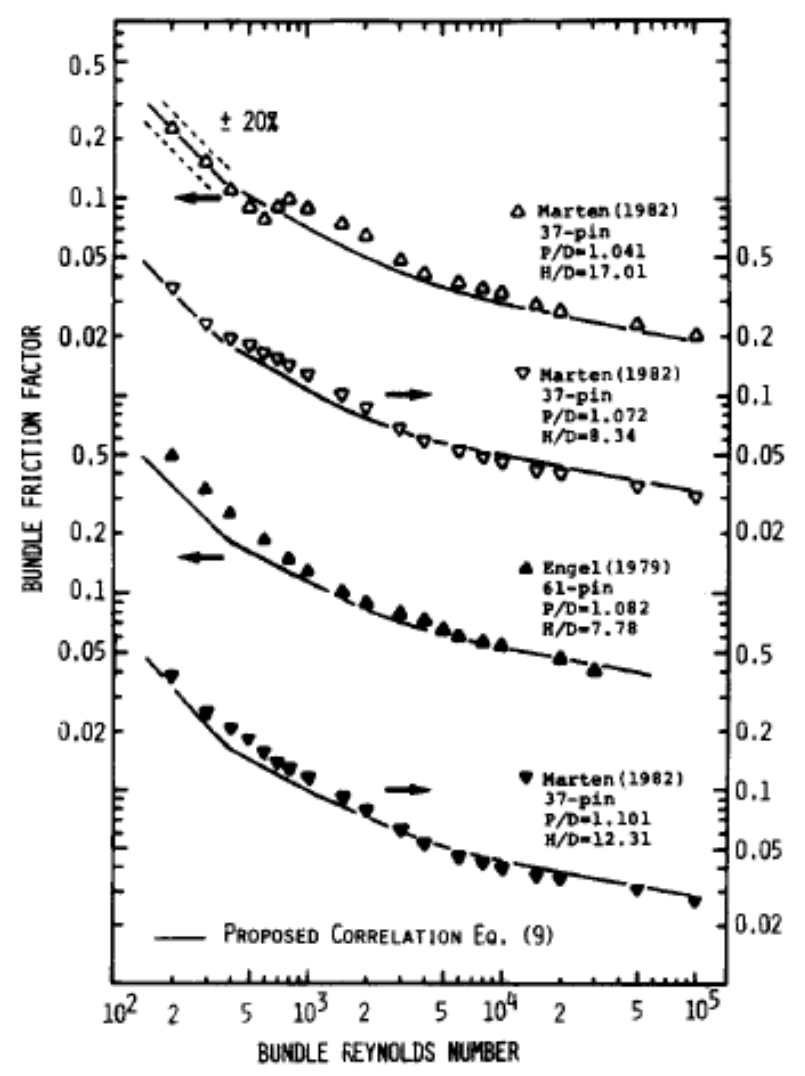

Fig. 18. Comparison between experimental data and predictions for wire-wrapped bundle friction factor: (water, Marten et al., 1982 (Marten K., Yonekawa S. and Hoffmann H, 1982; Cheng S.K. and Todreas N.E., 1986)) 
Based on the Marten et al (Marten K., Yonekawa S. and Hoffmann H, 1982) data provided in Ref. (Cheng S.K. and Todreas N.E., 1986), corresponding calculations were performed with the SIM-ADS code and the calculation results compared to the experimental data (presented in Fig. 18). Figs. 19 and 20 shows the comparison of the friction factor values for the wire-wrapped FA as calculated using different friction factor correlations (see section 3 and 4) with the experimental data (compare with Fig. 18). As can be seen from Figs. 19 and 20, friction factor correlations best fitting experimental data are in order: Novendstern and Sobolev. As it was already mentioned before, Sobolev and Novendstern correlations can be used only in turbulent region $(\mathrm{Re}>30009)$.

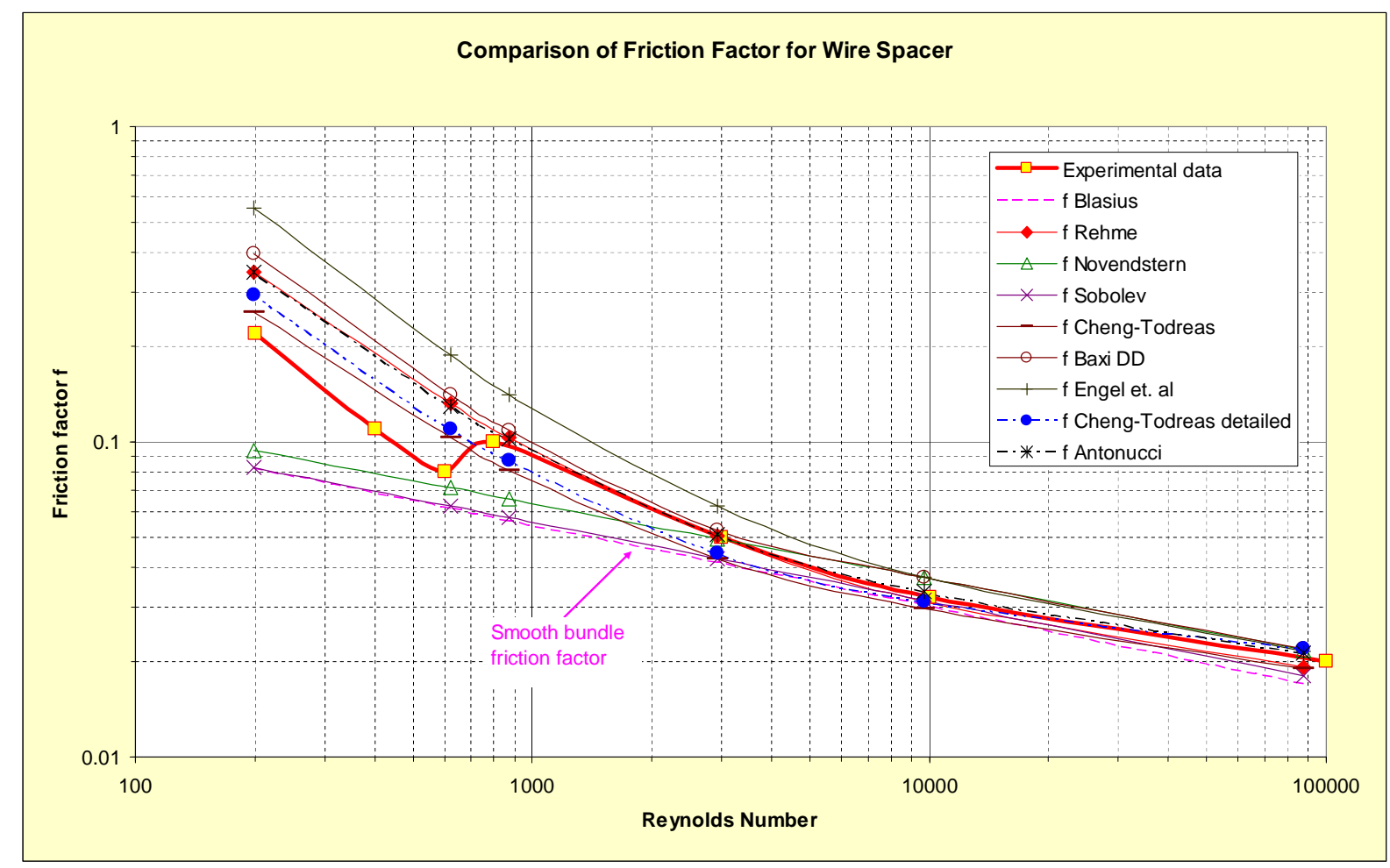

Fig. 19. Comparison of the SIM-ADS calculated and experimental friction factor values for the wire-wrapped fuel assembly (compare with Fig. 18, case $P / D=1.041$; $H / D=17.01$ ): (water, Marten et al., 1982) 


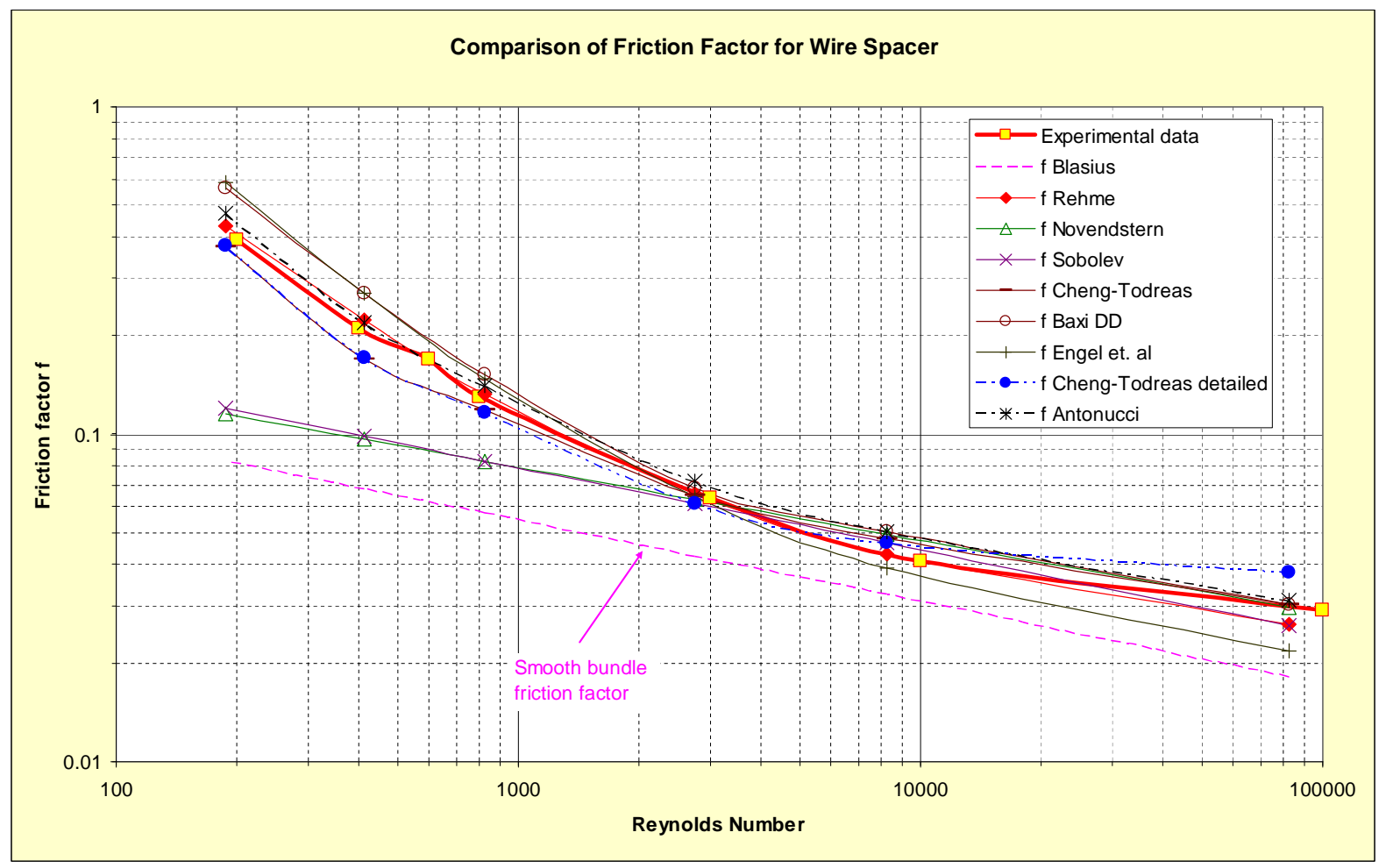

Fig. 20. Comparison of the SIM-ADS calculated and experimental friction factor values for the wire-wrapped fuel assembly (compare with Fig. 18, case $P / D=1.101$; $H / D=12.31$ ): (water, Marten et al., 1982)

\subsection{Itch, 1981 (Cheng S.K., 1984) water experiments}

Friction factor measurement results for wire wrapped fuel bundle as obtained by Itch (Cheng S.K., 1984) were presented by Cheng and Todreas in Ref. (Cheng S.K. and Todreas N.E., 1986) (see Fig. 21). Along with the experimental data, Fig. 21 also presents calculation results by Cheng and Todreas (curves - 'Proposed Correlation') using their own developed method for friction factor calculation in wire-wrapped rod bundles (Cheng S.K. and Todreas N.E., 1986). Rod bundle parameters for the Itch (Cheng S.K., 1984) experimental setup are: number of pins/rods are 127 and 169, pitch to diameter ratios are 1.176 and 1.214, wire lead length to diameter ratios are 38.0 and 47.39 , correspondingly; pin/rod diameter is assumed to be $12.0 \mathrm{~mm}$ (as no information is provided in Ref. (Cheng S.K. and Todreas N.E., 1986)). 


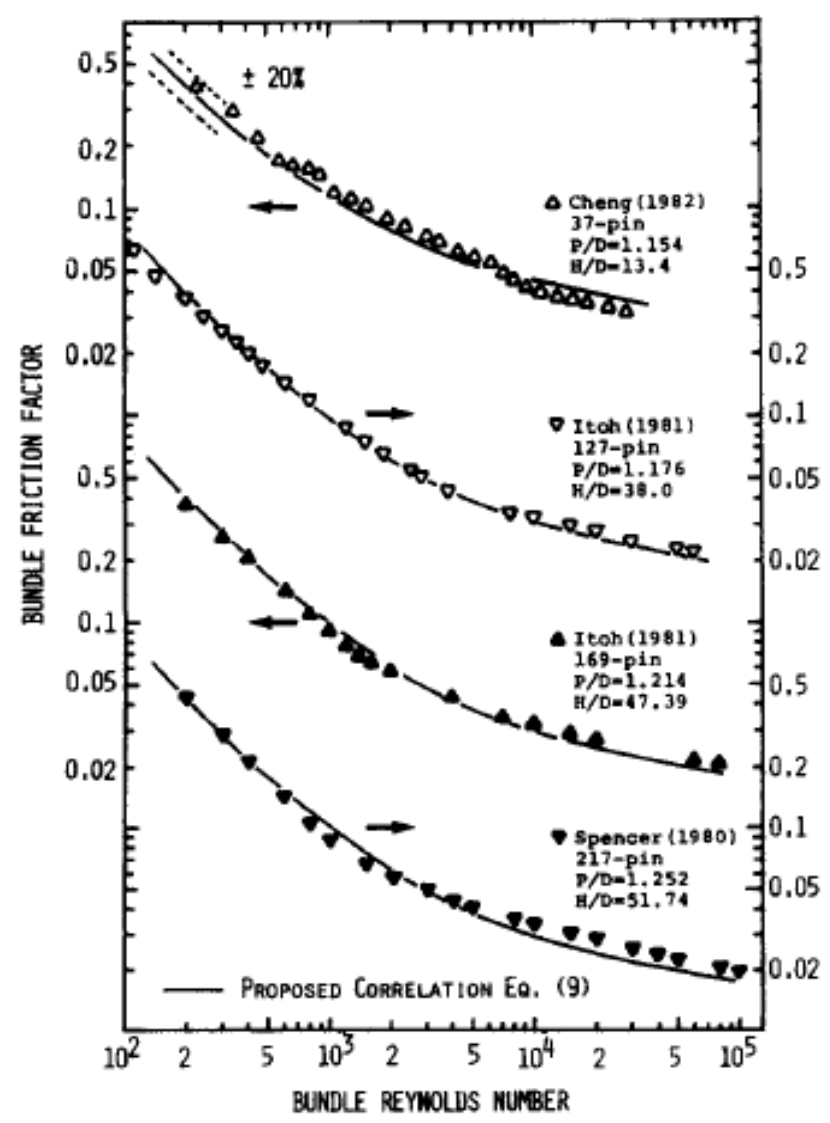

Fig. 21. Comparison between experimental data and predictions for wire-wrapped bundle friction factor: (water, Itch, 1981 (Cheng S.K. and Todreas N.E., 1986; Cheng S.K., 1984))

Based on the Itch (Cheng S.K., 1984) data provided in Ref. (Cheng S.K. and Todreas N.E., 1986), corresponding calculations were performed with SIM-ADS code and the calculation results compared to the experimental data (see Fig. 21). Figs. 22 and 23 shows the comparison of the friction factor values for the wire-wrapped FA as calculated using different friction factor correlations (see section 3 and 4) with the experimental data (compare with Fig. 21). As can be seen from Figs. 22 and 23, friction factor correlations best fitting experimental data are in order: all correlations - excellent fit, except Engel (modified) - good fit. As it was already mentioned before, Sobolev and Novendstern correlations can be considered only in turbulent region $(\operatorname{Re}>3000)$. 


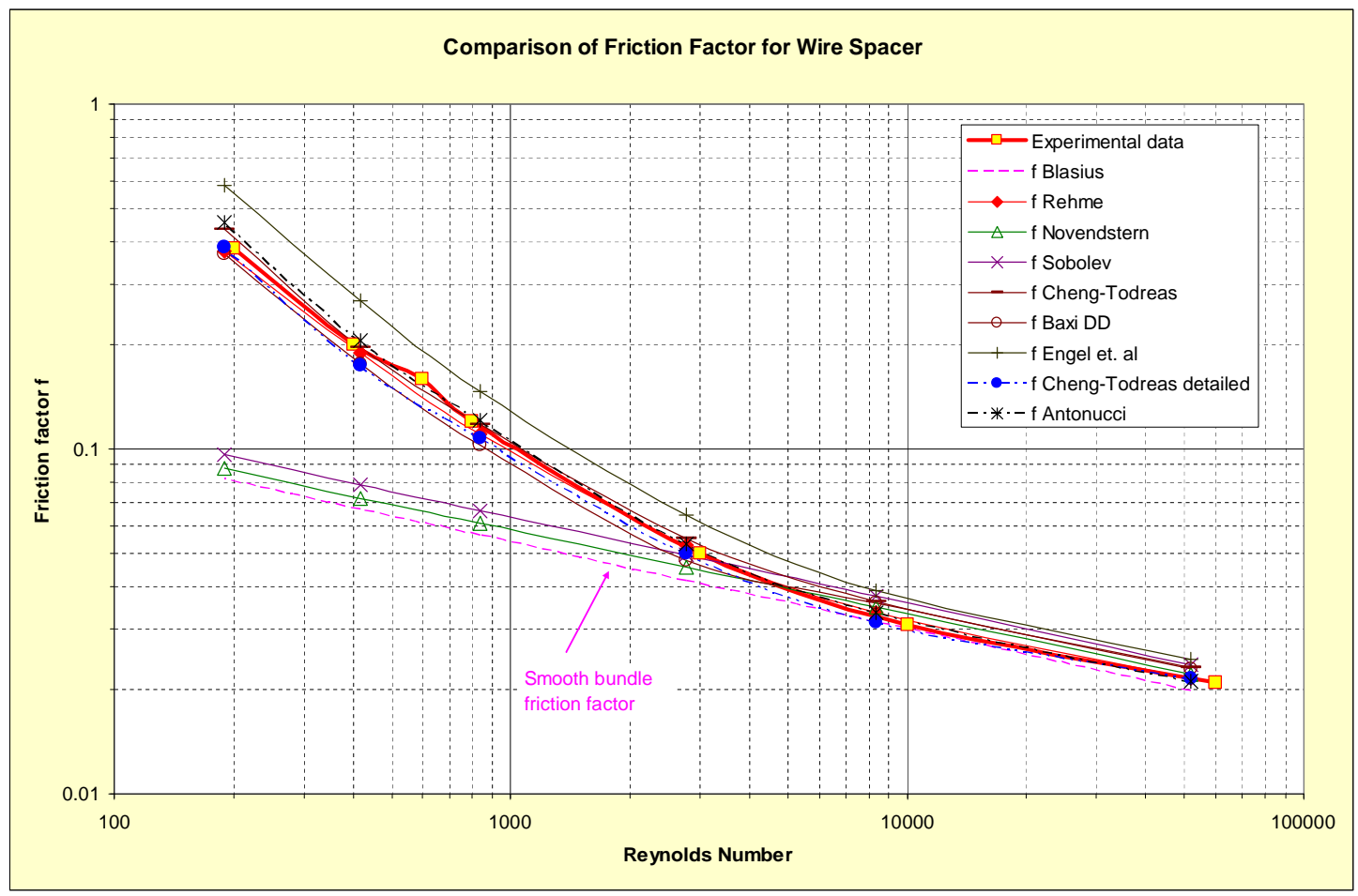

Fig. 22. Comparison of the SIM-ADS calculated and experimental friction factor values for the wire-wrapped fuel assembly (compare with Fig. 21, case 127-pin, $P / D=1.176$; $H / D=38.0$ ): (water, Itch, 1981)

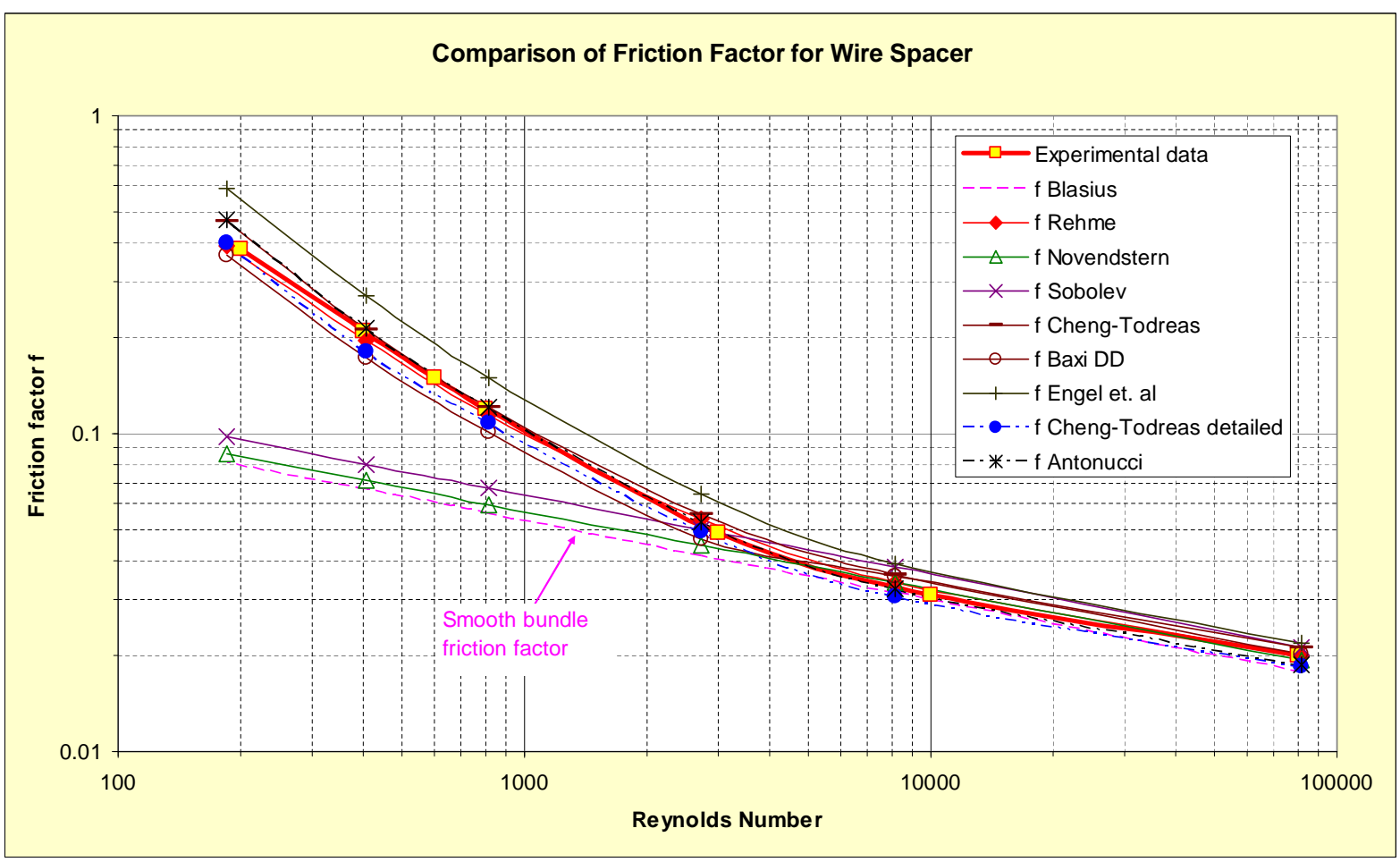

Fig. 23. Comparison of the SIM-ADS calculated and experimental friction factor values for the wire-wrapped fuel assembly (compare with Fig. 21, case 169-pin, $P / D=1.214$; $\mathrm{H} / \mathrm{D}=47.39)$ : (water, Itch, 1981) 


\subsection{Spencer, 1980 (Cheng S.K., 1984) water experiments}

Friction factor measurement results for wire wrapped fuel bundle as obtained by Spencer (Cheng S.K., 1984) were presented by Cheng and Todreas in Ref. (Cheng S.K. and Todreas N.E., 1986) (see Fig. 21). Along with the experimental data, Fig. 21 also presents calculation results by Cheng and Todreas (curves - 'Proposed Correlation') using their own developed method for friction factor calculation in wire-wrapped rod bundles (Cheng S.K. and Todreas N.E., 1986). Rod bundle parameters for the Spencer (Cheng S.K., 1984) experimental setup are: number of pins/rods is 217 , pitch to diameter ratio is 1.252 , wire lead length to diameter ratio is 51.74 ; pin/rod diameter is assumed to be $12.0 \mathrm{~mm}$ (as no information is provided in Ref. (Cheng S.K. and Todreas N.E., 1986)).

Based on the Spencer (Cheng S.K., 1984) data provided in Ref. (Cheng S.K. and Todreas N.E., 1986), corresponding calculations were performed with SIM-ADS code and the calculation results compared to the experimental data (see Fig. 21). Fig. 24 shows the comparison of the friction factor values for the wire-wrapped FA as calculated using different friction factor correlations (see section 3 and 4) with the experimental data (compare with Fig. 21). As can be seen from Fig. 24, friction factor correlations best fitting experimental data are in order: Rehme, Novendstern, Sobolev and Cheng-Todreas simplified. As it was already mentioned before, Sobolev and Novendstern correlations can be considered only in turbulent region $(\operatorname{Re}>3000)$. 


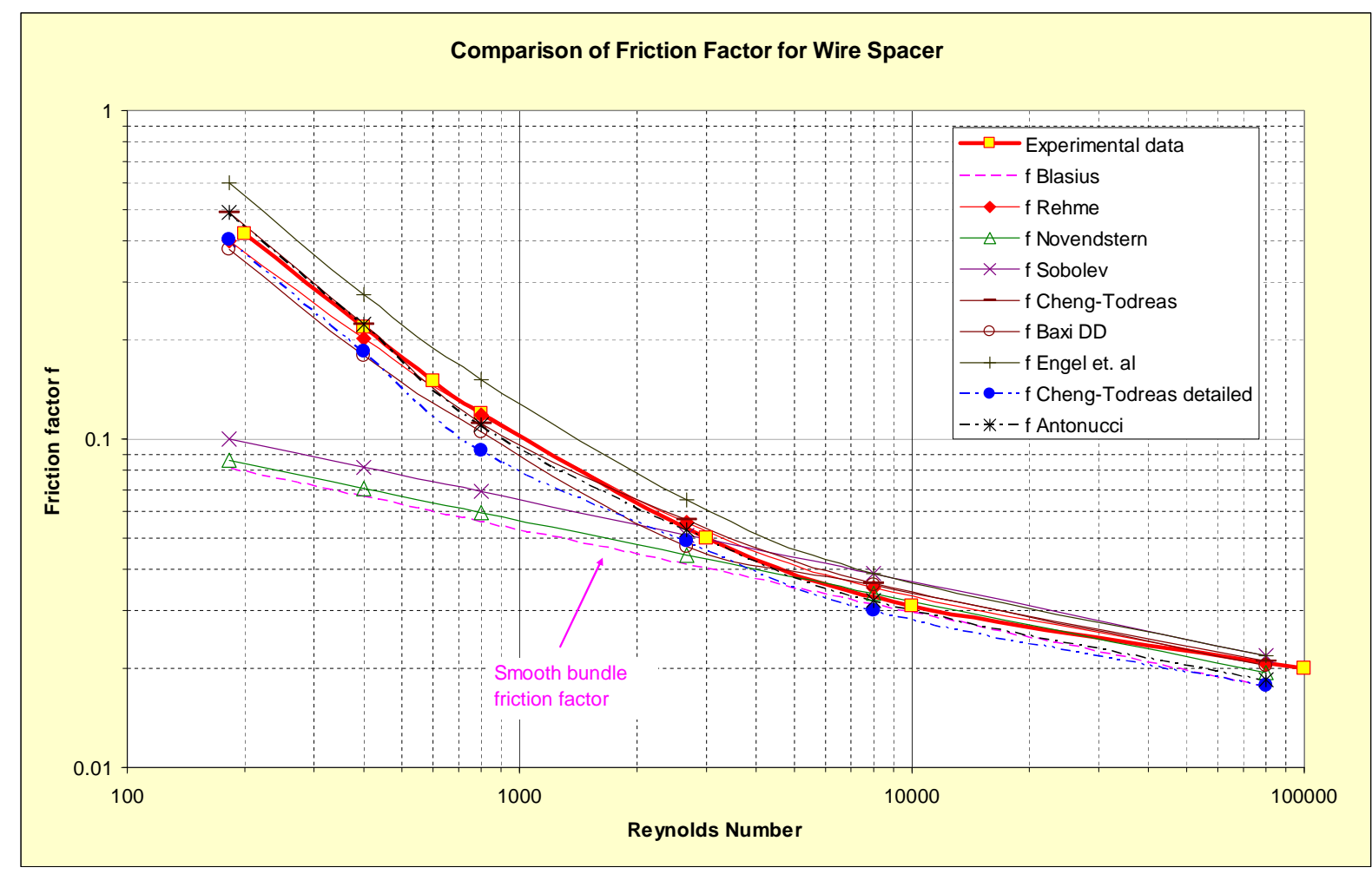

Fig. 24. Comparison of the SIM-ADS calculated and experimental friction factor values for the wire-wrapped fuel assembly (compare with Fig. 21, case 217-pin, $P / D=1.252$; $H / D=51.74)$ : (water, Spencer, 1980)

\subsection{Rehme, 1973 (Rehme K., 1973) water experiments}

Friction factor measurement results for wire wrapped fuel bundles as obtained by Rehme (Rehme K., 1973) are presented in Ref. (Rehme K., 1973) in a series of figures. Results presented in Figs. 4, 5, 6 and 8 of the Ref. (Rehme K., 1973) are analyzed below in this report. Experiments on wire-wraps as spacers were conducted in a water loop the water of which was circulated by a centrifugal pump (mass flow rate $\sim 360 \mathrm{~m}^{3} / \mathrm{h}$ with a differential pressure at the test section of $\Delta \mathrm{p}=12$ bar) from the storage tank to a cooler, where the heat added in the pump was removed and then forced through the horizontal test section. The amount of water passing through the test section was controlled partly by a bypass and partly by throttling. The length of the test section was $1500 \mathrm{~mm}$. The stainless steel rods of a diameter $12 \mathrm{~mm}$ and length $940 \mathrm{~mm}$ were inserted into a hexagonal channel. The polished surface of the cores resulted in a perfectly smooth surface of the channel (Rehme K., 1973). 
Systematic measurements of the pressure loss performance of the wire wrapped rod bundles in hexagonal arrays were carried out by $\mathrm{K}$. Rehme. The important parameters varied in that study are the pitch-to-diameter ratio of the rods by using different wire diameters with the same rod diameter, the lead of the wire wraps and the number of rods in the rod bundles. The pitch-to-diameter ratio studied ranged between 1.125 and 1.417 , the lead of the wire wraps between 100 and $600 \mathrm{~mm}$, and the number of rods between 7 and 61 rods (Rehme K., 1973).

The first set of the Rehme experimental data analyzed here - Fig. 25 demonstrates the effect of different leads of wire wraps on the friction factor for 19 rods and the highest pitch-to-diameter ratio tested - 1.417. It is obvious that the friction factor increases with decreasing wire wraps pitch. One can see a strong increase in the friction factor with a high pitch-to-diameter ratio of the rods (Rehme K., 1973).

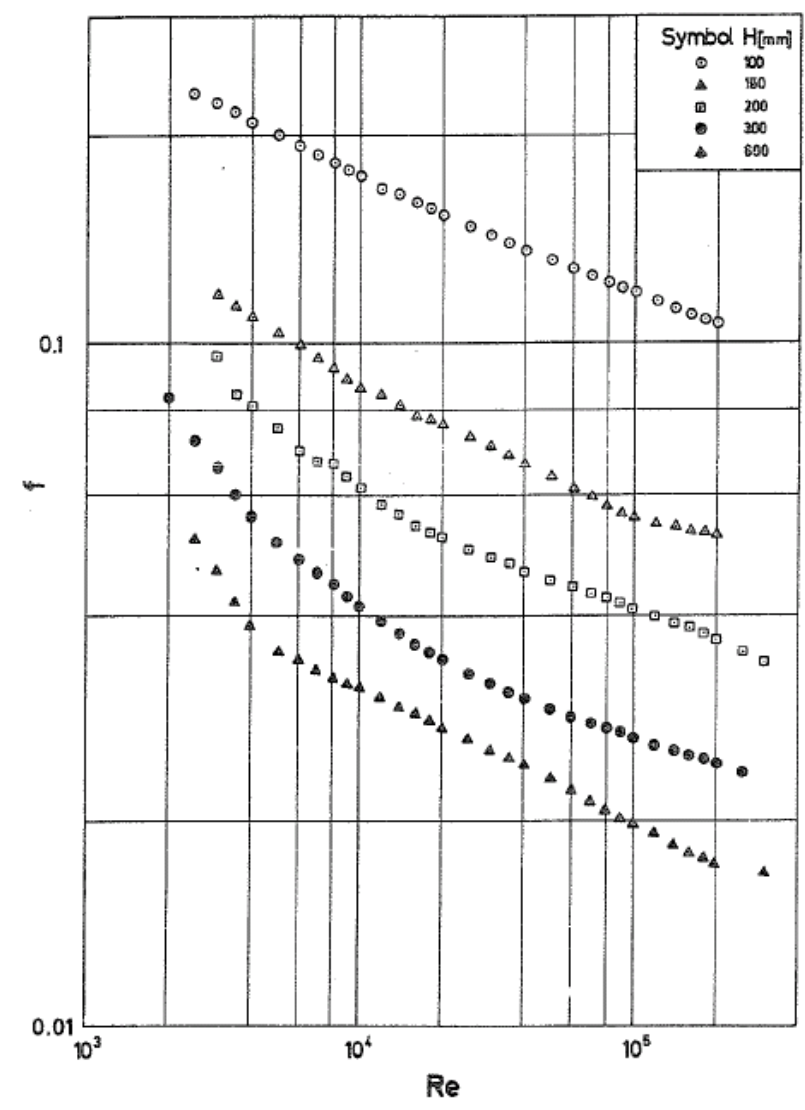

Fig. 25. Friction factor $f$ as a function of the Reynolds number Re for different leads of wire wraps. Test parameters: pitch-to-diameter ratio 1.417, 19 rods bundle (Fig. 4, (Rehme K., 1973)): (water, Rehme, 1973) 
Based on the Rehme experimental data (see Fig. 25) provided in Ref. (Rehme K., 1973), corresponding calculations were performed with SIM-ADS code and the calculation results compared to the experimental data (presented in Fig. 25). Figs. 26 and 27 shows the comparison of the friction factor values for the wire-wrapped FA as calculated using different friction factor correlations (see section 3 and 4) with the experimental data (compare with Fig. 25). As can be seen from Figs. 26 and 27, friction factor correlations best fitting experimental data are in order: Rehme and Sobolev.

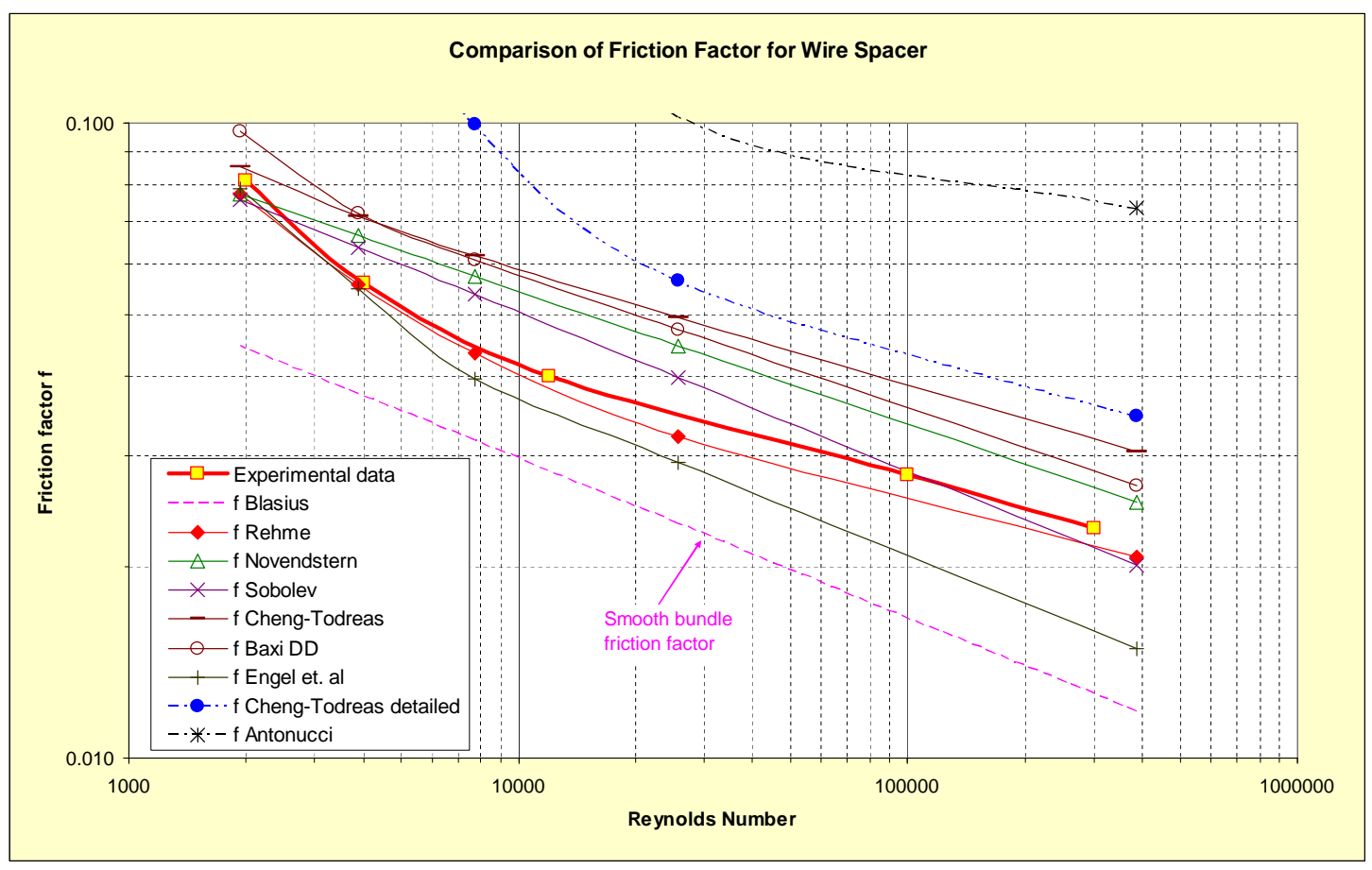

Fig. 26. Comparison of the SIM-ADS calculated and experimental friction factor values for the wire-wrapped fuel assembly (compare with Fig. 25, case 19-rods, $P / D=1.417$; wire lead length $300 \mathrm{~mm}$ ): (water, Rehme, 1973) 


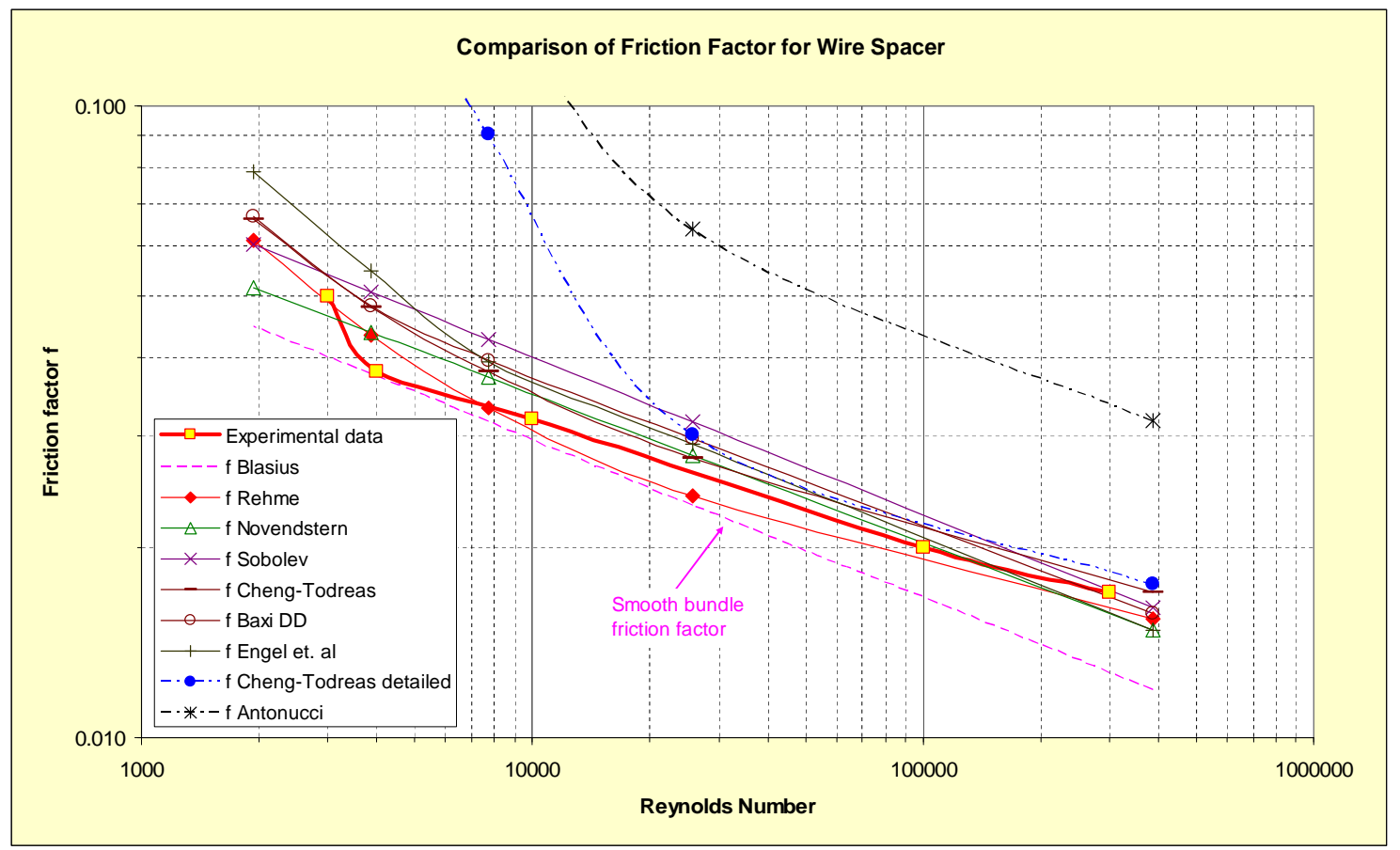

Fig. 27. Comparison of the SIM-ADS calculated and experimental friction factor values for the wire-wrapped fuel assembly (compare with Fig. 25, case 19-rods, $P / D=1.417$; wire lead length $600 \mathrm{~mm}$ ): (water, Rehme, 1973)

The second set of the Rehme experimental data analyzed here - Fig. 28 demonstrates again the effect of different leads of wire wraps on the friction factor for 19 rods and the lowest pitch-to-diameter ratio tested -1.125 . It is obvious that the friction factor increase with decreasing wire wraps pitch is smaller with a smaller pitch-to-diameter ratio of the rods. This fact can be explained by the decreasing blockage of the flow area caused by the wire wraps with decreasing pitch-to-diameter ratio of the rods (Rehme K., 1973). 


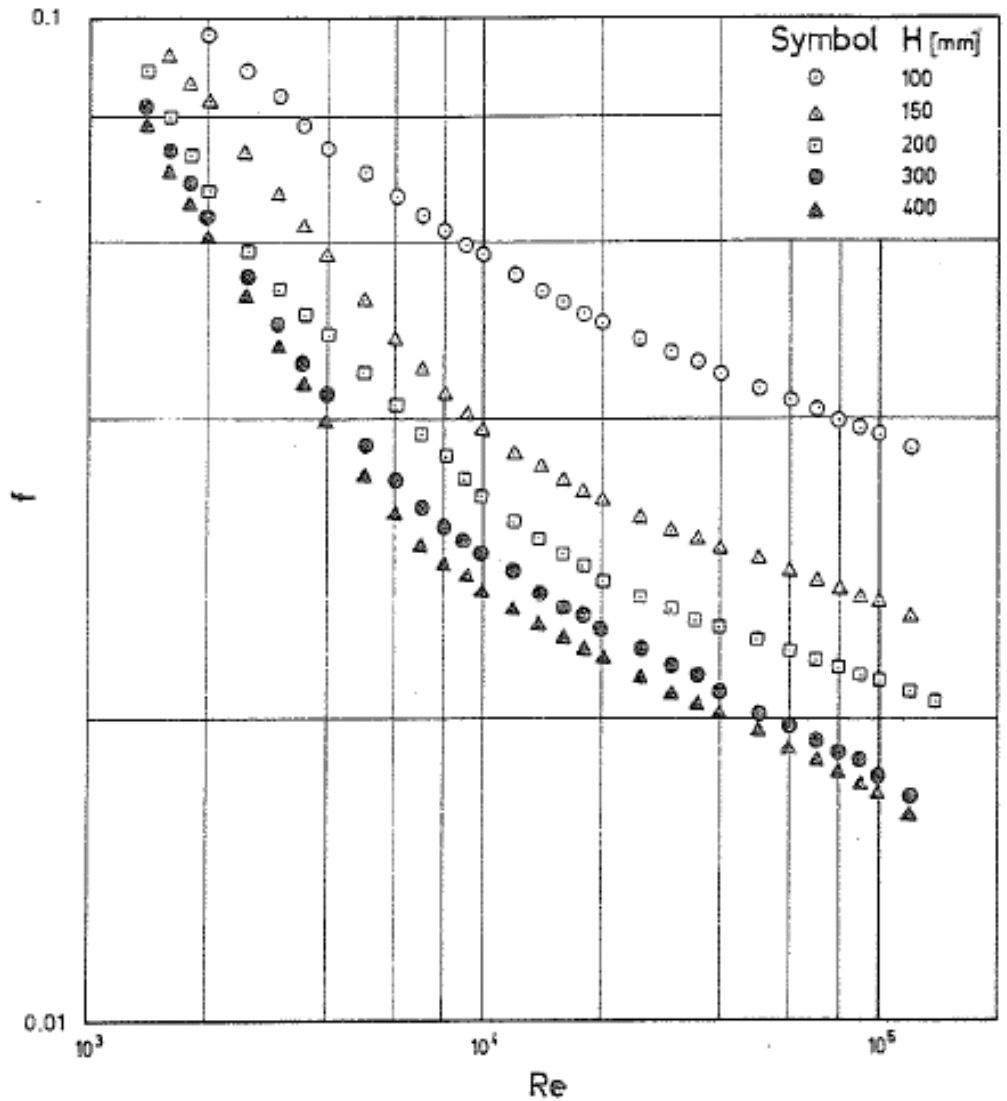

Fig. 28. Friction factor $f$ as a function of the Reynolds number Re for different leads of wire wraps. Test parameters: pitch-to-diameter ratio 1.125, 19 rods bundle (Fig. 5, (Rehme K., 1973)): (water, Rehme, 1973)

Based on the Rehme experimental data (see Fig. 28) provided in Ref. (Rehme K., 1973), corresponding calculations were performed with SIM-ADS code and the calculation results compared to the experimental data (presented in Fig. 28). Figs. 29 and 30 shows the comparison of the friction factor values for the wire-wrapped FA as calculated using different friction factor correlations (see section 3 and 4) with the experimental data (compare with Fig. 28). As can be seen from Figs. 29 and 30, friction factor correlations best fitting experimental data are in order: Rehme - excellent fit, others - good fit. 


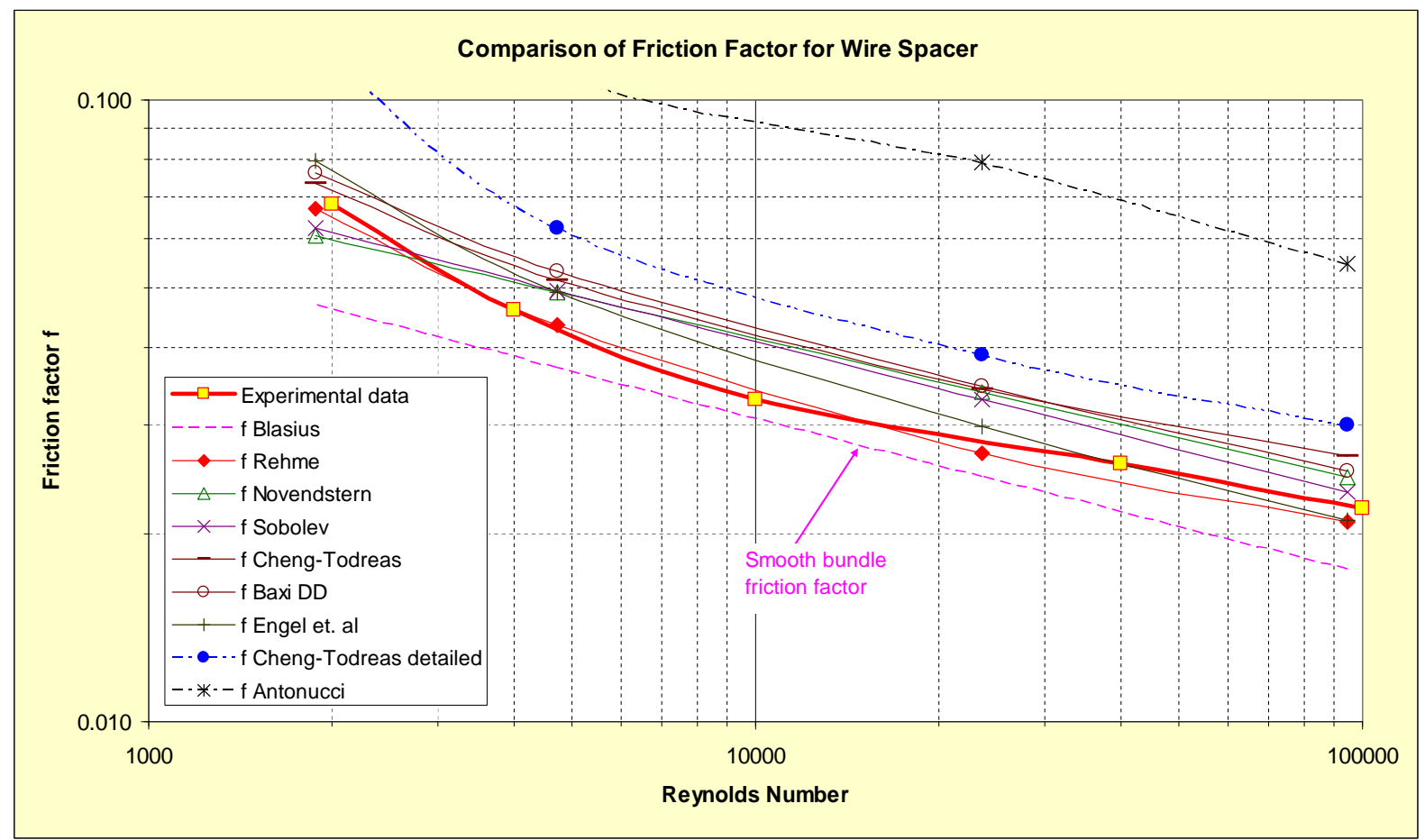

Fig. 29. Comparison of the SIM-ADS calculated and experimental friction factor values for the wire-wrapped fuel assembly (compare with Fig. 28, case 19-rods, $P / D=1.125$; wire lead length $200 \mathrm{~mm}$ ): (water, Rehme, 1973)

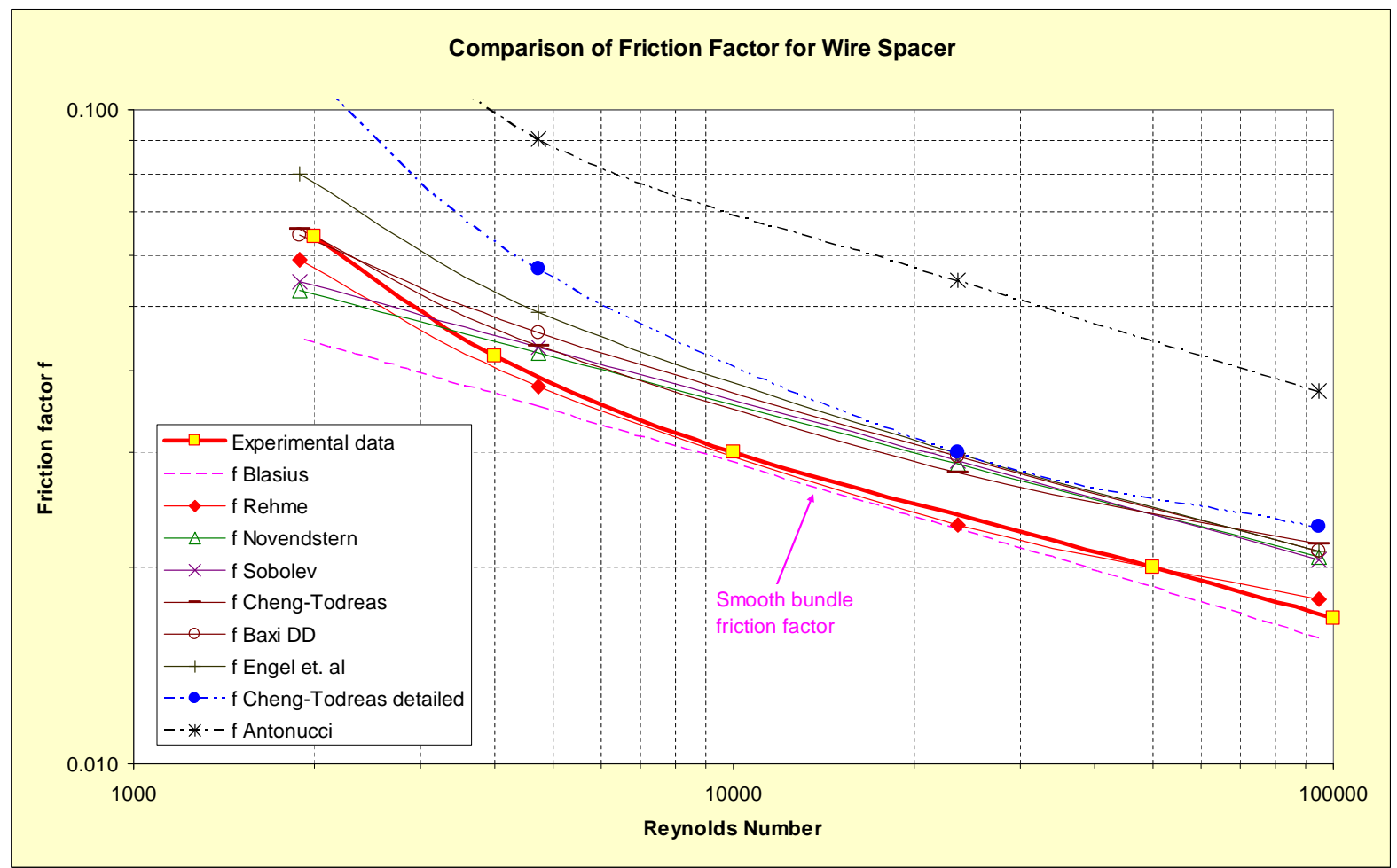

Fig. 30. Comparison of the SIM-ADS calculated and experimental friction factor values for the wire-wrapped fuel assembly (compare with Fig. 28, case 19-rods, $P / D=1.125$; wire lead length $300 \mathrm{~mm}$ ): (water, Rehme, 1973) 
The third set of the Rehme experimental data analyzed here - Fig. 31 demonstrates more clearly the effect of different pitch-to-diameter ratio on the friction factor for 7 rods and the smallest pitch of wire wraps $(100 \mathrm{~mm})$ configuration as a function of Reynolds number. The dependence of pitch-to-diameter ratio on the friction factor is much stronger for smaller pitch of wire wraps value $(100 \mathrm{~mm})$ than for higher pitch of wire wraps value (e.g. $600 \mathrm{~mm})$ (Rehme K., 1973).

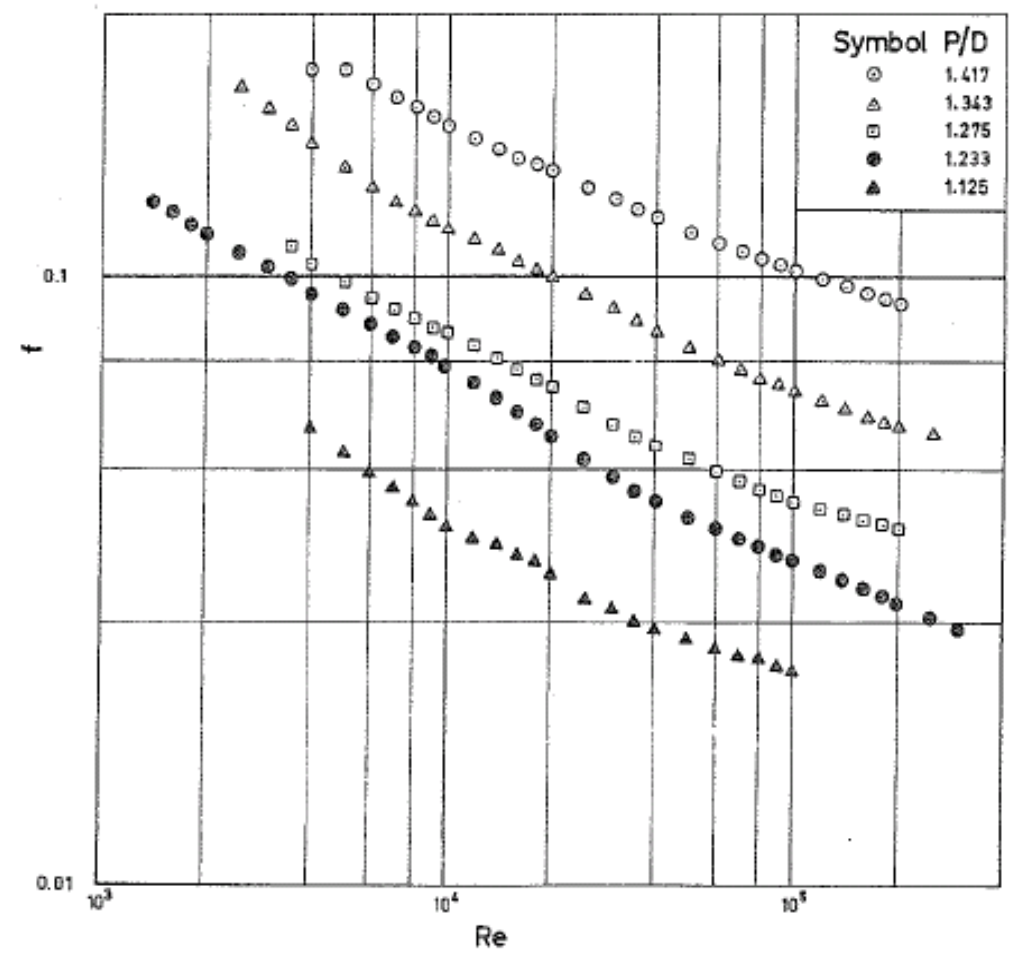

Fig. 31. Friction factor $f$ as a function of the Reynolds number Re for different pitch-todiameter ratios. Test parameters: lead of the wire-wrap $100 \mathrm{~mm}, 7$ rods bundle (Fig. 6, (Rehme K., 1973)): (water, Rehme, 1973)

Based on the Rehme experimental data (see Fig. 31) provided in Ref. (Rehme K., 1973), corresponding calculations were performed with SIM-ADS code and the calculation results compared to the experimental data (presented in Fig. 31). Figs. 32 and 33 shows the comparison of the friction factor values for the wire-wrapped FA as calculated using different friction factor correlations (see section 3 and 4) with the experimental data (compare with Fig. 31). As can be seen from Figs. 32 and 33, friction factor correlations best fitting experimental data are in order: Rehme and Sobolev. 


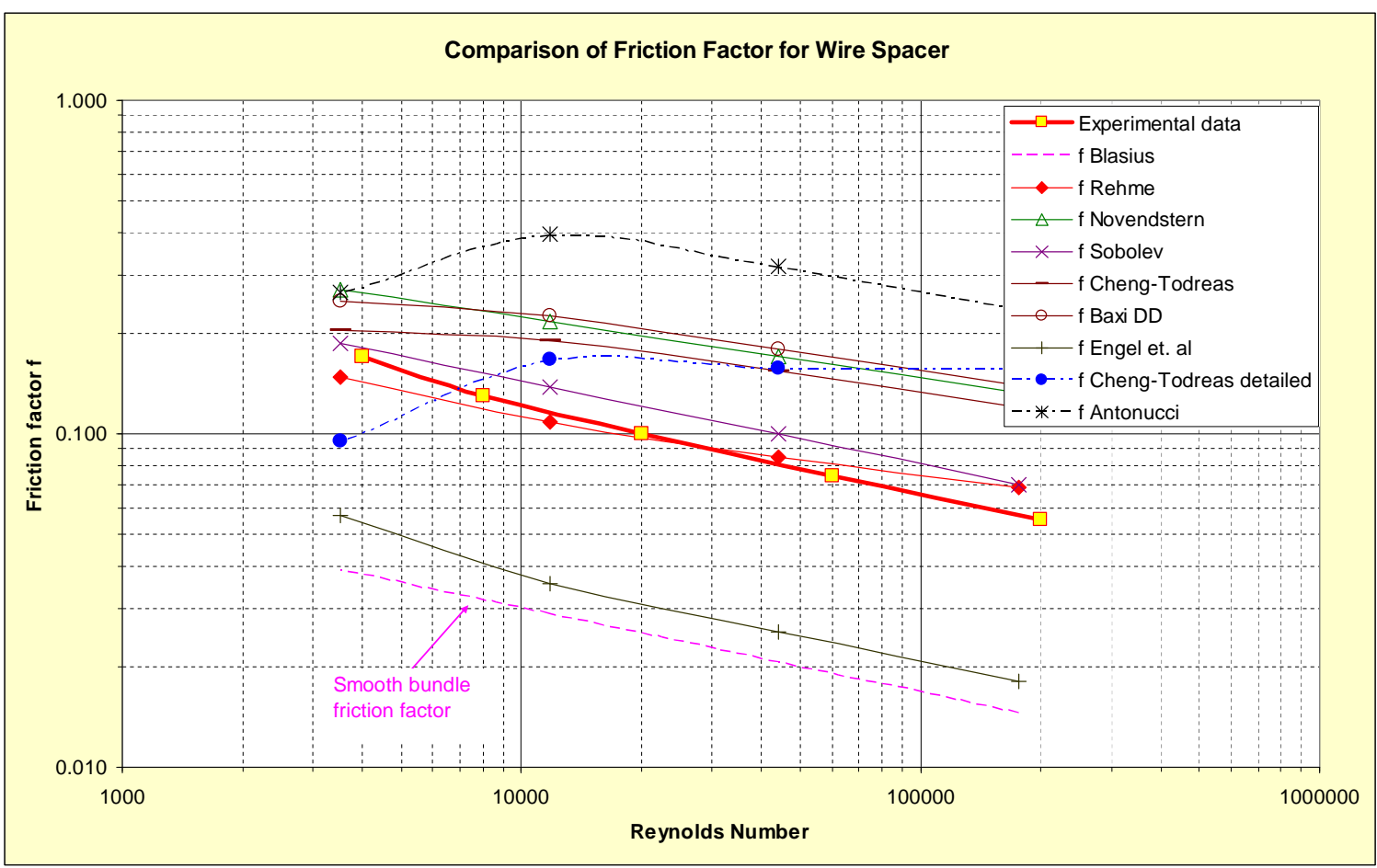

Fig. 32. Comparison of the SIM-ADS calculated and experimental friction factor values for the wire-wrapped fuel assembly (compare with Fig. 31, case 7-rods, $P / D=1.343$; wire lead length $100 \mathrm{~mm}$ ): (water, Rehme, 1973)

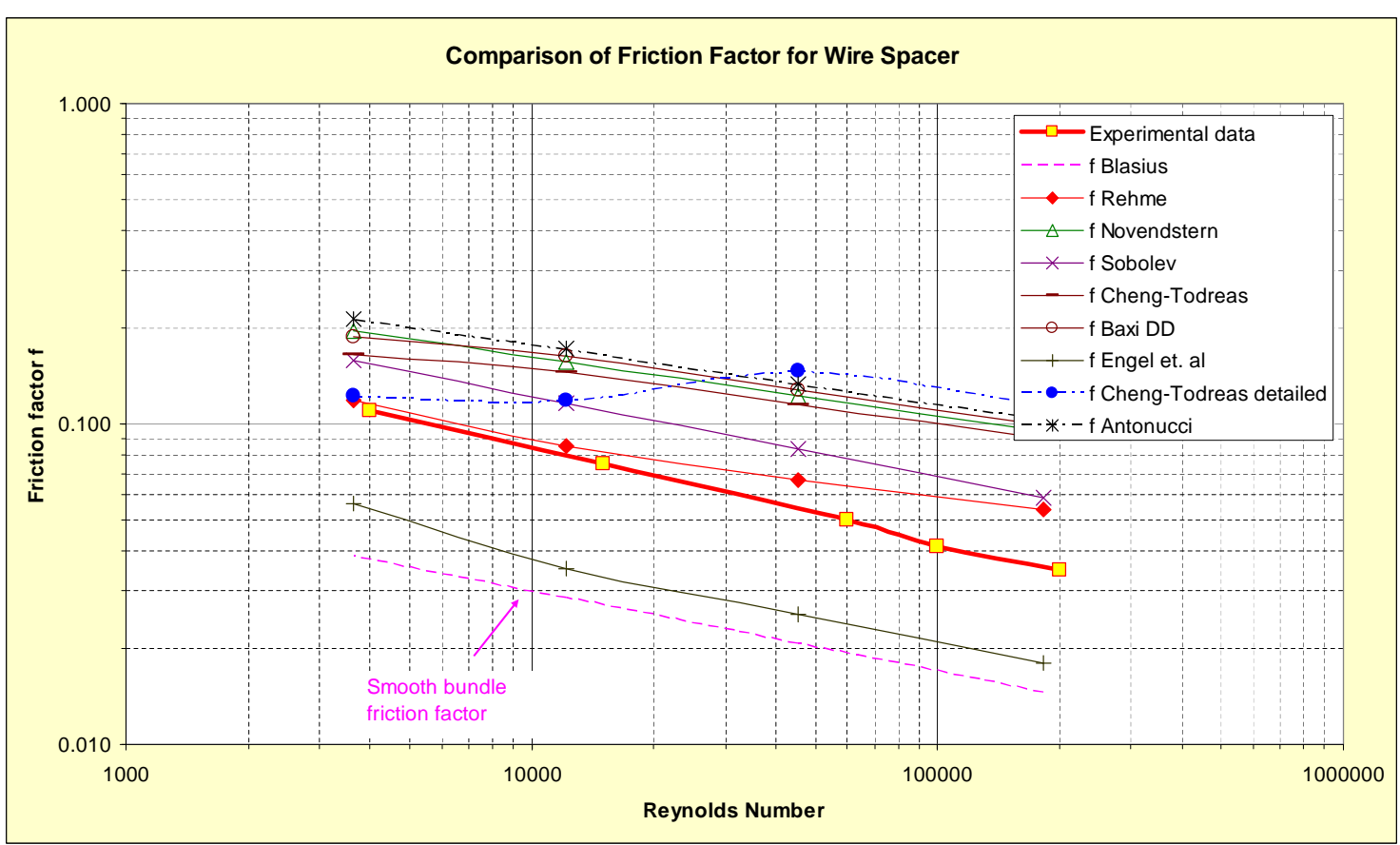

Fig. 33. Comparison of the SIM-ADS calculated and experimental friction factor values for the wire-wrapped fuel assembly (compare with Fig. 31, case 7-rods, $P / D=1.275$; wire lead length $100 \mathrm{~mm}$ ): (water, Rehme, 1973) 
The fourth set of the Rehme experimental data analyzed here - Fig. 34 demonstrates how the friction factor depends on the number of rods in a rod bundle. The friction factor increases with increasing number of rods. This effect can be explained by the fact that the influence of the smooth channel wall results in a lower pressure loss. Since rod bundles with only a few rods include a relatively higher part of channel wall with respect to the total wetted perimeter, the total pressure drop is lower (Rehme K., 1973).

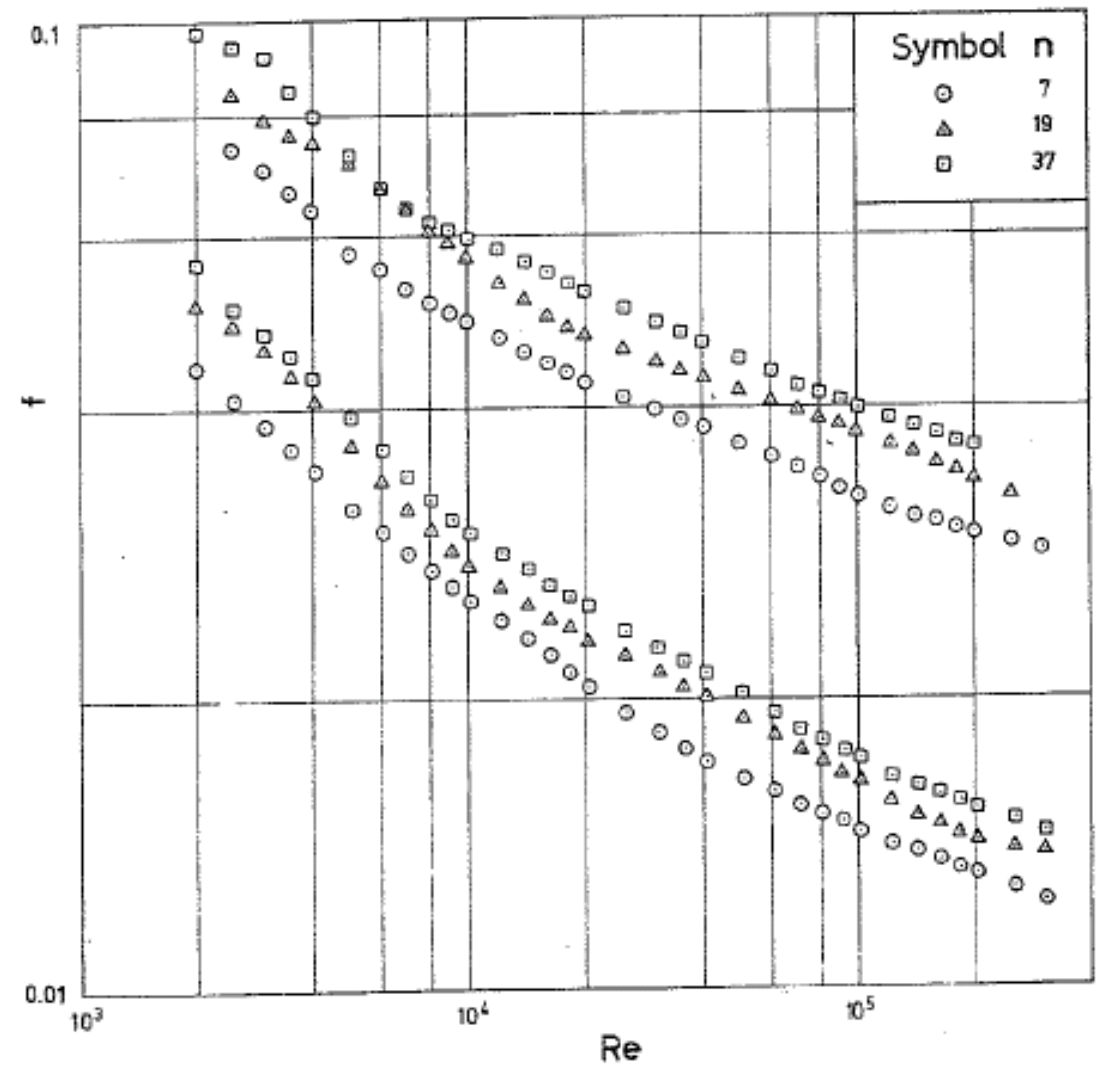

Fig. 34. Friction factor $f$ as a function of the Reynolds number Re for different numbers of rods in a rod bundle. Test parameters: pitch-to-diameter ratio 1.275, lead of the wire-wrap $150 \mathrm{~mm}$ for the upper 3 curves and $600 \mathrm{~mm}$ for the lower 3 curves (Fig. 8, (Rehme K., 1973)): (water, Rehme, 1973)

Based on the Rehme experimental data (see Fig. 34) provided in Ref. (Rehme K., 1973), corresponding calculations were performed with SIM-ADS code and the calculation results compared to the experimental data (presented in Fig. 34). Figs. 35 and 36 shows the comparison of the friction factor values for the wire-wrapped FA as calculated using different 
friction factor correlations (see section 3 and 4) with the experimental data (compare with Fig. 34). As can be seen from Figs. 35 and 36, friction factor correlations best fitting experimental data are in order: Rehme and Sobolev.

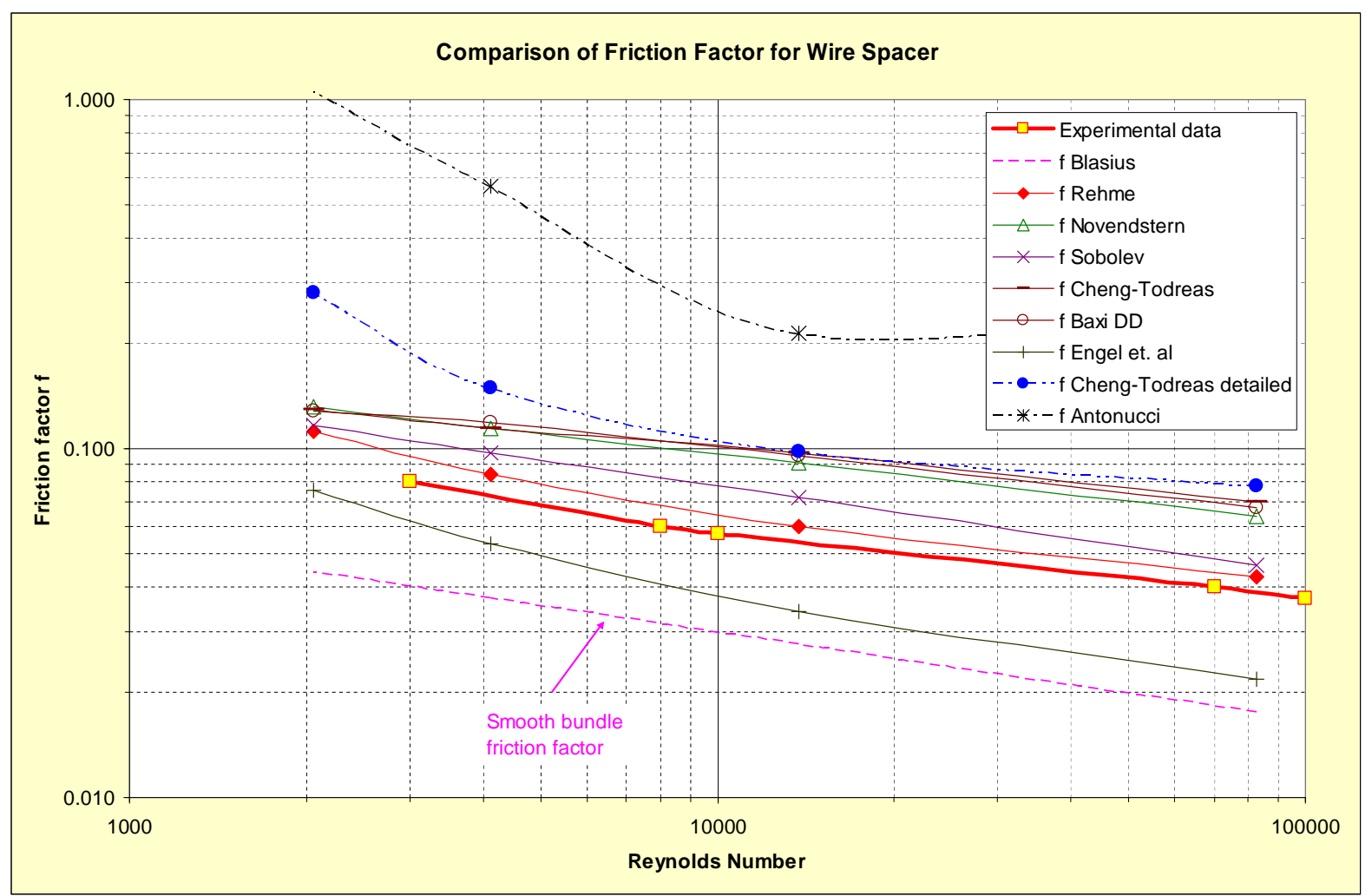

Fig. 35. Comparison of the SIM-ADS calculated and experimental friction factor values for the wire-wrapped fuel assembly (compare with Fig. 34, case 19-rods, $P / D=1.275$; wire lead length $150 \mathrm{~mm}$ ): (water, Rehme, 1973) 


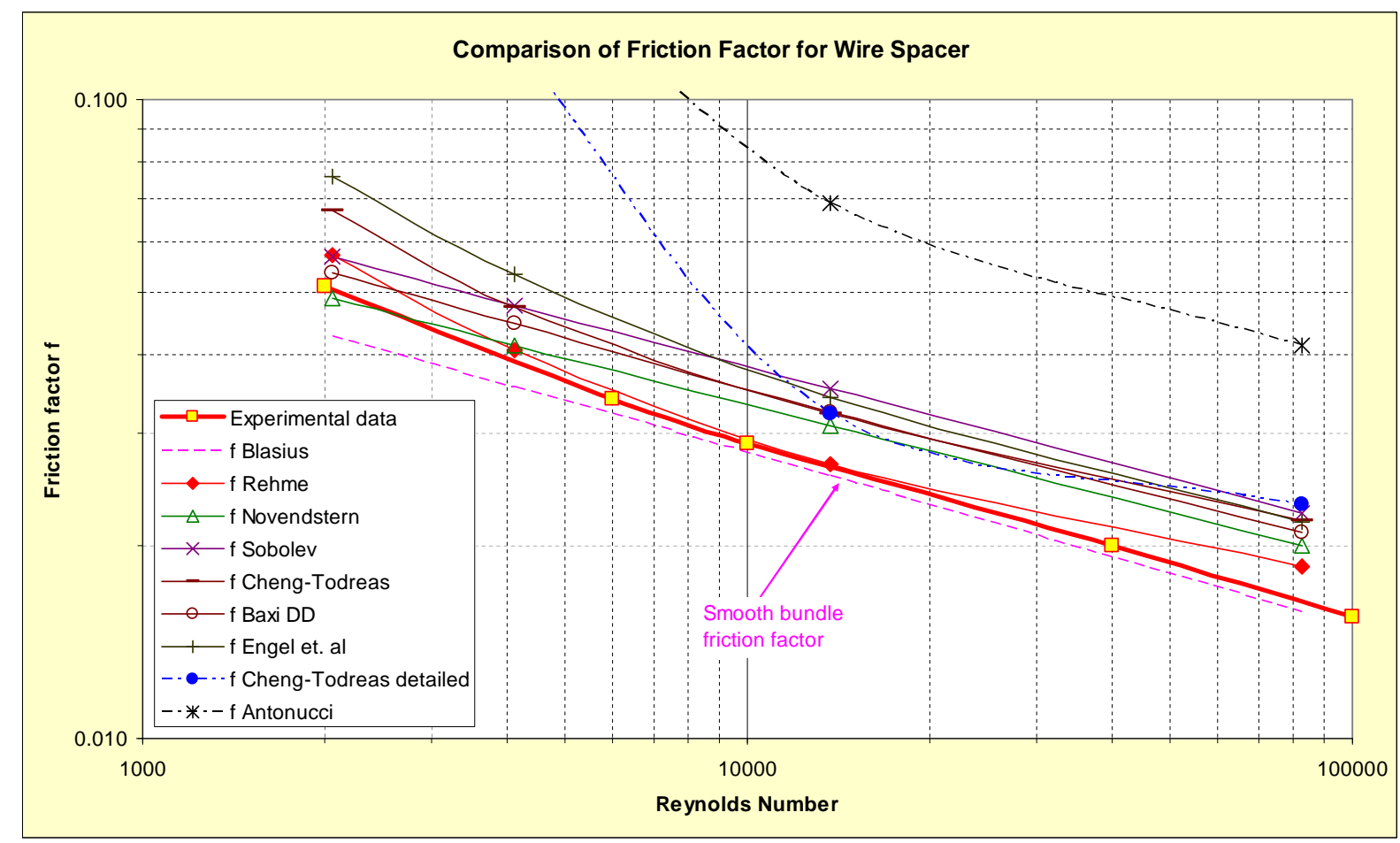

Fig. 36. Comparison of the SIM-ADS calculated and experimental friction factor values for the wire-wrapped fuel assembly (compare with Fig. 34, case 19-rods, $P / D=1.275$; wire lead length $600 \mathrm{~mm}$ ): (water, Rehme, 1973)

\subsection{Vijayan et al., 1999 (Vijayan P.K. et al, 1999) water experiments}

Two different test facilities, one a low pressure facility ( 7 bar) and the other one a high pressure, high temperature facility $\left(125\right.$ bar, $\left.300^{\circ} \mathrm{C}\right)$ were used for the experiments described in Ref. (Vijayan P.K. et al, 1999). The low pressure facility was used for generating low and medium Reynolds number data (up to $\sim 50,000$ ) whereas the high pressure facility was used to generate high Reynolds number $(10,000$ to 550,000$)$ data. Both these facilities had more or less similar features in the context of their use for pressure drop experiments.

The schematic of the low pressure flow test facility used by Vijayan et al (Vijayan P.K. et al, 1999) to measure the pressure drop in a 19-rod wire wrapped fuel bundle is shown in Fig. 37. This facility has the possibility to connect any test section between the flanges of the suction and discharge headers of the pumps. Two centrifugal pumps in parallel with the flexibility to operate either one or both are provided to circulate the flow through the loop. The 
test section flow can be adjusted to the required value with the help of control valves at the inlet and outlet (Vijayan P.K. et al, 1999).

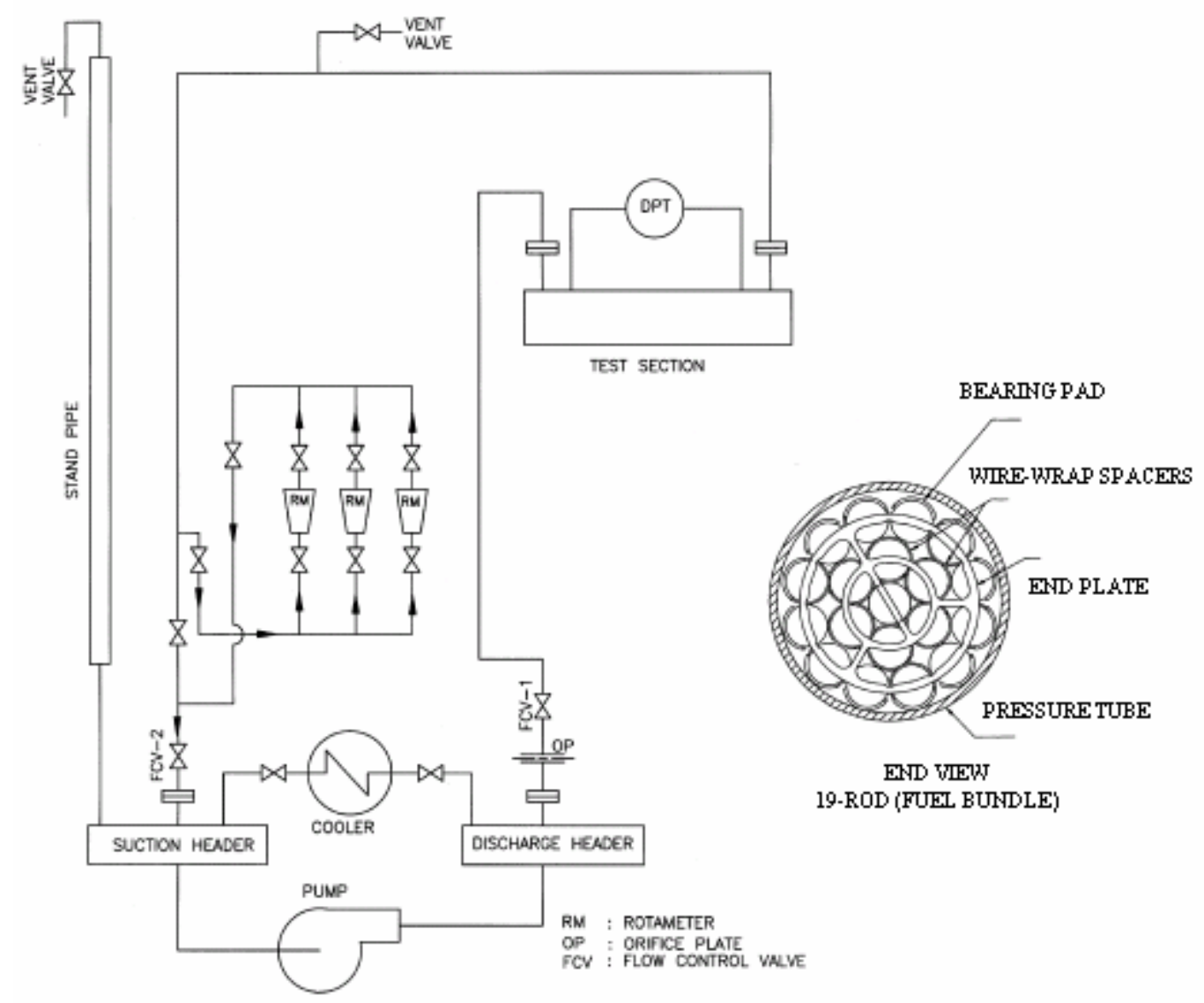

Fig. 37. Schematic of the low pressure flow test facility : (water, Vijayan et al., 1999 (Vijayan P.K. et al, 1999))

Experiments were carried out in a prototype fuel channel with 12 fuel bundles stacked one after another. The experiments were carried out in two stages. In the first stage, pressure drop under normal operating conditions was measured in a high pressure, high temperature facility covering a Reynolds number range of $10,000 \pm 330,000$. Later, experiments were carried out in the low pressure test facility to generate pressure drop data in the Reynolds number range of $70 \div 50,000$. All the experiments were carried out with demineralised water as the working fluid. The geometric details of the fuel channel and the bundles used are the following: channel inside diameter $0.08255 \mathrm{~m}$, flow area $0.0018851 \mathrm{~m}^{2}$, hydraulic 
diameter $5.88 \mathrm{~mm}$, total wetted perimeter $1.28226 \mathrm{~m}$, number of bundles per channel 12 , clad outside diameter $15.21 \mathrm{~mm}$, centre-to-centre spacing of elements $16.43 \mathrm{~mm}$, length of one bundle $0.4953 \mathrm{~m}$, lead of the wire wrap $0.231775 \mathrm{~m}$, wire diameter $\sim 1.22 \mathrm{~mm}$, wire length $0.4877 \mathrm{~m}$, number of wires per bundle 24 , pitch to diameter ratio 1.0802 , wire lead to diameter ratio 15.24. The water flowrate ranged from 0.017 to $18.3 \mathrm{~kg} / \mathrm{s}$ (Vijayan P.K. et al, 1999).

The values of the friction factor obtained from the experimental pressure drop data are presented in Fig. 38. The first two curves in Fig. 38 are the curves fitting experimental data as proposed by the authors of the Ref. (Vijayan P.K. et al, 1999). The next two curves are the curves obtained by Vijayan et al. using Engel et al. and Cheng and Todreas friction factor correlations for wire-wrapped FAs while trying to retrace the experimental data.

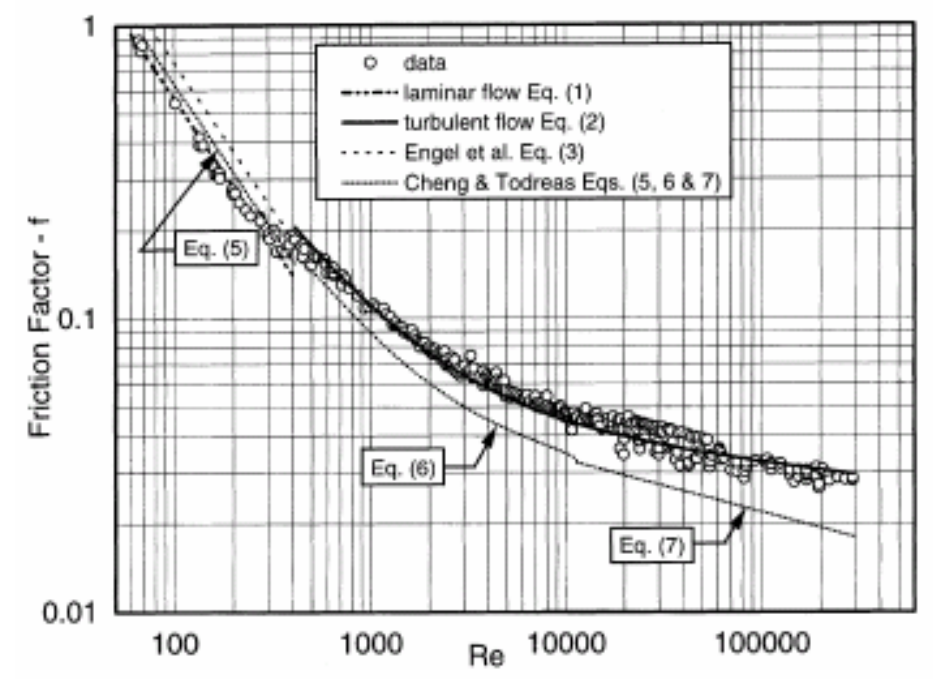

Fig. 38. Friction factor data for 19-rod bundle (wire-wrap spacers): (water, Vijayan et al., 1999 (Vijayan P.K. et al, 1999))

Based on the data provided in Ref. (Vijayan P.K. et al, 1999), corresponding calculations were performed with the SIM-ADS code and the calculation results compared to the experimental data (presented in Fig. 38). Fig. 39 shows the comparison of the friction factor 
values for the wire-wrapped FA as calculated using different friction factor correlations (see section 3 and 4) with the experimental data (compare with Fig. 38). As can be seen from Fig. 39, friction factor correlations best fitting experimental data are in order: Cheng-Todreas (detailed), Cheng-Todreas (simplified) and Novendstern. As it was already mentioned before, Sobolev and Novendstern correlations can be considered only in turbulent region $(\mathrm{Re}>$ 3000).

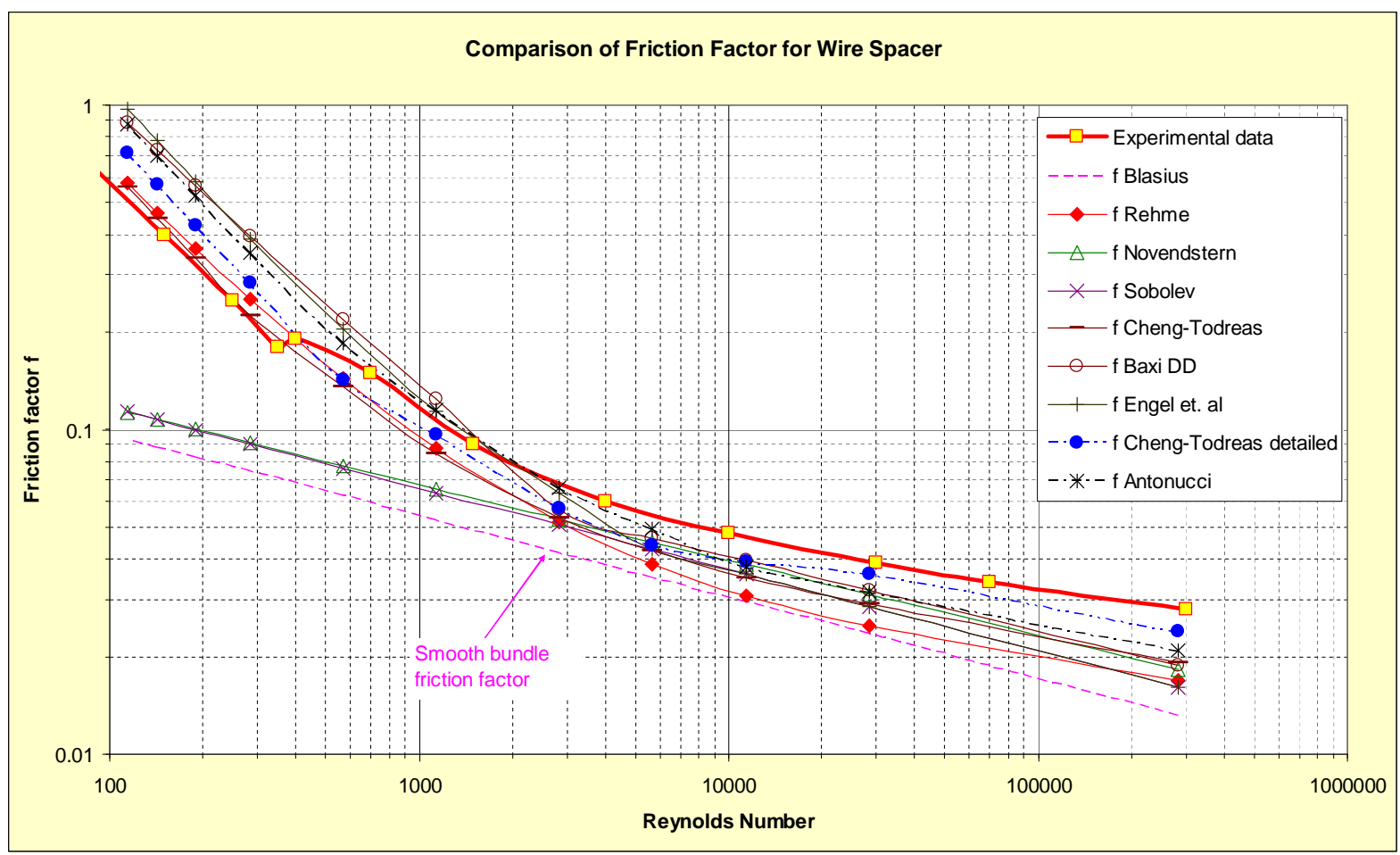

Fig. 39. Comparison of the SIM-ADS calculated and experimental friction factor values for the wire-wrapped fuel assembly (compare with Fig. 38): (water, Vijayan et al., 1999) 


\section{Analysis of the CFD modeling results based on Gajapathy et al., 2007 (Gajapathy R. et al., 2007) sodium cooled PFBR fuel bundle investigation}

The sodium cooled fuel bundle, investigated by Gajapathy et al (Gajapathy R. et al., 2007) with a CFD code, consists of seven fuel pins of diameter $6.6 \mathrm{~mm}$ arranged in a triangular pitch of $8.28 \mathrm{~mm}$ which is that of the Indian Prototype Fast Breeder Reactor (PFBR) under construction at Kalpakkam. The width across flat of the hex-can is $24.52 \mathrm{~mm}$. The helical wire diameter is $1.65 \mathrm{~mm}$ with a lead of $150 \mathrm{~mm}$. Only one pitch height of the helical wirewrapped pin bundle is considered. The hydraulic diameter of the bundle with spacer wire is $4.0 \mathrm{~mm}$ and the same for the bundle without spacer wire is $4.9 \mathrm{~mm}$. Reynolds number in this study is varied from 1000 up to 100,000 . The inlet mass flow rate of sodium and the inlet sodium temperature are $1.7 \mathrm{~kg} / \mathrm{s}$ and $397^{\circ} \mathrm{C}$, respectively. The Reynolds number for this flow rate is 86,430 and is well in the turbulent flow regime. The heat flux, $1850 \mathrm{~kW} / \mathrm{m}^{2}$, specified over the surface of the pins corresponds to PFBR FA at full power (Gajapathy R. et al., 2007).

The values of the friction factor obtained by Gajapathy et al (Gajapathy R. et al., 2007) from the CFD study of the seven pin fuel assembly of PFBR with and without wirewrap are presented in Fig. 40. 


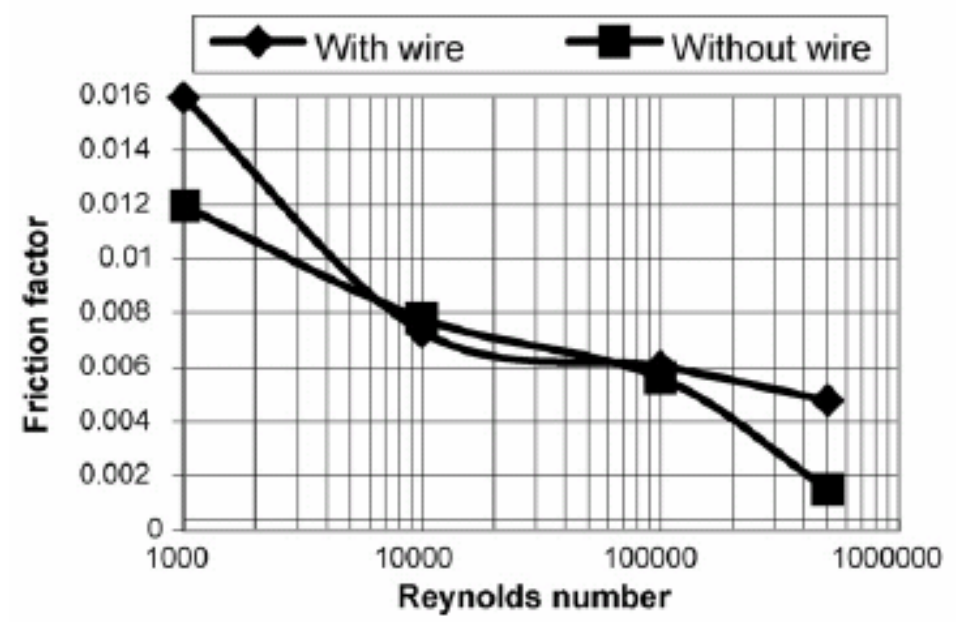

Fig. 40. Comparison of pin bundle friction coefficient with and without helical wire-wrap: (sodium, Gajapathy et al., 2007 (Gajapathy R. et al., 2007))

Based on the data provided in Ref. (Gajapathy R. et al., 2007), corresponding calculations were performed with the SIM-ADS code and the calculation results compared to the CFD study data (presented in Fig. 40). Fig. 41 shows the comparison of the friction factor values for the wire-wrapped FA, as well as for the case without a wire-wrap, as calculated using different friction factor correlations (see section 3 and 4) with the CFD study data (compare with Fig. 40). As can be seen from Fig. 41, friction factor correlations best fitting CFD study data are: Rehme - excellent fit; Baxi and Dalle-Donne (modified), Engel (modified) - good fit. 
Analysis of the experimental data by Geffraye, 2008 (Geffraye G., 2008) based on ESTHAIR air experiments

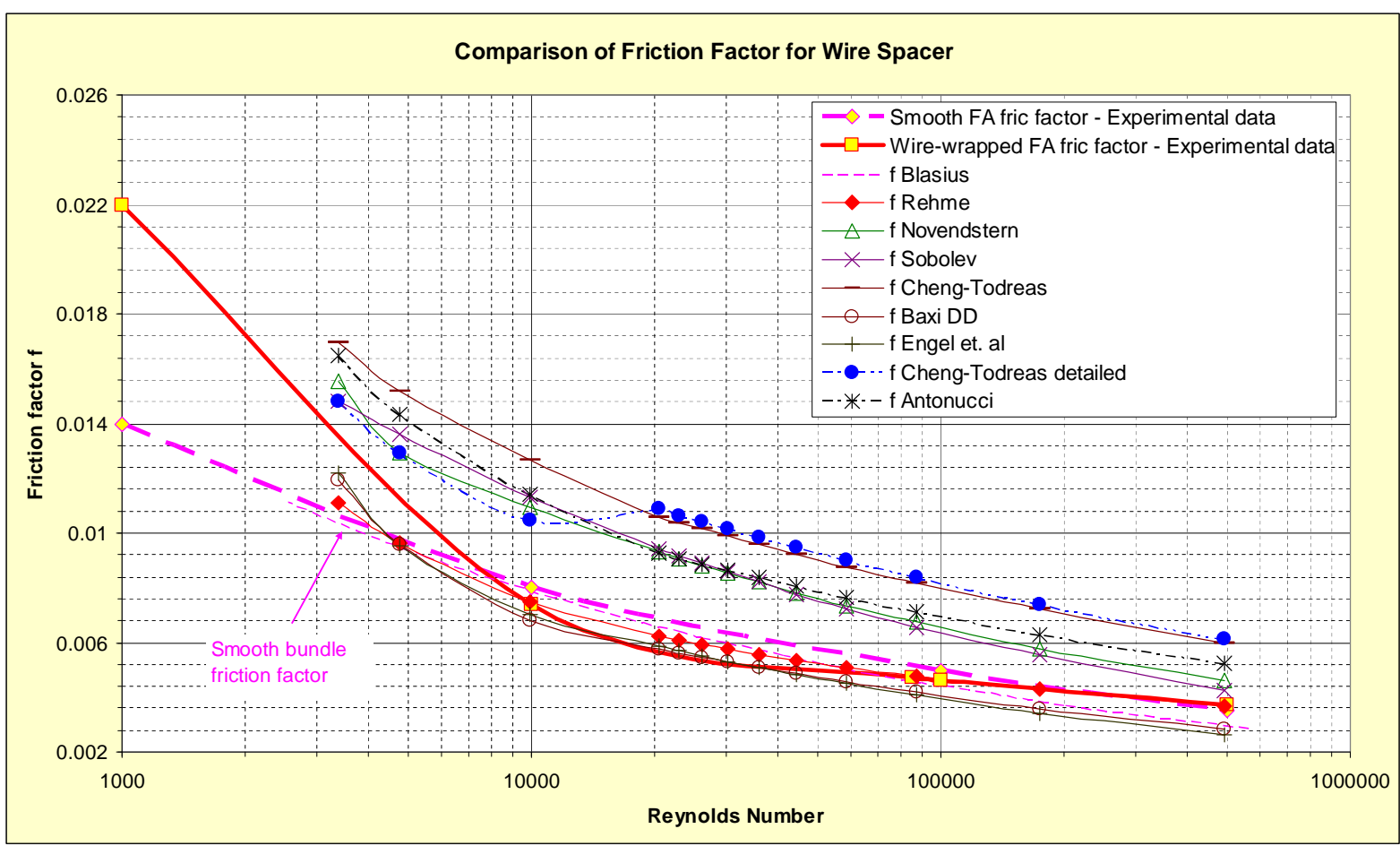

Fig. 41. Comparison of the SIM-ADS calculated and experimental friction factor values for the wire-wrapped fuel assembly, as well as for the case without a wire-wrap (compare with Fig. 40): (sodium, Gajapathy et al., 2007)

\section{Analysis of the experimental data by Geffraye, 2008 (Geffraye G., 2008) based on ESTHAIR air experiments}

View of the ESTHAIR test loop, as well as the fuel assembly, used by Geffraye et al (Geffraye G., 2008) to measure the pressure drop in a 19-pin wire wrapped fuel assembly cooled by air is shown in Fig. 42. ESTHAIR air test loop was build by the CEA in the frame of GCFR project. ESTHAIR program aims at producing estimations of pressure drop, heat exchange coefficients and hot spot risks for the various ETDR fuel assembly concepts. ESTHAIR experiments analyzed here were performed using air as a coolant and 19 electrically heated pins bundle in a hexagonal tube. 


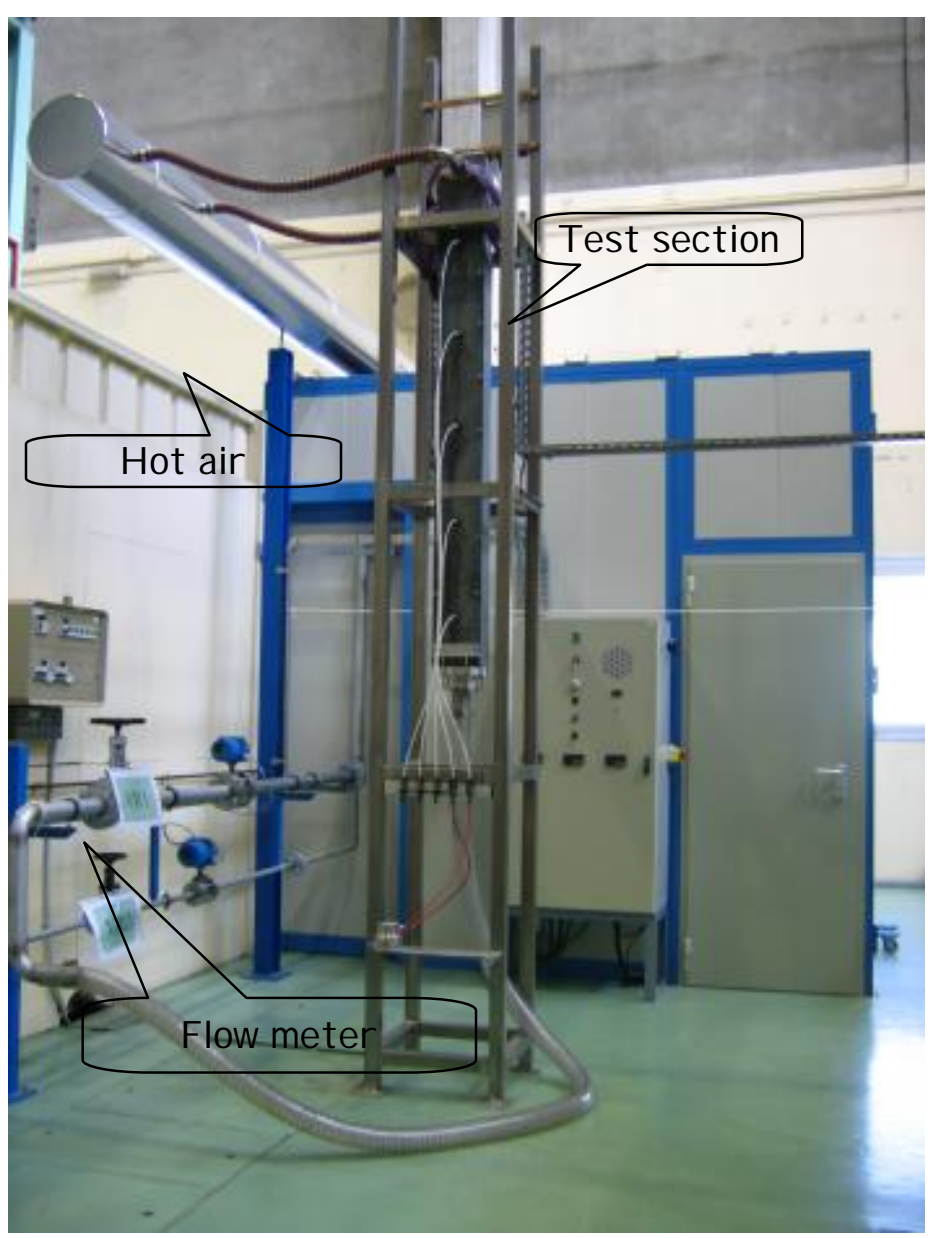

a)

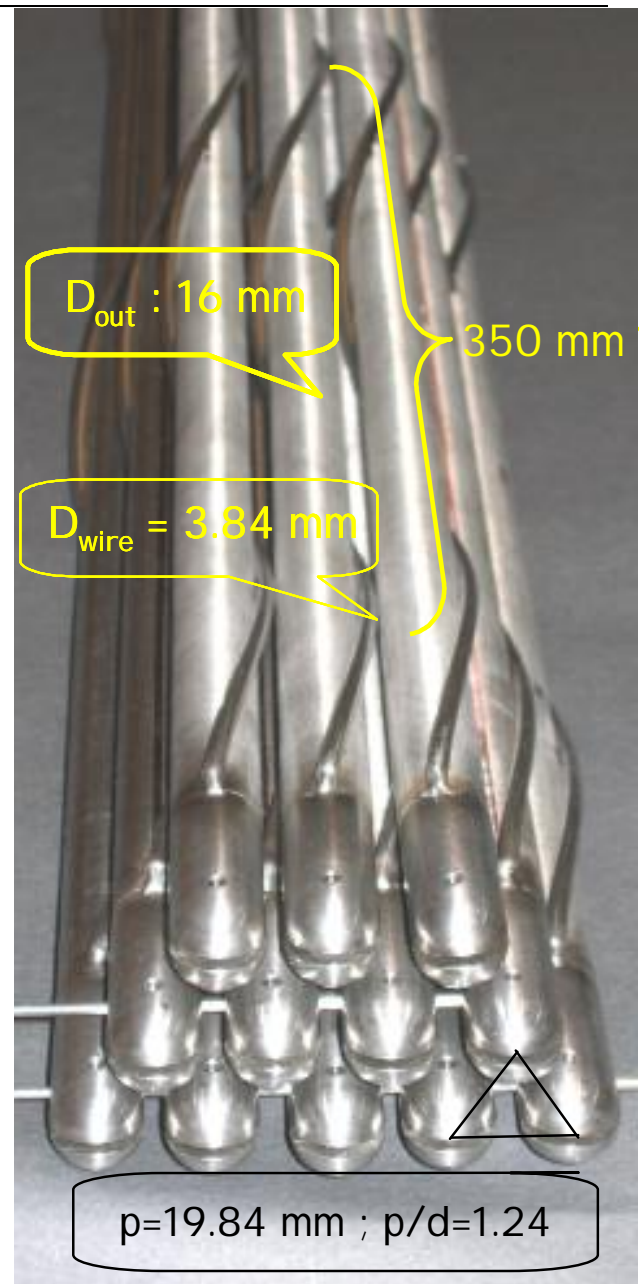

b)

Fig. 42. a) View of the test loop, b) View of the fuel bundle: (air, ESTHAIR exp. (Berthoux M., 2006))

The scaling and the heating characteristics of this 19-pin bundle were such as to have Reynolds similitude $(\operatorname{Re}$ scale $=1$ ) and the same relative variations of the physical properties as in the prototype. Main characteristics of the 19-pin bundle are: scale 2.44 , rod diameter 16 $\mathrm{mm}$, heating length $1.65 \mathrm{~m}$, wire lead $350 \mathrm{~mm}$, pins pitch $19.84 \mathrm{~mm}$, pitch to diameter ratio is 1.24, wire diameter is $3.84 \mathrm{~mm}$. There were five pressure sensors located along the heated length of the pin bundle. Distances for their location from the beginning of the heating length are: $0.175 \mathrm{~m}$ (first sensor), $4 \times 0.35 \mathrm{~m}$ between each of the following four sensors. Rod heating power is adjustable from 0 to $2 \mathrm{~kW}$ (Berthoux M., 2006). 
Analysis of the experimental data by Geffraye, 2008 (Geffraye G., 2008) based on ESTHAIR air experiments

Experimental data for the 19-pin assembly friction factor values obtained on ESTHAIR air loop are presented in Fig. 43 (Geffraye G., 2008). This figure shows the friction factor values versus Reynolds number obtained by the authors of Ref. (Geffraye G., 2008) for three test cases: unheated tests and two series of heated tests. Along with the experimental data one can see some predictions of the friction factors obtained by the authors of Ref. (Geffraye G., 2008) using several different friction factor correlations for smooth and wirewrapped FAs.

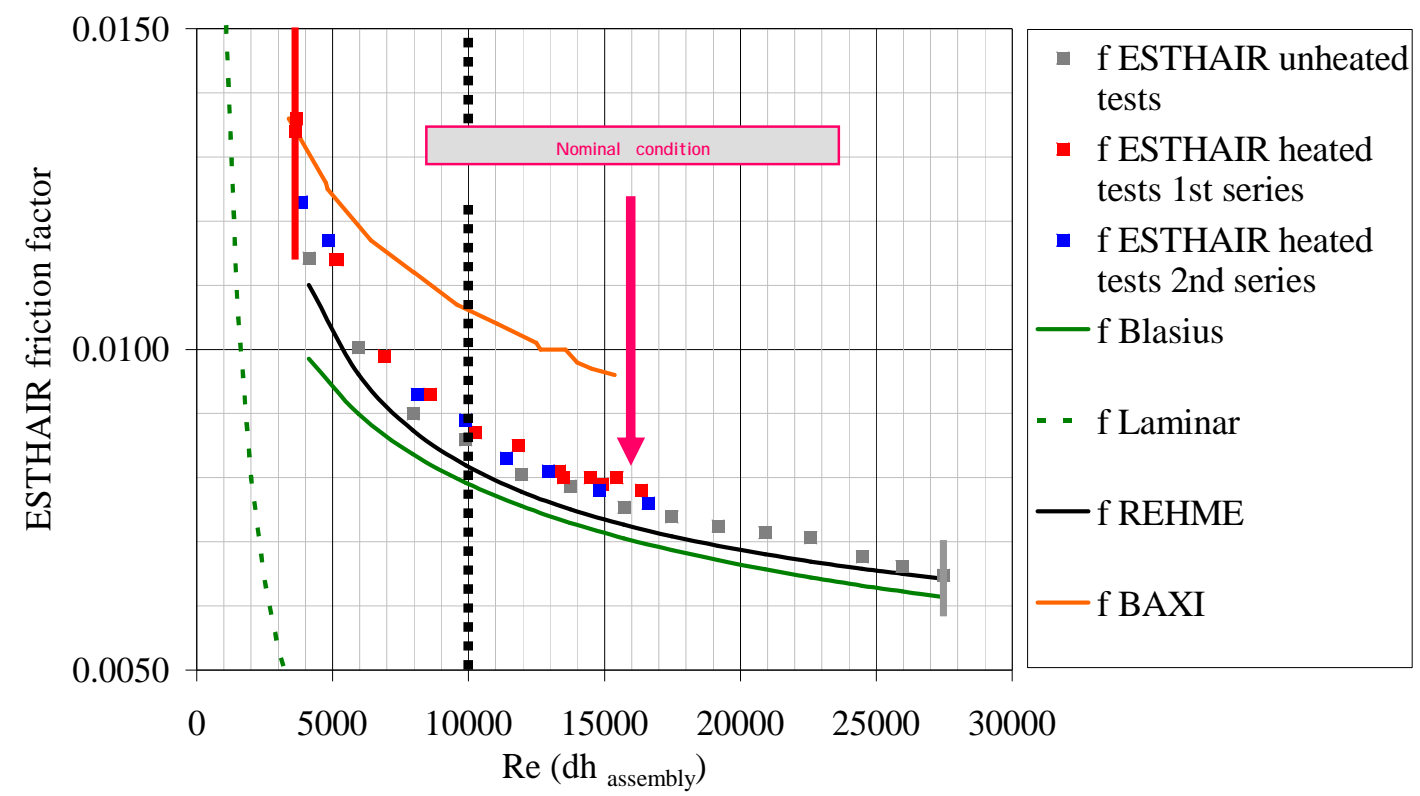

Fig. 43. Friction factor vs. Reynolds number as reported in Ref. (Geffraye G., 2008): (air, ESTHAIR exp. (Geffraye G., 2008))

Based on the data provided in Ref. (Geffraye G., 2008), corresponding calculations were performed with the SIM-ADS code and the calculation results compared to the experimental data (presented in Fig. 43). Fig. 44 shows the comparison of the friction factor values for the wire-wrapped FA as calculated using different friction factor correlations (see section 3 and 4) with the experimental data (compare with Fig. 43). As can be seen from Fig. 44, friction factor correlations best fitting experimental data are in order: Rehme - excellent fit, Engel (modified) - good fit. 


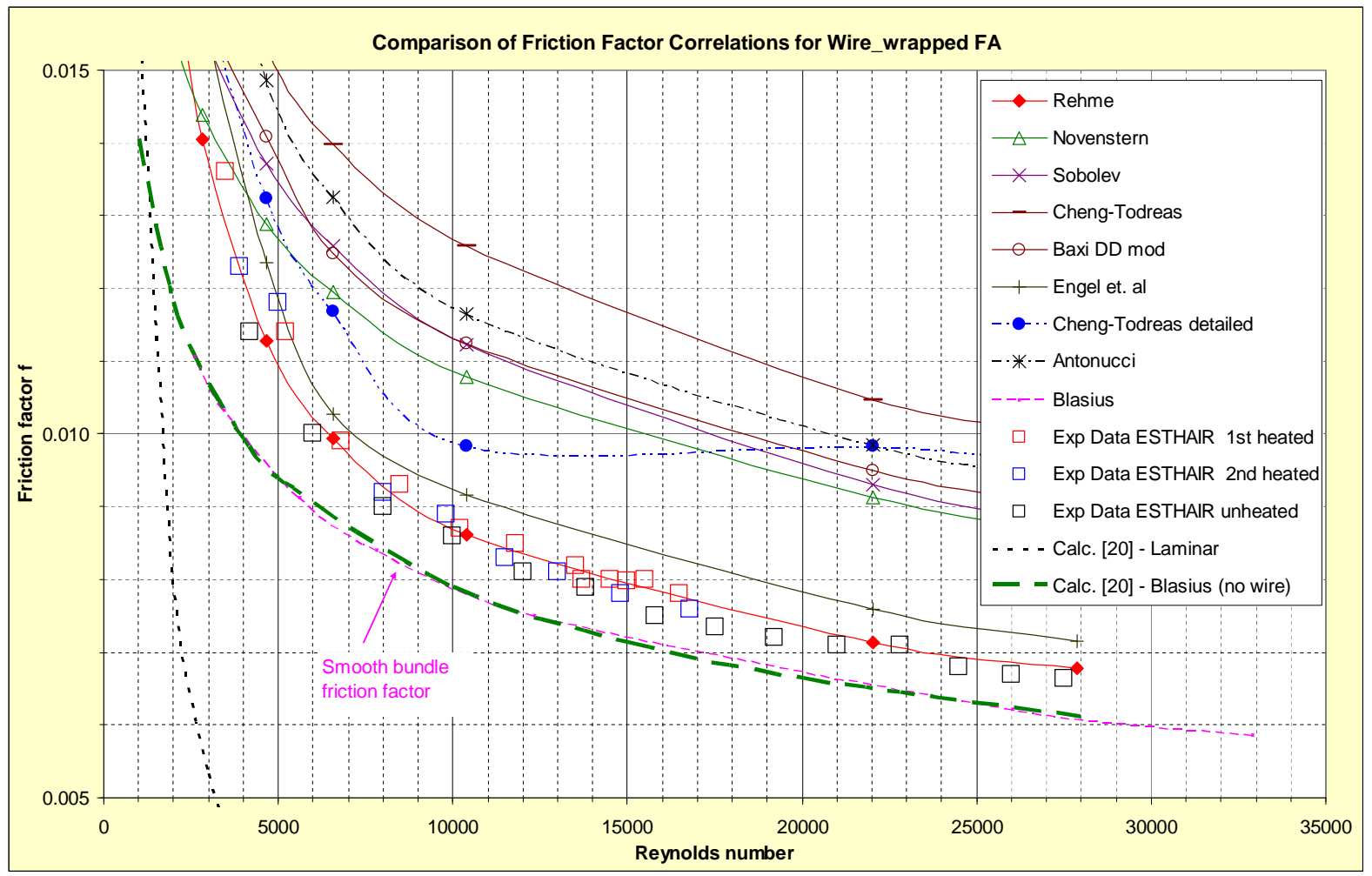

Fig. 44. Comparison of the SIM-ADS calculated and experimental friction factor values for the wire-wrapped fuel assembly (compare with Fig. 43): (air, ESTHAIR exp.)

When looking at the friction factor curve in Fig. 44 and Fig. 43, one can see some difference between the two predictions. The difference here is due to the Re value used when calculating friction factor as proposed by Rehme. In Fig. 44 the Rehme friction factor was calculated using $\mathrm{Re}$ value for the hot $\mathrm{SA}$ in wire-wrap configuration, while in Fig. 43 the Rehme friction factor was calculated using average Re value for the smooth pin configuration not taking into account the existing wire-wrap.

The latest information on the experimental data for the 19-pin assembly friction factor values obtained on ESTHAIR air loop are presented in Fig. 45 (Berthoux M. and Carenza A., 2008) and should be compared to those as presented in Fig. 43 (Geffraye G., 2008). Again, along with the experimental data one can see some predictions of the friction factors obtained by the authors of Ref. (Berthoux M. and Carenza A., 2008) using several different fric- 
Analysis of the experimental data by Geffraye, 2008 (Geffraye G., 2008) based on ESTHAIR air experiments

tion factor correlations for smooth, as well as wire-wrapped FAs. The only difference between the two figures is that now authors of Ref. (Berthoux M. and Carenza A., 2008) used the modified Re value (Re value for the hot SA in wire-wrap configuration) when calculating friction factor as proposed by Rehme. This now nicely corresponds also to our predictions as shown in Fig. 44 (friction factor values obtained using the Rehme correlation).

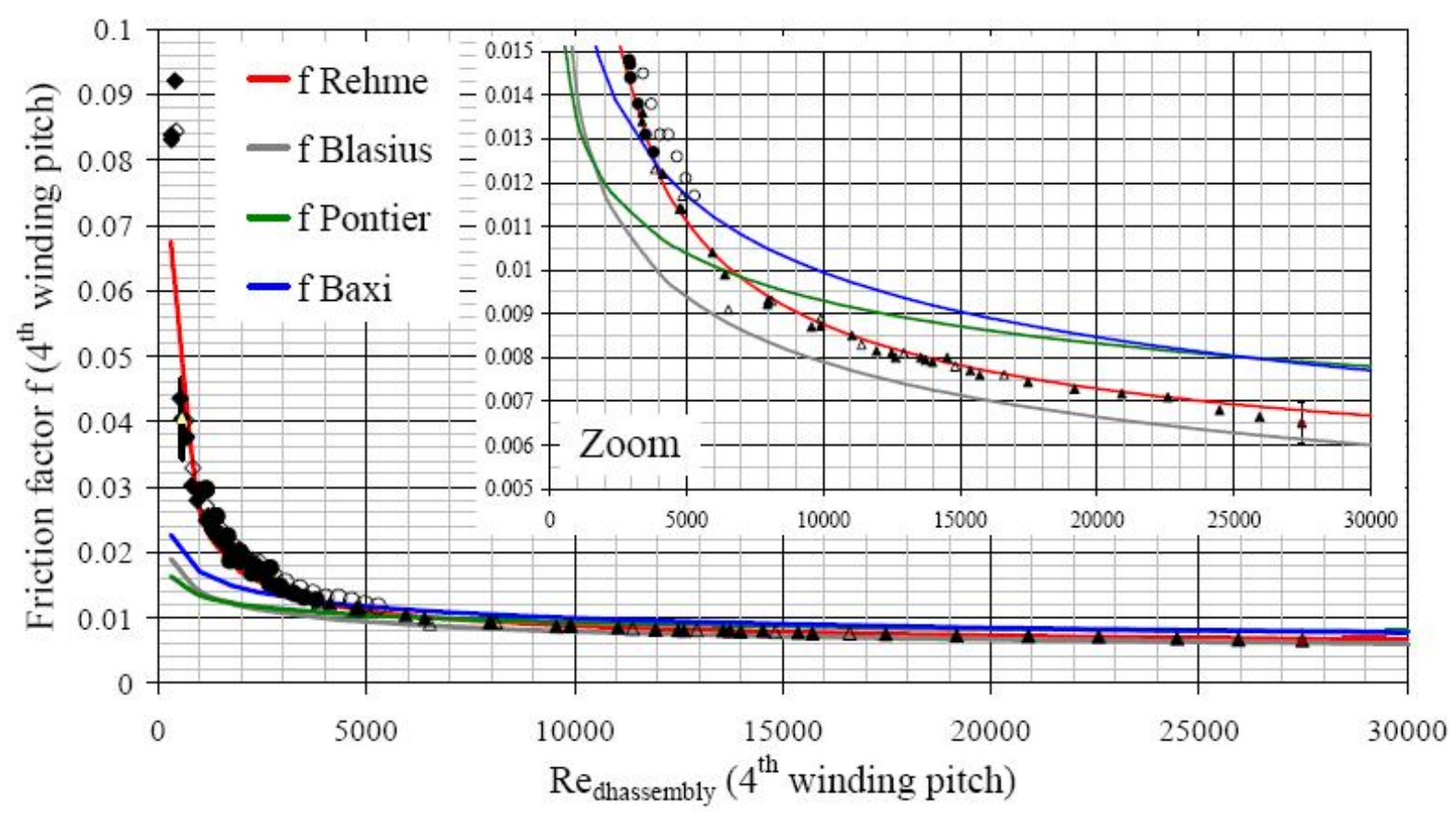

Fig. 45. Friction factor measured on the $4^{\text {th }}$ winding pitch. Comparison with existing correlations: (air, ESTHAIR exp. (Berthoux M. and Carenza A., 2008))

Once again it should be stressed here, that in all friction factor correlations presented in sections 3 and 4 of this report, all FA parameters used in these correlations should be taken for wire-wrap configuration and Re should be taken for the hot SA in wire-wrap configuration as well. Only under those conditions could good agreement be obtained between calculated friction factor values and the existing experimental data. 


\section{Summary and conclusions}

This report presents an overview of the existing wire-wrapped fuel bundle friction factor/pressure drop correlations and a qualitative evaluation which of the existing friction factor correlations is most appropriate in universally retracing the results of a large set of openly available experimental data on wire-wrapped fuel assemblies using different coolants.

For a qualitative estimation of the applicability of the various proposed wire-wrapped correlations, the following preliminary, somewhat arbitrary scheme, based on "engineering judgment, (i.e. visual inspection)", was used (see Table 1) until a more rigorous, scientific methodology is applied: a " 3 " was assigned in a case when really excellent agreement was observed between calculation results and the experimental data; a "2" was assigned in a case when good agreement was observed between calculation results and the experimental data; a "1" was assigned in a case when agreement between calculation results and the experimental data was only acceptable, and a "0" was assigned in a case when unsatisfactory agreement was observed between calculation results and the experimental data. Following this judgmental evaluation scheme, all the calculational results trying to retrace the available experimental data sets were evaluated, i.e. judged, and are summarized in Table 1.

A general conclusion was subsequently attempted which is the most appropriate, universally applicable friction factor correlation (model) fitting best the available experimental data. For the various coolants the following ordering was deduced from Table 1:

For water tests: Rehme, Sobolev, Novendstern, Engel (modified);

For air tests: $\quad$ Rehme, Engel (modified);

For sodium tests: Rehme, Engel (modified), Baxi and Dalle-Donne (modified). 
Table. 1. Judgmental evaluation (engineering judgment) of different friction factor correlations against experimental data sets

\begin{tabular}{|c|c|c|c|c|c|c|c|c|c|c|c|c|c|c|c|c|}
\hline \multirow{5}{*}{$\begin{array}{l}\text { Wire-wrapped FA } \\
\text { fric. fact. correlation }\end{array}$} & \multirow{3}{*}{\begin{tabular}{|c} 
Parameter \\
$\mathrm{N}$ \\
\end{tabular}} & \multicolumn{13}{|c|}{ Water tests } & \multirow{3}{*}{\begin{tabular}{c|} 
Air test \\
ESTHAIR \\
19
\end{tabular}} & \multirow{2}{*}{\begin{tabular}{l|} 
Sodium \\
Indian
\end{tabular}} \\
\hline & & Choi et al & Chun et al & Arwikar et al & Chiu 1979 & Tong 1968 & Marten et al & \begin{tabular}{|l|} 
Itch 1981 \\
\end{tabular} & Spencer 1980 & \multicolumn{4}{|c|}{ Rehme 1973} & Vijayan et al & & \\
\hline & & 271 & 19 & 61 & 61 & 19 & \begin{tabular}{|l|}
37 \\
\end{tabular} & $127 ; 169$ & \begin{tabular}{l|l}
217 \\
\end{tabular} & 19 & \begin{tabular}{l|l}
19 \\
\end{tabular} & 7 & $7-37$ & 19 & & 7 \\
\hline & \begin{tabular}{|l|}
$\mathrm{P} / \mathrm{D}$ \\
\end{tabular} & 1.2 & 1.256 & 1.05 & 1.063 & 1.205 & 1.041-1.101 & $1.176 ; 1.214$ & 1.252 & 1.417 & 1.125 & $1.125-1.417$ & 1.275 & 1.0802 & 1.24 & 1.255 \\
\hline & $\mathrm{H} / \mathrm{D}$ & 24.84 & 25 & 14.45 & $4 ; 8$ & $8 ; 16 ; 24$ & \begin{tabular}{|l|}
$8.34-17.01$ \\
\end{tabular} & $38 ; 47.39$ & 51.74 & $8.33-50$ & \begin{tabular}{|l|}
$8.33-33.33$ \\
\end{tabular} & 8.33 & $12.5 ; 50$ & 15.24 & 21.88 & 22.73 \\
\hline Rehme & $\begin{array}{c}7-217 \\
1.1-1.42 \\
8-50\end{array}$ & 3 & 2 & 2 & 3 & 3 & 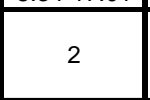 & 3 & 3 & 3 & 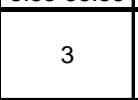 & 2 & 2 & 1 & 3 & 3 \\
\hline Novendstern & $\begin{array}{c}19-217 \\
1.06-1.42 \\
8-96 \\
\end{array}$ & 3 & 2 & 3 & 2 & 1 & 3 & 3 & 3 & 2 & 2 & 0 & 1 & 2 & 0 & 1 \\
\hline Sobolev & & 2 & 2 & 2 & 3 & 1 & 3 & 3 & 3 & 3 & 2 & 2 & 2 & 1 & 0 & 1 \\
\hline Baxi Dalle-Donne (modif.) & & 2 & 2 & 3 & 2 & 0 & 2 & 3 & 2 & 2 & 2 & 0 & 1 & 1 & 0 & 2 \\
\hline Engel et al (modif.) & \begin{tabular}{|c|}
$19-61$ \\
$1.067-1.082$ \\
$7.7-8.0$ \\
\end{tabular} & 3 & 3 & 3 & 1 & 2 & 1 & 2 & 2 & 1 & 2 & 1 & 1 & 1 & 2 & 2 \\
\hline Cheng-Todreas simpl. & \begin{tabular}{|c|}
$7-217$ \\
$1.067-1.35$ \\
$4-52$ \\
\end{tabular} & 2 & 2 & 2 & 1 & 0 & 2 & 3 & 3 & 2 & 2 & 0 & 1 & 2 & 0 & 0 \\
\hline Cheng-Todreas detail. & \begin{tabular}{c|}
$7-217$ \\
$1.067-1.35$ \\
$4-52$ \\
\end{tabular} & 2 & 2 & 2 & 1 & 0 & 2 & 3 & 2 & 0 & 1 & 0 & 0 & 3 & 0 & 0 \\
\hline Antonucci algorithm & & 2 & 2 & 2 & 2 & 1 & 2 & 3 & 3 & 0 & 0 & 0 & 0 & 1 & 0 & 1 \\
\hline & Correlation & oundaries & & & & Best correla & tions fitting $\epsilon$ & experimental & data & & & & & & & \\
\hline Rehme & $\mathrm{Re}=2000-3$ & 00000 & & Water tests: & & Rehme, Sobc & olev, Novends & stern, Engel ( $n$ & 1odif.) & & & Evaluation: & 3 & excellent agr & ment & \\
\hline Novendstern; Sobolev & $R e=2600-2$ & 00000 & & Air test: & & Rehme, Enge & el (modif.) & & & & & & 2 & good agreem & & \\
\hline Engel & $\mathrm{Re}=400-1$ & 00000 & & Sodium test: & & Rehme, Enge & el (modif.), Ba & xi Dalle-Donn & (modif.) & & & & 1 & acceptable a & reement & \\
\hline Cheng-Todreas & $\mathrm{Re}=50-1 \mathrm{C}$ & 00000 & & General: & & Rehme, Sobc & olev, Novends & stern, Engel ( $\mathrm{n}$ & (odif.), Baxi Dalle & -Donne (m & odif.) & & 0 & unsatisfactor & agreement & \\
\hline
\end{tabular}


Generally, the friction factor correlations providing a good fit to most of the available experimental data analyzed in this report (for three types of coolants) are in order: Rehme, Sobolev, Novendstern, Engel (modified), Baxi and Dalle-Donne (modified).

Based on the above statement, one can state that the friction factor correlation providing generally a good fit to all the various experimental data sets for different wire-wrapped $\mathrm{rod} /$ fuel bundle configurations and different coolants is the Rehme friction factor correlation for wire-wraps. We thus recommend that the Rehme friction factor correlation should therefore be used in the thermalhydraulic evaluations in the estimation of the pressure drops in wire-wrapped rod/fuel bundles for all reactor types, i.e. coolants.

\section{Acknowledgement}

The authors of this report would like to acknowledge the support of Mr. Carlomaria Antonucci (ENEA, Italy) who provided us with the algorithm for the investigation of friction factors for wire-wrapped fuel bundle configurations, based on Cheng and Todreas detailed model. 


\section{References}

Arwikar K. and Fenech H, 1979. Heat transfer, momentum losses and flow mixing in a 61tube bundle with wire-wrap, Nuclear engineering and design, Vol. 55, pp. 403-417, 1979.

Berthoux M. and Carenza A., 2008. Pressure Loss and Heat Exchange in a Rod Bundle Representative of ETDR Start-up Core ESTHAIR Experiment in Hot Air Similarity, Paper 289 to be presented at NUTHOS-7: The $7^{\text {th }}$ International Topical Meeting on Nuclear Reactor Thermal Hydraulics, Operations and Safety, Seoul, Korea, October $5-9,2008$.

Berthoux M., 2006. ESTHAIR experimental program (Core thermal hydraulic for advanced gas cooled systems), GCFR STREP Work Package 1.2 ETDR Design, Knutsford meeting presentation, Dec 2006

Bianchi F. et al., 2006. Status and trend of core design activities for heavy metal cooled accelerator driven system, Energy Conversion and Management, Vol. 47/17, pp. 2698$2709,2006$.

Carajilescov P. and Fernandez E. F., 1999. Model for sub-channel friction factors and flow redistribution in wire-wrapped rod bundles, Journal of the Brazilian society of mechanical sciences, ISSN 0100-7386, Vol. 21, No. 4, 1999.

Cheng S.K. and Todreas N.E., 1986. Hydrodynamic models and correlations for bare and wire-wrapped hexagonal rod bundles - bundle friction factors, sub-channel friction factors and mixing parameters, Nuclear engineering and design Vol. 92, pp. 227-251, 1986. 
Cheng S.K., 1984. Constitutive correlations for wire-wrapped sub-channel analysis under forced and mixed convection conditions, Ph.D. Thesis, Nuclear engineering department, MIT, August 1984.

Chiu C. et al, 1979. Pressure drop measurements in LMFBR wire-wrapped blanket bundles, Trans. ANS, Vol. 22, pp. 541-543, 1979.

Choi et al, 2003. Measurement of pressure drop in a full-scale fuel assembly of a liquid metal reactor, Journal of pressure vessel technology, Vol. 125., pp. 233-238, 2003.

Chun M.H. and Seo K.W., 2001. An experimental study and assessment of existing friction factor correlations for wire-wrapped fuel assemblies, Annals of nuclear energy, Vol. 28, pp.1683-1695, 2001.

Engel F. C. et al, 1979. Laminar, transition and turbulent parallel flow pressure drop across wire-wrap-spaced rod bundles, Nuclear science and engineering, Vol. 69, pp. 290296.

Gajapathy R. et al., 2007. CFD investigation of helical wire-wrapped 7-pin fuel bundle and the challenges in modeling full scale 217-pin bundle, Nuclear engineering and design, Vol. 237, pp. 2332-2342, 2007.

Geffraye G., 2008. Thermalhydraulics tools and their validation, GFR International Workshop, Paris, Feb 2008.

Marten K., Yonekawa S. and Hoffmann H, 1982. Experimental investigation on pressure drop in tightly packed bundles with wire wrapped rods, IAHR second international specialists meeting on thermal-hydraulics in LMFBR rod bundles, Rome, September 1982. 
Novendstern E. H., 1972. Turbulent flow pressure drop model for fuel rod assemblies utilizing a helical wire-wrap spacer system, Nuclear Engineering and design, Vol. 22, pp. 1927.

Pergamon Press, 1981. Heat Transfer and Fluid Flow in Nuclear Systems, Edited by Henri Fenech, ISBN 0-08-027181-2, Pergamon Press, 1981.

Rehme K., 1973. Pressure drop correlations for fuel element spacers, Nuclear technology, Vol. 17, pp. 15-23, 1973.

Schikorr W. M., 2001. Assessment of the kinetic and dynamic transient behavior of subcritical systems (ADS) in comparison to critical reactor systems, Nuclear Engineering and Design, Vol. 210, pp. 95-123.

Sobolev V., 2006. Fuel Rod and Assembly Proposal for XT-ADS Pre-design, Coordination meeting of WP1\&WP2 of DM1 IP EUROTRANS, Bologna, 8-9 February, 2006.

Tong L.S., 1968. Pressure drop performance of a rod bundle, in Heat transfer in rod bundle, ASME winter annual meeting, NY, 1968.

Vergnes J. and Lecarpentier D., 2002. The AMSTER concept (ㄸctinides Molten $\underline{\text { Salt }}$ TransmutER), Nuclear Engineering and Design, Vol. 216/1-3, pp. 43-67, 2002.

Vijayan P.K. et al, 1999. Experimental studies on the pressure drop across the various components of a PHWR fuel channel, Experimental thermal and fluid science, Vol. 20, pp. $34-44$. 


\section{Annex A Nomenclature}

A - axial average (total) flow area, $\left(\mathrm{m}^{2}\right)$

$A_{i}$ - flow area of $i$-th sub-channel, $\left(\mathrm{m}^{2}\right)$

BWR - boiling water reactor

$D_{\mathrm{r}}-$ rod diameter, $(\mathrm{m})$

$D_{w}-$ wire (spacer) diameter, $(m)$

$D_{e}-$ bundle equivalent hydraulic diameter, $(m)$

DHRS - decay heat removal system

ETDR - Experimental Technology Demonstration Reactor

$f-$ friction factor

FA - fuel assembly

FM - flow meter

GCFR - Gas Cooled Fast Reactor

$\mathrm{H}$ - wire lead length (pitch), (m)

$\mathrm{HX}$ - heat exchanger

$\mathrm{K}-$ friction coefficient

$L-$ axial length of $F A,(m)$

LBE - lead-bismuth eutectic 
LWR - light water reactor

$\mathrm{N}_{\mathrm{i}}$ - number of i-th sub-channels

$\mathrm{N}_{\mathrm{r}}$ - number of fuel pins

$\mathrm{p}$ - pressure, $(\mathrm{Pa})$

$P_{t}=D_{r}+1.0444{ }^{*} D_{w}-$ rod pitch for wire-wrap configuration, (m)

$\mathrm{P}_{\mathrm{w}}$ - wetted perimeter, $(\mathrm{m})$

PFBR - (Indian) Prototype Fast Breeder Reactor

PWR - pressurized water reactor

Re - Reynolds number (for hot SA and wire-wrap configuration)

$\mathrm{Re}_{\mathrm{s}}-$ Average Reynolds number for non-wire-wrap configuration of the fuel bundle

$\mathrm{S}_{\mathrm{t}}-$ total wetted perimeter, $(\mathrm{m})$

$\mathrm{T}_{\mathrm{w}}-$ wall temperature, $(\mathrm{K})$

$\mathrm{T}_{\mathrm{B}}-$ coolant bulk temperature, $(\mathrm{K})$

$v$ - bundle average flow velocity, $(\mathrm{m} / \mathrm{s})$

$X$ - flow split parameter

$\rho$ - density, $\left(\mathrm{kg} / \mathrm{m}^{3}\right)$

$\mu$-dynamic viscosity, (Pa.s)

$\Psi$ - intermittency factor 


\section{Annex B Subscripts}

1, 2, 3 - denote center, side and corner sub-channels, respectively

i - index of sub-channel type

I, L - laminar

t, T - turbulent 